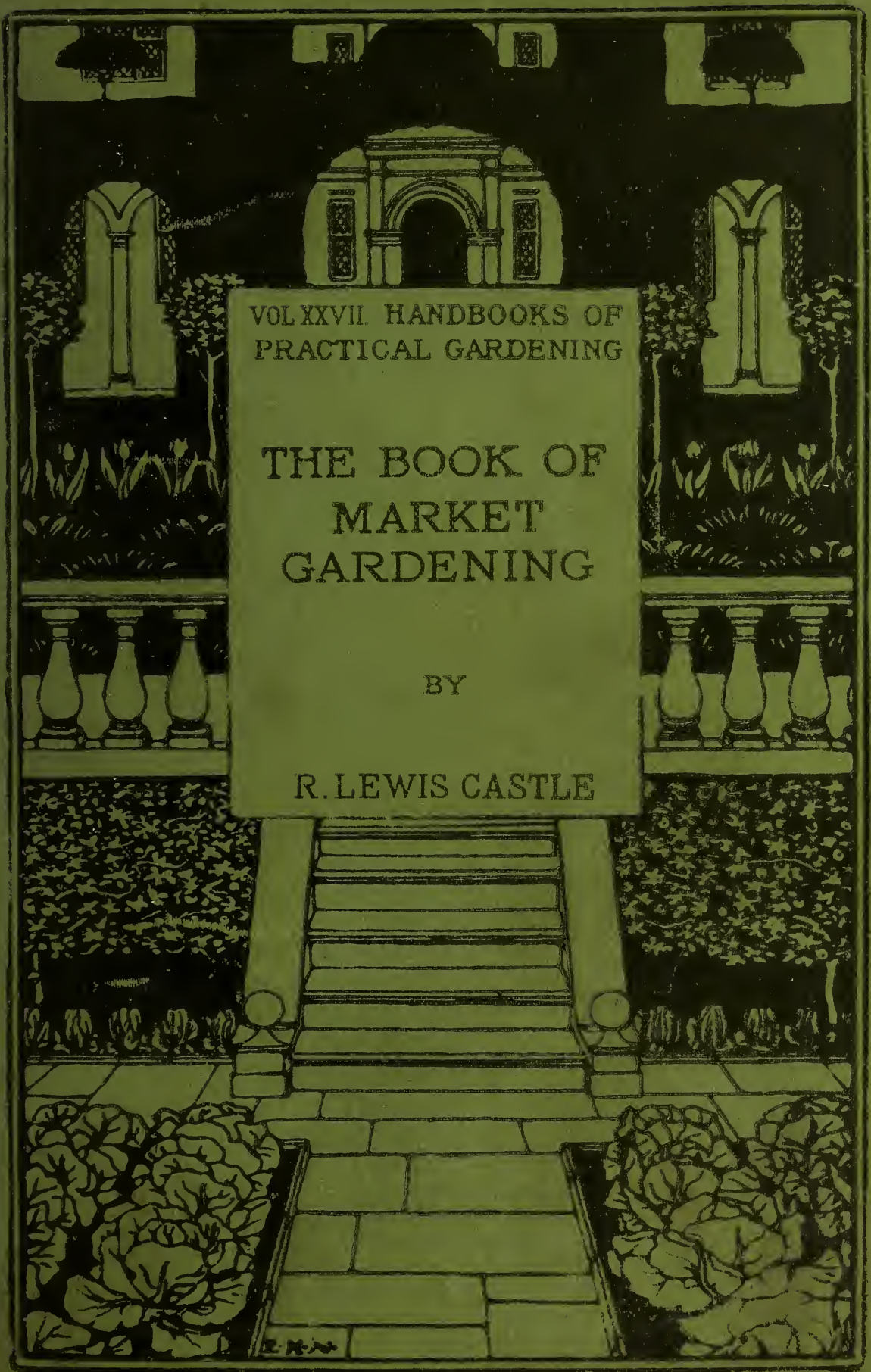



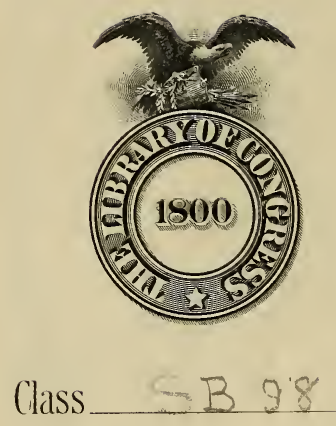

Book_.C3 



2 
HANDBOOKS OF PRACTICAL GARDENING EDITED BY HARRY ROBERTS

THE BOOK OF MARKET GARDENING 




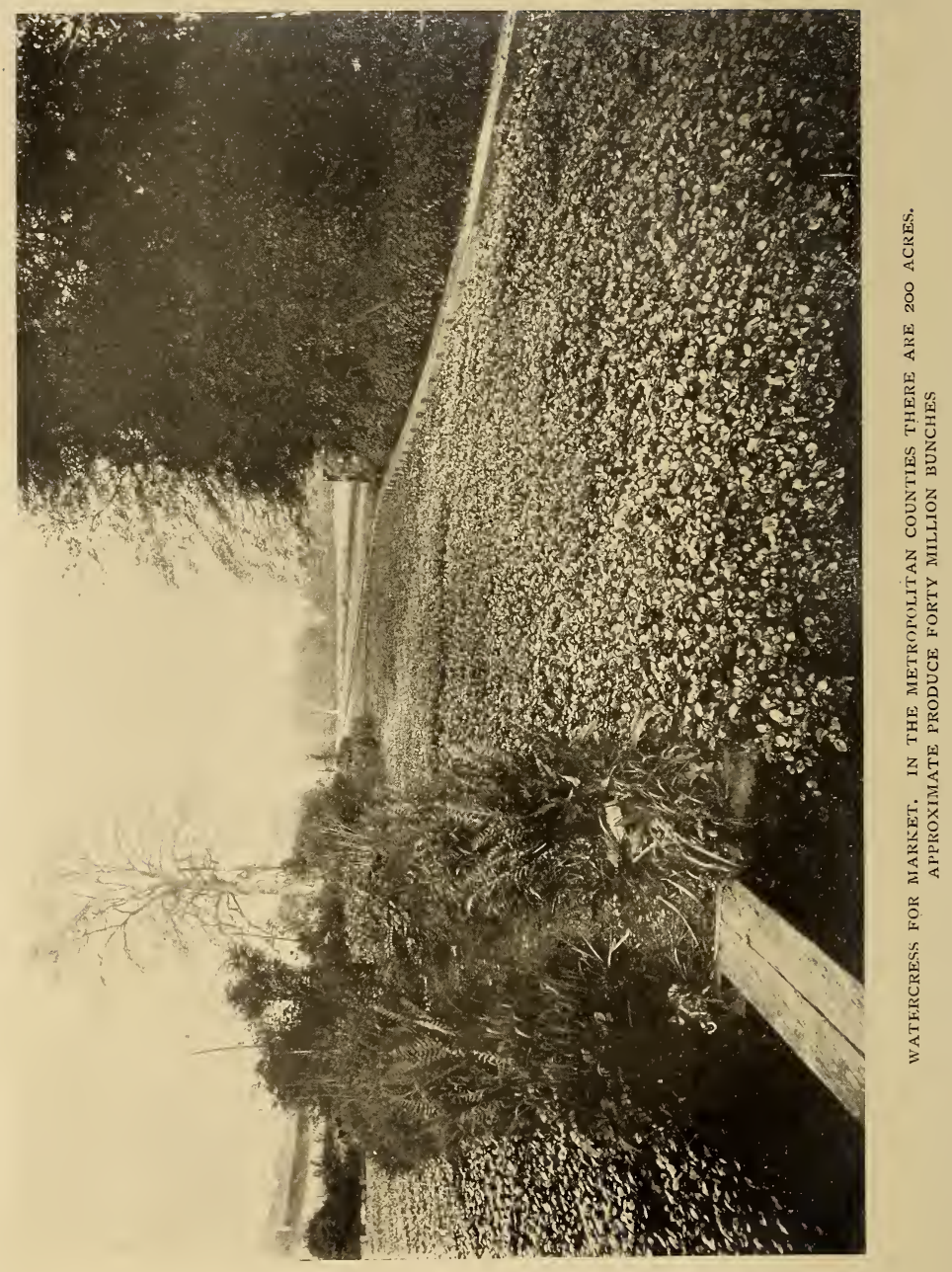




\section{THE BOOK OF}

\section{MARKET GARDENING}

BY

R. LEWIS CASTLE

FORMERLY MANAGER, NEVILL COURT GARDENS AND NURSERIES

RIDGMONT FRUIT FARM, AND HAMPTON PARK FARM

AUTHOR OF " COMMERCLAL FRUIT GROWING"

(PRIZE ESSAY, ROYAL HORTICULTURAL SOCIETY, AND DR HOGG'S SILVER MEDAL) AND "GRADING AND PACKING FRUITS AND VEGETABLES"

(GOLD MEDAL ESSAY, FRUITERERS' COMPANY)

LONDON : JOHN LANE, THE BODLEY HEAD NEW YORK : JOHN LANE COMPANY. MCMVI 

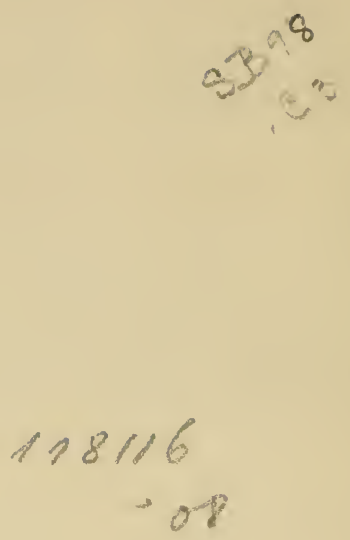

$\therefore \vdots \vdots$

Turnbull \& Spears, Printers, Edinburgh 


\section{PREFACE}

LORD OnsLow's Committee, appointed in 1903 to investigate subjects connected with commercial fruit culture, recommended that a sub-department of the Board of Agriculture be established to deal with horticulture and pomology. If substantial official recognition be accorded to that suggestion, important benefits may accrue to market gardening as a form of intensive cultivation which greatly concerns landowners, tenants, and the public. Parliamentary aid is urgently needed in the promotion of many reforms, and with such assistance on judicious lines considerable and profitable advance might be made.

In the following pages an attempt has been made to indicate the directions in which cultivators can help their own progress with advantage, and to show the methods adopted by many growers who have made commercial gardening a highly successful business. The author's only object has been to set out in plain language the results of thirty years' practical experience and close study in the United Kingdom and on the Continent.

Cultural details of all the principal crops are fully dealt with in other manuals of this series. .

R. L. C. 



\section{CONTENTS}

Preface

PAGE

vii

INTRODUCTION $\quad . \quad$. $\quad . \quad$.

The Selection of Land-

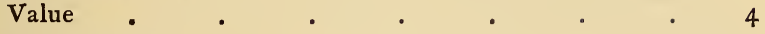

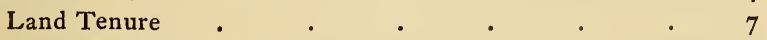

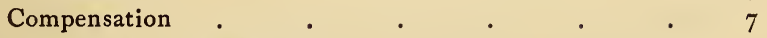

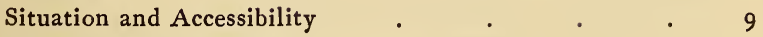

Special Districts, Climatic Characters . . . 10

Soil, Aspect, Altitude . $\quad . \quad$. $\quad$. $\quad$. 13

Labour Questions and Difficulties-

Permanent and Temporary Workers . . . 19

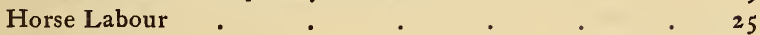

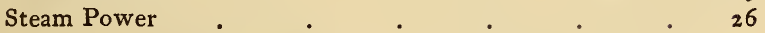

Crops, Methods, and Management-

Specialisation $\quad$. $\quad$. $\quad$. $\quad$. $\quad$. $\quad$. 27

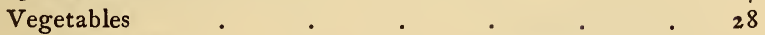

Hardy Fruits . $\quad . \quad$. $\quad . \quad$. 30

Plants and Flowers . . . . . . 3 . 3

Arrangement of Crops . . . . . $\quad . \quad 32$

Economy in Production . . . . . . 34

Fertilisers, The Use of . $\quad . \quad$. $\quad . \quad . \quad . \quad 36$

Insects and Diseases $\quad . \quad$. $\quad . \quad . \quad . \quad . \quad 36$

Cultivation under Glass . $\quad$. $\quad$. $\quad$ • 37

A Summary of Cultural Essentials . . . 43

Important Details in Commercial Gardening-

Selection of Kinds and Varieties . . . . $\quad$. 47

Variety Trials $\quad . \quad$. $\quad . \quad$. $\quad . \quad$. 49

Earliness . $\quad . \quad$. $\quad . \quad$. $\quad . \quad$. 5 I

Productiveness $\quad . \quad$. $\quad . \quad$. $\quad . \quad 52$

Constitution and Duration $\quad . \quad$. $\quad . \quad$. 53

Appearance and Quality . $\quad . \quad$. $\quad . \quad 54$ 
Preparing Produce for Sale-

PAGE

Gathering and Collecting Crops .

Grading for Profit-

Packages and Materials .

Packing Garden Produce .

Packing Materials

Methods of Packing-

Packing Fruits

Bunching Vegetables

Packing Cut Flowers

Packing Plants

The Distribution of Produce-

Consignment to Market Salesmen

Growers as Salesmen

126

Supplying Retailers

Markets and Auction Sales

128

130

133

Consignment direct to Consumers

The Converance of Produce-

By Road .

Motors and Tractors . . . . . $\quad$ I 42

By Rail

By Canals

By Parcel Post

Subjects Worth ATtention-

Co-operation

Assessment, Taxes, Rates

Compensation and Insurance

Fruit Preserving Factories

Farming and Market Gardening .

Crop Returns, Values, and Profits

Vegetables.

Hardy Fruits 


\section{LIST OF ILLUSTRATIONS}

Watercress for Market

Market Garden Intercropping .

Arrangement of Crops-Dlagram I

$\begin{array}{lll}" & , & , \\ , & , & , \\ \text { ", } & \text { ", } & \end{array}$

Mixing Compost .

Cabbagrs on a Small Holding.

Sussex TruCK Basket

Swedish Chip Fruit-Basket

Fruit and Flower Basket

PARSLEY FOR MARKET

Apples and Nuts for Market .

Patent Folding Wooden Crates

Parcel Post Boxes (Cardboard)

Chip Punnets for Fruits

Mushrooms in a Shed

Square Willow Baby-Baskets

BoX For Cucumbers

Carnations OUT-OF-DOORS

Motor Market VAN .

Market Road Tractor.

Messrs Lobjoit's Tractors

Foden Wagon for Market

Agricultural Motor

WELLINGTON TRACTOR
PAGE

Frontispiece

Toface 6

. II

. $\quad 17$

. 23

29

35

To face 40

,, 50

60

65

65

To face 70

, 74

. 83

. 86

- 92

To face 100

- 106

- 108

To face 110 .

, 120

$\because 128$

, 134

,. 140

.9 146

$\because \quad 152$ 



\section{INTRODUCTION}

MARKET gardening in its widest sense, comprising every department of productive commercial horticulture, must always rank in populous countries amongst the most important industries connected with land cultivation. Though mainly concerned in providing a material portion of the food of the people, it also contributes largely to the health, to the pleasures, and to the artistic tastes of all classes. The concentration of workers in the cities has increased the necessity for abundant fresh fruits and vegetables, and the demand has advanced rapidly; while the self-supplying members of the community have been reduced in numbers by the depopulation of rural districts, and the totally inadequate provision of garden ground to urban residences. With increased facilities for the economical distribution of produce, there can be no reasonable doubt that for many years market gardening will extend over greater areas of land; the domain of the farmer will be more and more invaded, and the wider adoption of intensive methods of cultivation will gradually bring back to usefulness thousands of acres that have almost become derelict under out-of-date and exhausted systems.

The enormous proportions assumed by imported fruits, flowers, and vegetables, together with the increasing number of home growers, have naturally created a keen and general competition attended by reduced prices, leaving, even under the best systems, narrow margins of profit. Such competition, too, will probably become still more acute in the future, 
notwithstanding the demands caused by the advance of population. The position of the market gardener may therefore be briefly summarised as follows : he is secure of a great and increasing market for his produce, but except for that of the highest quality, always in limited demand, prices will rule low; and to meet this his methods must be rigorously revised, wherever there is the slightest chance of improving returns by extra care, or reducing expenses by better systems.

The productive power of good land under the best cultivation is only fully understood by those who have spent a life in its study; it is one of the greatest blessings accorded to well-directed industry. British growers can claim in this respect that they are rivalled by few and excelled by none, where attention has been concentrated upon the best types of market gardening. It is not in general cultivation that defects are so conspicuous as in the neglect of details, in imperfect organisation, and in rough methods of placing their produce before the public. Any business that is worthy of a man's utmost exertions, both bodily and mentally, must pay for starting and conducting in a systematic manner. Certainly, in modern market gardening this is one of the first essentials, otherwise the expenditure of capital and labour will be heavily discounted, and the greatest skill in cultivation will not suffice to ensure financial success. Organisation and directing power are as much a necessity as the physical strength required in the work.

The purpose of the following pages is to review the chief stages of a market gardening business; to point out the most notable and prevailing defects, with such remedies as long experience in horticulture has found to be generally effective, suggesting also methods which are worthy of trial, and indicating the lines upon which the most successful businesses are conducted. Intended 


\section{INTRODUCTION}

mainly for those who are familiar with cultural methods, about to start in the trade or desirous of extending their operations, it is also hoped that others may derive some assistance from a careful perusal of the facts set before the readers. 


\section{THE SELECTION OF LAND}

\section{VALUE}

THE reduced value of agricultural land at the present time favours the cultivator who wishes to break fresh ground and who is prepared with the means to purchase large areas. The official returns of the gross income derived from the ownership of land (excluding groundrents and gardens under one acre) for I902-3 were the lowest in a period of thirty years, amounting to the following totals, which are compared with the highest totals of the period named.

Lowest Year, 1902-3.

England and Wales . $£ 36,624,408$ Scotland
Highest Year, I 876-77. $£ 5$ I,8I I, 234 $7,689,7$ I 7

This represents a total decrease for Great Britain of nearly seventeen million pounds.

Many farms and country estates have come under our notice for examination and report, where the price asked for the freehold has been as low as $£ 8$ or $£$ Io per acre, including residence and farm-buildings. This has ranged upwards to $£ 50$ per acre, the amount depending much more upon the situation than the quality of the land. Planted with fruit trees or other permanent stock, or having glass-houses, the selling prices rise rapidly, from $£ 100$ to over $£ 400$ per acre being asked and paid.

The actual price per acre is not the only consideration 
which demands the attention of the market gardener. In the first place, especially at starting, he is seldom prepared with the capital for either buying or working farms of several hundred acres. However tempting the chance may appear, it is folly to take more land than can be satisfactorily cultivated. The outlay upon labour must be heavy, and there is the possibility of hard seasons to be faced. With a large area in hand to keep up to the best conditions, and a small capital available for the purpose, the prospect is not encouraging.

A part from other considerations, this has led to more failures, both in farming and gardening, than lack of skill or application. It is responsible for a large proportion of the foul, neglected land which is found on many of the great estates, and which in some cases the owners have turned into game preserves or rabbit warrens as the last resource. There is a confirmed reluctance to break up large farms into smaller ones, yet the applicants for the latter are far more numerous and the rents obtainable much larger in proportion. Numbers of examples could be quoted in proof of this, but two will suffice for our purpose, both of which are on a large agricultural estate within fifty miles of London. In one case 20 acres were obtained at $f_{2}^{2}$, Ios. per acre, and in the other 50 acres were rented at $\delta_{2}$ per acre. Both were cut out of farms which were rented at Ios. to I5s. per acre, and the small holders did not share in any reductions for bad seasons. Each of the small men devoted the land to market garden purposes, partly fruits and partly vegetables, maintaining a condition that was a credit to the district. The whole of the fruit trees were planted on a yearly tenancy, so that the land was being improved, while much of the other cheaply rented land was as steadily decreasing in value.

How far the formation of smaller holdings in agricultural districts could be carried out with success depends 


\section{THE BOOK OF MARKET GARDENING}

mainly upon the situation, the soil, and the local demand. The question is too large and involved to be entered upon here, but it is an absolute fact that on many estates such a scheme could be partially adopted with advantage to both owners and tenants. In special districts which have proved to be fitted for fruit and market gardening generally, the rents obtained at the present time vary from 30 s. up to $£ 50$ per acre, for plots ranging from Io acres downwards, the last-named extraordinary rent being that charged on small town plots of garden ground which have been under cultivation for hundreds of years. Yet, with a rental of over 6s. per square rod, occupiers have proved that, taking a series of years, they sold enough produce (fruit chiefly) to pay their rent, besides supplying themselves with what was required. In one case this was considerable, because the tenant held a restaurant in the town. To purchase the tenant-right of such land requires an enormous capital, and we know small holders who have obtained for well planted fruit land from $f_{5} 50$ upwards per acre under the Evesham system. For larger areas similarly planted from $f$ IOO to $f_{2} 200$ per acre is asked. One plantation in the home counties, comprising 50 acres, was recently offered at $f_{1} 10,000$, or $f_{2} 200$ per acre.

The Channel Islands afford a good illustration of how greatly the value of land in special situations is increased under horticultural methods. Mr A. Collinette, F.C.S., stated before the British Dairy Farmers' Association recently that the value of land per acre in Guernsey was as follows :-

Poor Land, $f_{0} 8$.

Good farm land, $f, 100$ to $f, 150$.

Land on horticultural estates, f I 50- f 300 .

Extreme prices lately realised (actual sale values), f. $500-6,600$. 


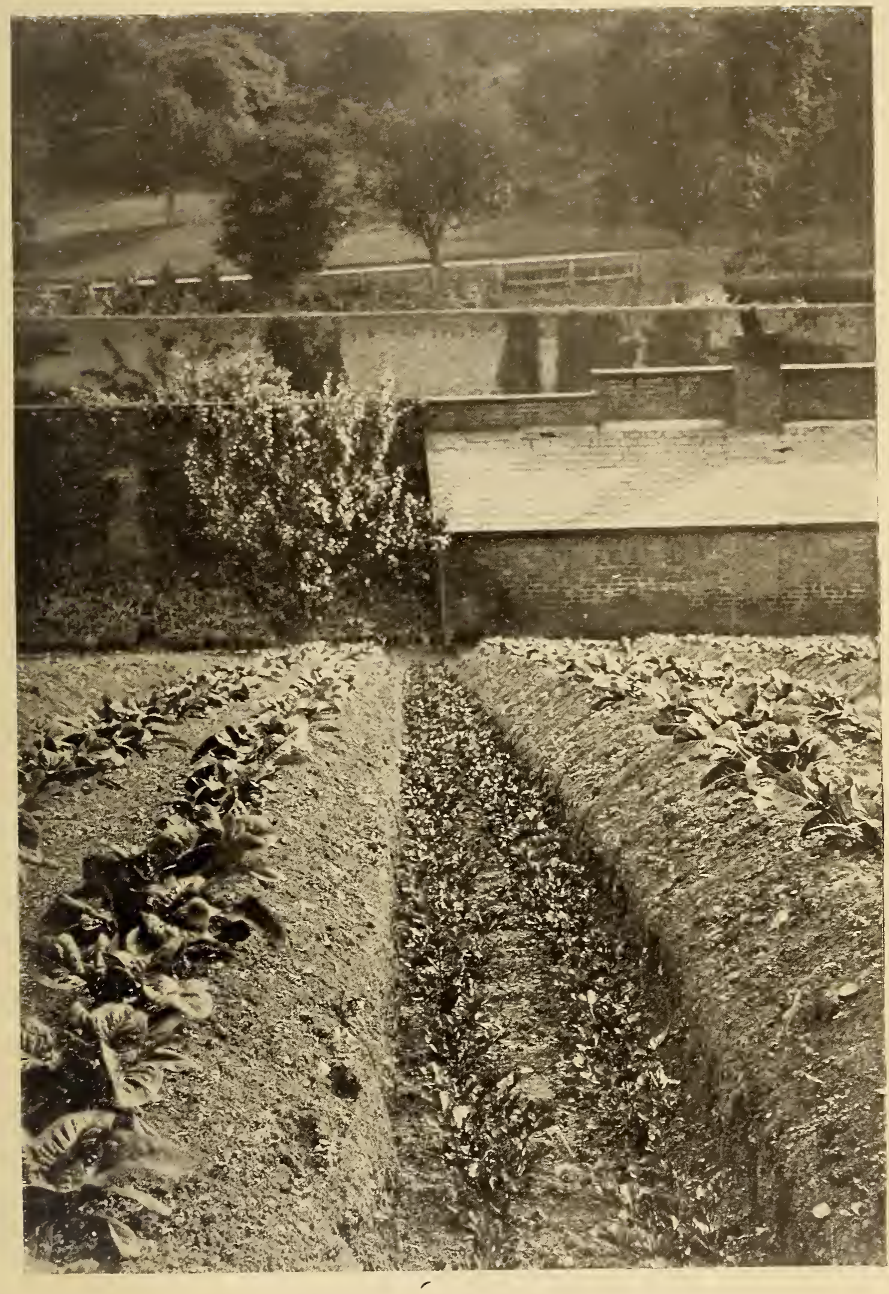

MARKET CARDEN INTERCROPPING I, 400 SCORES OF LETTUCES PER ACRE

I,OOO BUNDLES OF CELERY PER ACRE 

He estimates that " a fair average value, taking the last five years' sales as a guide, is equal to $f_{2} 250$ per acre." But this would be reduced now to $f_{2} 200$.

\section{Land Tenure}

The majority of beginners in market gardening require from 10 to 20 acres, and if the freehold of suitable land could be purchased at $f_{0}$ io to $f_{0} 20$ per acre there would be plenty of buyers. Even if it could be had on leases of twenty-one years with the option of purchase, tenants could be readily found who would give from 3 os. to $£_{4}$ per acre, according to the quality of the land and the position. It is the difficulty of obtaining such small blocks which induces some men to take plots of land on building leases of 99 years; but if the erection of houses within a specified time and of a stated value is required, such holders frequently find themselves involved in considerable difficulties.

It encourages a man to exert himself to the utmost when he is working upon his own land, or with some security of tenure over a definite period; but failing the opportunity or the means to purchase freehold land, or to obtain sufficiently long leases, the majority are reduced to renting land on yearly tenure, the basis upon which most farm land is let on large estates. Near towns the rapidly increasing value of land for building renders owners unwilling to let it on leases for horticultural purposes, so the market grower is either compelled to take it on yearly agreement, or go farther out from the centres of population.

\section{Compensation}

Protection is afforded by law, whatever may be the terms of tenure, provided the land is let for market garden purposes, distinctly stated in writing. Under 


\section{THE BOOK OF MARKE'T GARDENING}

the Agricultural Holdings Act and the Market Gardeners' Compensation Act, compensation can be claimed for permanent improvements, like the planting of fruit trees and the erection of buildings which come within the scope of the business. Much attention has been called to the custom prevailing in the Evesham district in reference to the compensation for fruit trees, etc., on land held on yearly tenure. The Departmental Committee of the Board of Agriculture, appointed to consider operations relating to fruit culture, strongly recommend that some modification of the Evesham custom should be made generally applicable by law. In that district, if a tenant wishes to quit his holding he secures another man who is willing to take it, and to pay the valuation of the permanent stock on the ground. His name is then submitted to the landlord for approval, but the latter may not arbitrarily or without adequate reason refuse to accept a tenant thus obtained. If he do refuse without sufficient reason, or because he wishes to retain the land himself, he becomes liable for the compensation, exactly as if he had given the tenant notice to quit. When the incoming tenant is duly accepted the outgoing tenant gives notice in accordance with the terms of his agreement.

As it stands, this custom is of especial value in reference to fruit planted before the Market Gardeners' Compensation Act, I 895, came into operation. But though it carries weight in the district, it would be of little avail elsewhere. The fact that the Act in question is not retrospective is rightly considered as extremely hard upon men who have been paying increased rent on their own improvements, and who yet have no claim for compensation when they quit. The Fruit Committee named recognised this, and recommended that Section 4 of the Act should be made retrospective, and it may be hoped that this will be carried into effect. 


\section{THE SELECTION OF LAND}

The purchase value of freehold land is reckoned on the annual rent; thus a farm or holding let at $f_{0}$ I per acre would be worth, at eighteen years' purchase, $f_{0} \mathrm{I} 8$ per acre freehold; at twenty-five years' purchase the value would be $f 25$. Those are the two extremes. For some agricultural land eighteen years' purchase has been considered a fair basis in recent years, and in few cases has it risen above twenty-five years: the majority of sales would average from twenty to twenty-two years. Rents vary enormously, from IOs. or 15 s. per acre for neglected farm land to $£_{4}$ or $£ 5$ for the most fertile land without permanent crops; planted with fruit trees, the rental rises from $f 5$ to 6 , Io per acre, depending upon the age and condition of the trees. But where the tenantright custom prevails, the rent often does not exceed $f_{2} 2$, Ios. per acre, though the price paid for incoming is equivalent to rent.

\section{Situation and Accessibility}

The position selected for a market garden will be partly determined by the special objects of the grower, but in any case it is important to be either near a town or within a moderate distance of a station on a good railway line. The distance to be covered in the conveyance of produce must always be more or less of a disadvantage, whatever means are at command. The reduction of such distance to the minimum usually brings a corresponding increase in rent, and the gain in one direction has to be weighed against the loss in another. It therefore becomes a question that must be settled in every instance in accordance with the grower's particular requirements.

There is, however, a conspicuous cultural advantage in going beyond the smoke area of large cities, and many growers have thus changed their quarters with 
substantial gain in many respects. The prevalence of south-west winds in Great Britain needs consideration in this connection, because as a rule the smoke trouble is less serious in the west or south-west quarters of a city, or at least the area of danger does not extend so far. It is not only in the poisonous substances carried by smoke and dense fogs that injury is found, it is also the diminution of light which affects vegetation unfavourably.

The accessibility of a place is of much importance, including good roads and a convenient approach. Serious defects in these matters will greatly decrease the value of land, while probably forcing expenses upon the occupier that may cripple his resources severely. We know instances where the loss incurred in time wasted, with damage to the goods on bad roads or in the expense occasioned by repairing and maintaining such roads in fitting condition, has nearly doubled the rental of the land. Low prices or low rents sometimes tempt a man to take a place without duly considering these points, and estimating the outlay that will be essential to bring it into proper form.

\section{Special Districts, Climatic Characters}

The question is often asked, Where is the best district to start market gardening ? The answer is that if the essential conditions can be secured which are here enumerated an energetic and skilful cultivator can found a business in any English county, or in many parts of Scotland, Ireland, and Wales. At the same time the special advantages of some localities, and the objects of the grower, should be kept distinctly in view. If early outdoor produce is desired, the warmer sheltered situation and aspects must be chosen, so that the more northern and populous manufacturing centres can be supplied in advance of their own districts. It is useless 
$\odot$

$x \quad x \quad x$

$x \quad x \quad x$

$\otimes$

SMALL VEGETABLES

$\odot$ FRUITS

$\otimes$

$x$

$x$

*

8

C

$x$

$x$

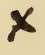

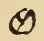

$\odot$

\section{8}

\section{$x$}
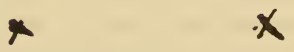

Diagram I.-Mixed Plantations. (See page 32.)

Standard Apple Trees $(X)$, $3 \circ$ feet by $3 \circ$ feet, cropped between the lines with small fruits or vegetables, or these crops in alternate breadths. Standard Plums $(\odot)$ can be planted at half distances, i.e. I 5 feet, or Dwarf Apples, Pears, and Plums $(\otimes)$ at Io feet in the rows.

$[$ Scale, $\mathbf{I}$ inch $=30$ feet. 


\section{THE BOOK OF MARKET GARDENING}

going into exposed bleak places on cold heavy soils with the idea of competing in early crops from the land. Favourable situations are not restricted to the extreme southern and western counties, though these naturally offer many advantages; good sites occur even far north, but knowledge, experience, and judgment are needed in their determination. The principal climatic characters affecting outdoor gardening that demand attention are the rainfall, the sunshine, and the exposure to winds. As regards the first, the difference between the extreme eastern and western counties of England is very marked : the average annual rainfall in some of the latter amounts to three times that recorded in the eastern counties. Apart from other effects, the annual duration of sunshine is reduced where the rainfall is greatest, though, upon the cold East Coast, fogs are apt to be prevalent, and, in certain districts especially, produce a similar effect, particularly in the river valleys. Except in the worst coast localities wind influences can usually be counteracted by suitable planting.

The advantages derived from selecting land in districts where market gardening is a well established industry are chiefly found in the facts that good land is obtained, labour of a suitable character is more readily secured, and probably special facilities are available for the carriage of produce. Against these must be set the higher price or rent of the land, higher rates of wages, and a competition which renders local markets, or any within convenient reach of the grower, unprofitable outlets. There is, however, just as much overcrowding of growers in some districts, as there is too great a tendency to rush into a few markets. With more independent enterprise and courageous energy, growers might find plenty of excellent land where they could not only make a substantial business for themselves but initiate a new industry for the district. Many examples 


\section{THE SELECTION OF LAND}

of this having been accomplished are within our knowledge.

\section{Soil, Aspect, Altitude}

Commercial success in cultivation depends largely upon the fertility and physical character of the soil chosen. In both respects most soils can be vastly improved by adequate and continued attention, but the expense of doing this must be reckoned carefully, or the grower may find his resources exhausted before he has reaped the reward, which will fall to his successor. Excessively light, sandy, stony, or rocky land must be avoided on the one hand, while heavy, tenacious clays are equally unsuitable on the other. Thin surface soils resting upon deep chalk beds are of little value for market-garden purposes, nor are those which are peaty, marshy, or waterlogged likely to yield any return in comparison with the expense. Shallow soils resting upon a rocky or stony "pan" are valueless, unless the latter can be readily broken and the tilth deepened. A deep friable loam is the best for vegetable culture, but the land that can be rendered suitable may range from the alluvial soils of river valleys, often abounding in humus, to fairly heavy loams especially adapted for fruits. The heavier the soils the greater the expense in the labour needed to ensure due cultivation; they are also troublesome, perhaps actually unworkable, in wet weather, though they stand dry seasons admirably with plenty of surface culture. The lighter soils can be worked at much less cost; the operations are not materially checked by weather influences, but their crops are apt to suffer severely in times of drought, and larger applications of manure are required.

For men starting in a small way, who are mainly dependent upon their own labour, an easily workable soil is important, and this applies generally where manuul labour only is available. Where horse or steam power 


\section{4 THE BOOK OF MARKET GARDENING}

can be utilised it is not so urgent, though the cost must not be omitted from the calculations. To aid in economical and convenient working, market-garden land should also be reasonably level, though moderate slopes are not objectionable. Foul land should be avoided as far as possible, unless some substantial consideration is allowed in the rent or purchase price. When the soil is full of weeds and their seeds, or with those having creeping roots, such as Twitch or Bell Bine (Wheat Bine), a period of cleansing must be set down in the programme, which often means heavy expense and considerable delay before the plans can be carried out. In the same way, land that is liable to be water-logged through the absence of natural or artificial drainage, is not adapted for market-garden work, and it is one of the points requiring attention in taking farm land, to make sure that if drains exist they are operative with suitable outfalls into ditches and water-courses.

A favourable aspect adds greatly to the value of land for commercial purposes in any part, but the farther north we go the more important it becomes, as it may effectually counterbalance the disadvantages of lower average temperatures. There are few districts or seasons where too much warmth and sunlight are experienced in the spring months, when market garden crops most need such help; consequently any aspect which commands the fullest exposure to sun with shelter from north and east winds is preferable.

Altitude and elevation may be regarded separately for our purpose, the former referring to the height above sea-level, and the latter to the height in comparison with the surrounding land. For all cultural purposes as regards the Southern and Midland counties the altitude has less general influence than an elevation of fifty to one hundred feet above neighbouring land. This is especially applicable to fruits and to early vegetables. 
In low-lying districts the spring frosts are apt to cause much loss, which is to a great extent escaped on the higher land. This is also the case in early autumn, when many tender plants are cut off or seriously damaged much sooner on the lowlands than on higher though neighbouring elevations.

The fact that river valleys are so often the sites of extensive market gardening is due chiefly to the fertility and workableness of the soil, though it is often partly attributable to the vicinity of great cities, as in the Metropolitan area. In many other respects they are unfavourable, and the heavy losses experienced at times are only made up by still more intensive cultivation, or by the aid of glass-houses.

The supply of water is an important item in this matter, as not only is that more readily obtained near rivers by artificial means than on high ground, but there is usually abundance of moisture rising constantly from the lower soil layers in hot weather, which exerts an extremely beneficial influence far in advance of that afforded by artificial supplies on the surface. For vegetable crops and for flowers, apart from the danger of frosts in spring and autumn, such positions are suitable, but they are less so for fruits, though some thousands of acres are devoted to them in similar situations. The losses in these crops under such circumstances are frequent but variable, and local protection, sloping ground, aspect, and "air drainage" (i.e. free escape for the cold heavy air to lower levels) all exercise some. influence in the direction of safety.

Fences, hedges, or other boundaries with gates must have close attention in securing property for marketgardening, as if they are seriously defective heavy expenses may be incurred subsequently. Be careful also to ascertain exactly which hedges, etc., belong to the property in question. There is not, as a rule, much 


\section{I6 THE BOOK OF MARKET GARDENING}

difficulty in determining this when ditches are kept open, as they should always be on the side away from the owner's land, i.e. the hedges are planted on the land, and the ditch constitutes the boundary. Sometimes this guide is absent, and considerable difficulty and annoyance may be experienced if the facts are not determined at the time of purchase.

This is of the greatest importance where pastures adjoin the garden or farm, as it is incumbent upon the occupier to keep his hedges in order, not only for the protection of his own place, but to prevent the entry of cattle or horses from other persons' land. Failing this he has a doubtful claim for damage, which in the case of a garden or nursery may be of a serious character. In the same way the occupier of adjoining land is required to maintain his hedges in an effective state where they form the boundary of another's property.

Protection from adverse winds may exist as rising ground or as plantations of trees at a convenient distance, and in all cases adds to the value of the land for immediate use. Otherwise it will be necessary to plant hedges, groups, or belts of trees, to provide the shelter required. This is of more importance for fruit trees and flowering plants than for vegetables, except the earliest and most tender. But as wind breaks, compact dense hedges of moderate height are useful in most gardens, nurseries, or farms, only they must not be too near together so that the land is cut up into small plots, unless in exposed districts where particular shelter is needed for choice plants and flowers. A distinction must be made between hedges for boundaries and those for protection only. As an outside hedge nothing has yet been found to surpass the Common Quick or Whitethorn, but it is very slow in growth, and needs so much protection in its young state that it usually answers a market grower's purpose better to provide 


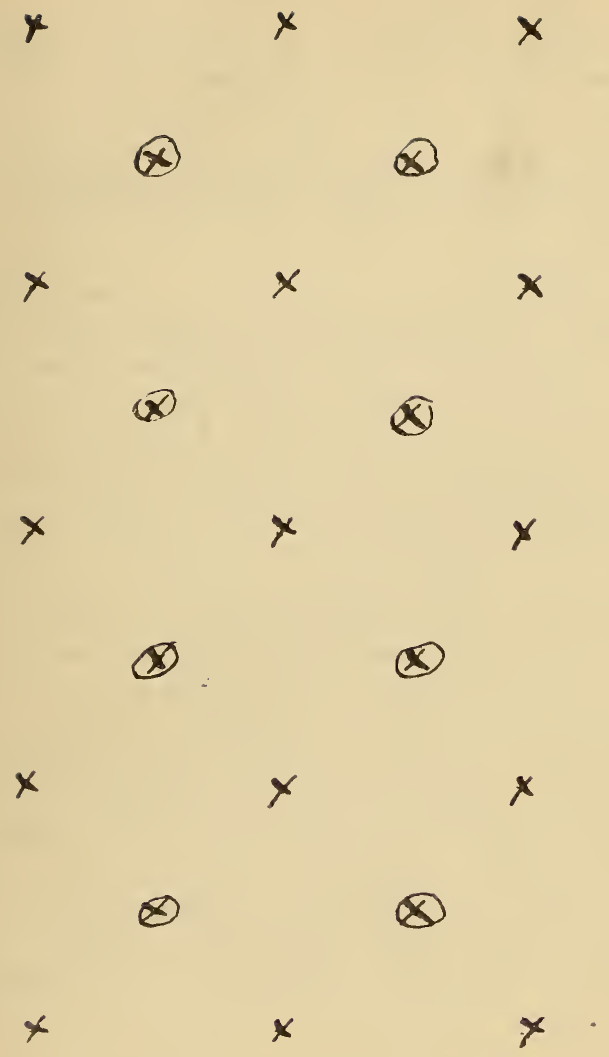

Diagram 2.-Mixed Fruit Plantation. (See page 32.)

Standard Apples ( $X$ ), 30 feet by 30 feet. Standard, half-standard or bush Plums, Apples, or Pears $(\bigotimes)$ in alternate lines.

[Scale, I inch $=30$ feet. 


\section{THE BOOK OF MARKET GARDENING}

fences where hedges do not exist, or do not admit of being readily restored. As protective hedges many trees and shrubs can be employed, either evergreen or diciduous. On heavy land we have found nothing quicker or cleaner than the Cherry Plum or Myrobalan. But profit-yielding hedges have been formed of Plums, Damsons, Bullaces, Ornamental Crabs, Apples, Roses, and other plants.

Protective belts or plantations of trees are more expensive, and need the most careful consideration, as there is not only the time required for them to become effective, but the space occupied and overshadowed is lost for cultivation. Still when hedges do not suffice, some provision of this kind must be made, and the points to be observed are to have quick-growing, compact trees, which should be further kept in bounds by pruning and lopping. Where low trees suffice, especially if the situation be damp, Willows may be useful in several ways; if tall trees are needed, Poplars are all quick in growth, and will bear any requisite amount of cutting. But their roots extend a long distance, and the trees are objectionable, as the resort of many injurious insects. The Common Plane is quick in growth, though it does not form a dense head, but it is of the greatest value in town districts. The Common Sycamore is also useful, and the Norway Maple is a strong grower, standing exposure well. The Wych Elm is fairly quick in growth, and succeeds on some of the roughest coast lands. 


\section{LABOUR QUESTIONS AND DIFFICULTIES}

THE manual labour required upon market-garden land may be divided into several classes, but the two principal which demand consideration come under the heads, (I) Permanent, (2) Temporary. Both present certain difficulties, and upon the way they are dealt with a large measure of the success attainable in results will depend. As pointed out elsewhere in this treatise, many labour difficulties are reduced in districts where market gardening is an established industry. Near towns also they are more easily overcome; but in rural districts, where farm land is being devoted to intensive cultivation, several matters of serious moment cannot be overlooked. The provision of cottages is one of the subjects which must be attended to at the outset. In many counties the depopulation is not due alone to the attractions of towns or the lack of employment, it is partly owing to insufficient housing accommodation. When an industry is started which offers work to ten times the number of hands upon the same area of land, it is obvious the matter assumes a serious aspect. For permanent workmen cottages must be provided, and thus a heavy outlay has to be at once faced if there be no adequate existing erections. Upon freehold land it can be regarded as a safe investment, and there would be no difficulty in obtaining the requisite capital upon such security. Suitable cottages can be erected at a cost of $\oint_{1} 50$ to $£_{200}$, provided the plans are passed by the local authorities, and the water-supply is sufficient in quantity and quality. In the latter case analysis must 


\section{THE BOOK OF MARKET GARDENING}

determine the satisfactory character of the water before occupation is authorised, and through not making a prior inquiry on this point considerable difficulties and expense have been caused at times. Lord Carrington has stated (see Times, Oct. I2, 1905) that upon his estates in Buckinghamshire and Lincolnshire, between the years I 873 and 1897,43 cottages have been erected at an average cost of $6 \mathrm{I} 56, \mathrm{I} 3 \mathrm{~s}$. each, and the rent charged to the occupiers is one shilling per week. In reply to inquiries upon the subject he further stated that the value of the land is reckoned at $£ 25$ per acre; and allowing a quarter of an acre to each cottage $(=£ 6,5$ s. $)$ and the estate agent's expenses in preparing plans, etc., at two shillings percottage, the total cost is brought to $£ 163$. Obviously the rent charged pays no appreciable interest upon the capital sunk, but the owner very truly adds, "A farm without security of labour does not command anything like such a high rent as one on which there are cottages for the labourers."

This applies with far greater force to land employed for fruit and market garden purposes, where there is more urgent need for manual labour; and as wages are higher, rents range from $2 \mathrm{~s}$. $6 \mathrm{~d}$. to $4 \mathrm{~s}$. per week. Upon a large holding the fact of having a sufficiency of permanent labour will increase the annual value of the land by 5s. to IOs. per acre, and in this way a substantial interest is certainly secured. We know practical business men who regard the matter in this light, and who consider their outlay as one of the most satisfactory parts of their expenditure.

The amount of permanent labour required must be regulated by the character of the cultivation, the crops, the nature of the land, and how far the arrangements or methods permit the employment of horse labour or steam power. Upon an agricultural estate in the Midlands we have found the average over some thousands of acres to 
be as low as one man and a boy per Ioo acres. With intensive cultivation, in which hand labour was chiefly employed, it has risen to one man per acre, and with glass houses added the permanent labour is enormously increased.

The rates of wages vary greatly in different districts, and local customs must to some extent be followed; but it is a safe and sound policy to give good wages and secure the most skilful and reliable men. They should also be allowed special encouragement whenever possible at busy times, by allotting them a share of piece-work, or by paying for overtime. The stoppage of outdoor labour by wet or frosty weather introduces a most difficult question as regards men in receipt of regular weekly wages. The best and fairest system is to keep in reserve certain work that can be done under cover, in sheds, etc., at such times. When long periods of severe weather occur in winter, and wages are stopped, wholly or partly, the men are subjected to great hardships, and it often takes the largest part of their summer's work to clear up the arrears of rent alone. At the same time a commercial establishment cannot be run on a system of paying wages without a return in labour. Where the cultivation of plants or fruits under glass forms a part of the business there is less difficulty in finding constant work for a permanent staff, and that is one of the advantages that accrue from a combination of the various departments of market gardening.

Temporary labour is always required at certain periods wherever extensive cultivation of fruits or vegetables is undertaken, and in rural districts at a distance from large towns, with only small villages to depend upon, this often occasions a great difficulty at critical periods. The numbers of women, with girls and boys old enough to leave school, that are obtainable under such circumstances are very limited. In a farming district with four or five 


\section{THE BOOK OF MARKET GARDENING}

villages within a radius of two or three miles and a total population of about 1000 , we have found it difficult to secure fifty temporary workers for gathering small fruits, etc., though the rates offered were in advance of those prevailing in the neighbourhood. Where the villages are still more distantly placed the difficulty is proportionately greater, and in such cases it is compulsory to import labour. If large towns can be reached by road, it is usual in some places to engage the hands required and bring the people out by vans, etc., returning them in the same way, each day, at the week's end or when the special work is finished. In the last two cases the provision of sleeping accommodation is a serious matter, as it rarely happens that villagers can provide lodgings for such "visitors," and if they are able to do so they are seldom willing. When temporary labour obtained in the way indicated (or by train) is required regularly every year, some market gardeners and farmers have found it advisable or even necessary to build wooden or corrugated iron sheds divided into cubicles, or small apartments, each with a separate door, and such structures can be put up in a simple way at a moderate cost. If large barns or other buildings exist they can be sometimes utilised in the same way, but tents might often be substituted with advantage, under suitable arrangements. Second-hand army tents are obtainable from some dealers at a moderate rate, and with due care and proper storage they may last for a considerable time.

All temporary labour employed on established undertakings should be paid by piece-work, or by the hour, the former being preferable in the majority of instances, and will necessitate a simple but exact method of checking. For land work it is an advantage to pay by measurement, which may be facilitated by having the ground set out in plots of a known area and numbered. In gathering, both weights and measures of capacity are 


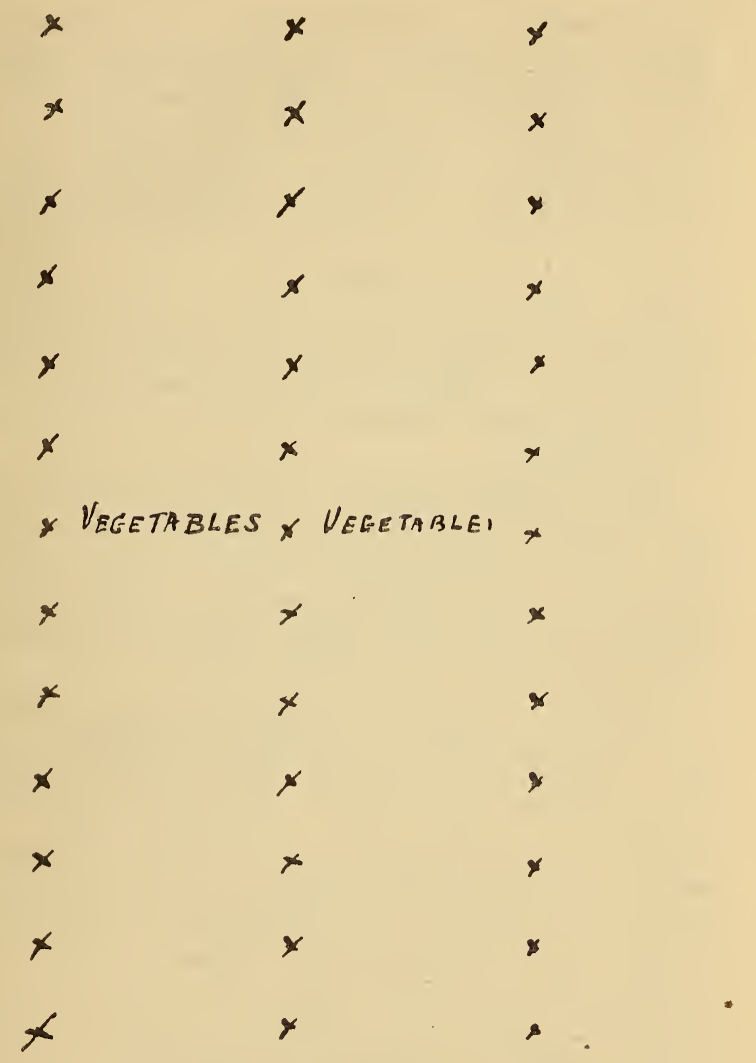

Diagram 3.-Fruit and Vegetables or Flowers. (See page 32.)

Standard Apples $(X)$ in single lines 30 feet apart in the rows, 30 yards between the rows. Plums, Apples, or Pears, with Bush fruits (as in Diagram I), in the lines of trees. The intermediate spaces cropped with vegetables or flowers.

[Scale, I inch $=30$ yards. 


\section{THE BOOK OF MARKET GARDENING}

utilised, and to avoid all trouble of booking it is sometimes the rule to pay the sum agreed upon to each individual when the basket or box is brought in. Otherwise numbered tickets or metal checks are given and payment is made daily or weekly as arranged, but daily payment or part-payment is commonly required by such workers. The actual rates are even more variable than those that apply to permanent wages, and in many instances they depend upon the amount of the crop, as the possible earnings will be regulated by the quantity available. In bunching or similar work, fixed rates are adopted, as the workers' earnings depend entirely upon their own skill and quickness.

As regards the relative value of men and women in temporary work of the kind indicated, there is little doubt that while the former are needed for most land work, especially on the heavier soils, the latter are the best adapted for the lighter forms, particularly gathering and bunching.

It should be added that wages for permanent hands range from $2 \mathrm{~s}$. $6 \mathrm{~d}$. to $4 \mathrm{~s}$. per day, according to the skill and experience of the men, while for some it may rise to $5 \mathrm{~s}$. or $5 \mathrm{~s}$. $6 \mathrm{~d}$. a day. In some extensive market gardens also it is the rule to have the smallest possible number of permanent hands, who practically act as foremen in different departments; the whole of the work is done by temporary labour by piece-work or payment by the hour, and printed bills are posted up at the entrance to the office or at the gateway, "No notice given or required to terminate work in this establishment."

Considerate treatment with judicious firmness and fairness is appreciated by the best men of all classes with which we have had to deal, and those who are not amenable to such management are not worth having. It is, however, always advisable to have a few plain 
rules regulating the hours of work, meal-times, etc., and stated times for the payment of wages. Such rules should be strictly enforced, especially with regard to the times for starting and ceasing work. In a large staff, laxity in these matters means considerable loss, and regularity is mainly a matter of habit.

\section{Horse Labour}

No more efficient means of cultivating the soil has been found than the operations of digging, forking, trenching, and hoeing by manual labour. Valuable as this is, the expense is so heavy that wherever possible it is reduced by the employment of other power, and the larger the area of land to be dealt with, the more necessary it becomes to utilise cheaper sources of labour. With the aid of the best ploughs of various forms, and the many excellent cultivators now in the market, horse power can be turned to good purpose, especially on heavy soils, which need so much strength to break them up sufficiently. It is only at particular times that the soil is in the right condition for operations of the kind named, and it is therefore necessary to complete them as quickly as the means at command will permit. The satisfactory preparation of any heavy soils by horse labour depends entirely upon the frequency with which they can be worked before they are too wet. For many of the refractory soils (which are not, however, those usually selected for market garden crops) a period of exposure in a roughly turnedup state to the action of frost and weather is also essential, and when that can be provided the condition is improved in a surprising manner. On light and medium soils, simple horse ploughs and cultivators can be used to good purpose; but on the more substantial loams, two and three-horse machines are requisite, and in some instances we have had to employ four horses to 


\section{THE BOOK OF MARKET GARDENING}

carry the work out in a thorough manner without unduly distressing the horses. All the cultivators we have tried are fitted with tines, shares, or blades that are movable, so that they can be raised or lowered for light or deep draught respectively. They can be reduced in number if desired, and in some cases the machines can be widened or contracted to fit them for working in rows of different widths in horse-hoeing. The Planet Junior Machines are very useful in this way on medium soils.

\section{Steam Power}

On farms and market gardens of the largest extent, and with heavy soils, steam power is often a desirable aid in ploughing and cultivating, or in breaking up old pasture or arable land that requires to be deepened for special planting. When the engines and tackle can be conveniently hired and brought on to the land, it is the cheapest form of preparing large areas of land, but it will not pay on small extents, or when a portion only can be done at the one operation. It is usual for the hirer to provide and cart the coal for the engines, also to keep them supplied with water, and this is a serious item, especially when it has to be carted a distance. When water is not procurable or only at a serious cost in labour, it is useless to think of steam cultivation. Otherwise where speedy preparation is important the power is both cheap and valuable, but if the soil is heavy and has not been efficiently cultivated it must be remembered that the work is apt to be done in a rough manner, necessitating much after-treatment to reduce it, or a prolonged period of exposure to effect the same object. Some forms of Agricultural Motors have been tried with varying results, but improvements are being constantly effected, so that we may look for really useful machines in this direction. 


\section{CROPS, METHODS, AND MANAGEMENT}

\section{SPECIALISATION}

IN commercial gardening, as in other forms of business, the truth of the old homely adage that it is unwise to have all your eggs in one basket has been often proved. These are days of specialisation, and it is well to have some crop to which particular attention is paid, to excel if possible in its production, and to gain a proportionate reputation. But the uncertainties of British weather, and the variability of British taste in some matters, are apt to lead to unexpected failures, with disastrous results if there is nothing else to depend upon. The advice given by the savant with regard to general knowledge, "learn everything of something, and something of everything," is just as applicable to gardening for profit, as the wider the range of a man's cultural knowledge, the more likely is he to keep up to the times and ahead of his rivals. At the same time, it is not advisable to attempt too much, or that may lead to equally bad results. It has been proved that gigantic businesses can be created in the production of a few special crops like Grapes, Cucumbers, or Tomatoes amongst under-glass fruits; Roses, Chrysanthemums or Daffodils amongst flowers ; Celery, Onions, Asparagus, Cabbages, Cauliflowers, Brussels Sprouts, or Potatoes amongst vegetables; and Apples, Pears, Strawberries, Raspberries, Currants, or Gooseberries amongst hardy fruits and such exceptional crops as Mushrooms both outdoors or under cover. 


\section{THE BOOK OF MARKET GARDENING}

It is sometimes found that a man can make a profitable business with one group of plants alone, as with Ferns, for instance, or even with one kind of plant, as Lilies of the Valley, or any of those already mentioned. Such results may be brought about by special experience and skill, by the help of local conditions or circumstances, or by the grower's perception of an increasing demand which it pays to supply. It is unquestionable that a material aid to any undertaking is yielded by an easily produced speciality, and under exceptionally favourable conditions it may be developed into a substantial business. Still, the majority of those who engage in market-gardening cannot depend upon one crop alone, especially when the land held covers an extensive acreage, and a combination of crops becomes a necessity.

\section{VEGETABLES}

Near populous cities vegetables are always largely grown, as the demand is constant for fresh produce, and where bulky or heavy crops of that kind can be conveyed by road, it is advantageous to the grower. Another point in their favour is that under the best systems of cultivation several crops can be raised from the same land in one season. Soil which has been brought to the highest state of productiveness by constant working and heavy manuring is independent of any precise system of rotation; it is only a question of time, weather, and good management to have the land constantly occupied, or ready for the reception of another crop as soon as one is removed. Again, too, when fresh land is taken in hand, a course of cultivation under vegetables is an excellent preparation for what are to constitute the permanent crops. Very large returns are also obtained from well-grown vegetables of the more important kinds, and it is not therefore 


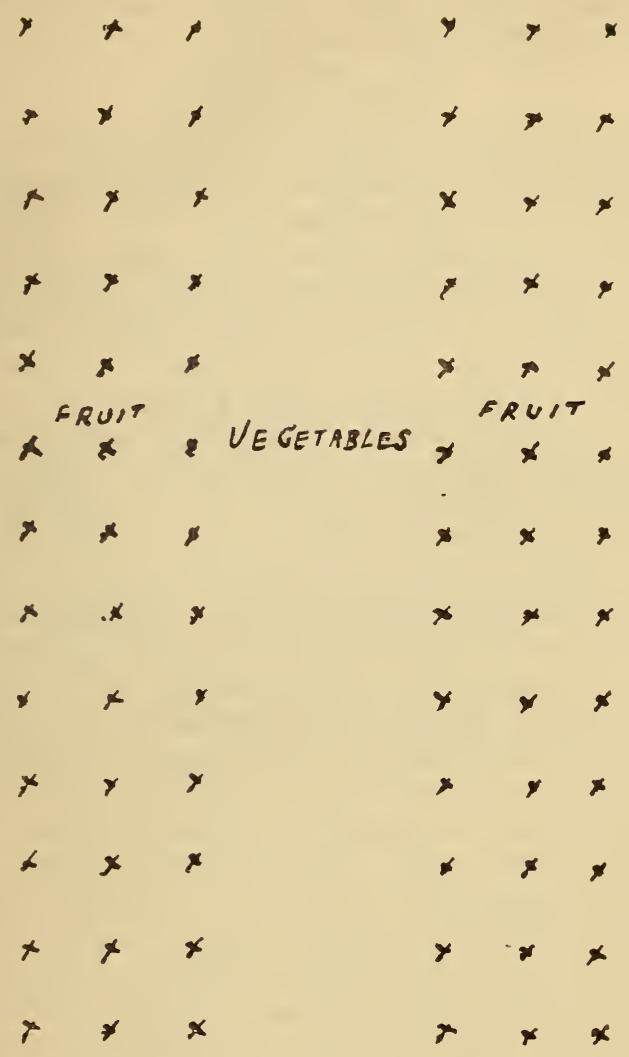

Diagram 4.-Fruit and Vegetables or Flowers. (See page 32.)

Apples at 30 feet by 30 feet in three lines. The intermediate spaces 30 yards wide, cropped with vegetables or flowers. Between the trees as in Diagram 1 or 3 .

$[$ Scale, $\mathbf{I}$ inch $=30$ yards. 
surprising if these crops rank high amongst those to which a grower turns his attention.

\section{HARDY Fruits}

Hardy fruits are indispensable wherever the soil and situation are suitable, and the best varieties well grown constitute a most important part of a market-man's assets. In favourable seasons the returns will always be substantial for the space occupied, and occasionally special crops of choice fruits will yield a profit unsurpassed by any other form of out-door cultivation. But there are always the weather risks to be reckoned upon, the spring frosts being the most disastrous, though high winds at the time when Apples, Pears, Cherries, or Plums are maturing may bring equally bad results in damage to the fruit.

If it were not for these uncertainties, fruit-growing would be the most profitable form of utilising the land; and even with these difficulties to contend against, taking a series of years, the average returns under the best systems and in the right situations compare very favourably with those from any other crops. When grown in combination with both vegetables and flowers, arranged upon the most economical methods, with the highest cultivation, the gross returns per acre often exceed any other form of land utilisation for cultural purposes. The kinds of fruits especially adapted to the soil should always have precedence : thus in one district Apples may thrive the best, in another Plums. Amongst small fruits, Strawberries would form the best paying crop in one place, and in another Currants or Gooseberries will be more profitable. These are points that each grower has to determine for himself, and they are worthy of his best attention, for if work is started with a mixed plantation it is soon ascertained which crop is likely to yield the best returns in the locality. 


\section{CROPS, METHODS, MANAGEMENT 3 I}

The Board of Agriculture Committee appointed to investigate matters relating to fruit-culture has stated that the total approximate area under fruit in Great Britain is about 300,000 acres. Though this is but a small proportion of the total amount of cultivated land ( 32 million acres for Great Britain and I5 million acres for Ireland are returned as under crops and grass), "the fruit industry appears to be most progressive, in fact it is the only form of agriculture which has exhibited any sign of progress in recent years." 1

\section{Plants and Flowers}

Plants grown out of doors to supply flowers for cutting constitute an important department, which can be well included with the others named in a general business. Where fruit-trees are grown as standards, not too closely planted, the ground beneath can be cropped with many spring-flowering plants, and this system has been adopted in the metropolitan counties for many years. Wallflowers are chiefly grown in this way, but many others can be included where the spaces between the rows of trees are sufficiently wide for the purpose. Such positions are, however, naturally best fitted for plants that flower before the trees are in full leaf. Of other plants that are largely grown out of doors for their flowers, the principal are Roses, Violets, Bulbs (comprising Daffodils, Tulips, and Lilies), Irises, Asters, Dahlias, Gaillardias, Lilies of the Valley, Pæonies, and early Chrysanthemums. Just as with the vegetables and fruits, some of these form specialities in certain localities, while a few constitute a trade in themselves, like the Daffodils in the Scilly Isles.

Plants grown for sale from the open ground are

1 The last official return of Market Garden acreage in Great Britain (1896) gives the total as 96,981 acres, which includes some fruit land. 
mostly hardy perennials, of which large quantities are consigned to the markets in the early spring months. The demand for these has increased greatly in recent years, but the period during which they can be dealt with is of limited duration. Where a combination of the nursery business with market gardening is carried on, as some growers do very successfully, hardy trees and shrubs are included in the stock, besides a general collection of fruit-trees and bushes. When a stock is once raised, the space required for its maintenance is comparatively small, and an annual auction sale is a convenient means of disposing of the surplus. But in some country markets growers make up bundles of trees for the sale day throughout the winter. Unfortunately so much carelessness is often displayed in the selection and naming of such consignments, that they have fallen generally into bad repute. The remedy for this state of affairs is in the hands of every grower.

\section{Arrangement of Crops}

Where vegetables, fruits, and flowers are grown upon one holding for market purposes, the three chief methods of arrangement in use are: (I) the mixed system, where the fruit trees are planted closely with bush fruits as under-crops, and all intermediate spaces are filled, as long as the growth of the trees and bushes will permit, with vegetables or flowers; (2) the separate method, each crop being allotted distinct plots of land; and (3) the alternate system, where fruits and vegetables, or fruits and flowers, are planted in alternate blocks. The first is practised largely, and is regarded as the most economical in some districts, but it is attended by several disadvantages in connection with routine cultivation, in the gathering of the fruits or under-crops, and in securing the best results with them. 
The second enables cultivation to be carried out thoroughly and conveniently, but as regards the fruit quarters the land cannot always be utilised to the fullest extent, and it often happens that the best aspect and the best soil for the fruits are also those where vegetables, especially early crops, would succeed most satisfactorily.

The third, or alternate method, provides a combination of the recommendations of the other systems, with a reduction of the defects to a minimum. The best positions can be equally utilised for all crops, and if any kind of rotation is desirable or necessary, it can be readily arranged. In addition to this the fruit trees, if in single, double, or triple lines, are more fully exposed to atmospheric and sun influences, they develop into finer specimens, the wood is better ripened, and the fruits assume a superior colour and flavour to those borne by trees in dense plantations. Then, too, the operations of spraying, pruning, and gathering are more conveniently performed; while, if the lines are kept to certain varieties, and any of these fail, they can be removed and others put in their places without disturbing the arrangement of a whole plantation. Upon moderate slopes, towards the south, such systems are excellent in all respects.

The distances allowed between the lines of trees may be varied according to convenience and the fruits or other crops which are to be grown. We know examples where the distances allowed are from 20 yards to 60 yards or more, but within reasonable limits the trees afford a measure of protection to the other crops, so that can be borne in mind when preparing the plans, as local surroundings would require consideration. Usually such blocks can be only cultivated in one direction, following that of the tree lines, but cross-cultivation is not of so much moment where the land is subjected to the constant working of market 


\section{THE BOOK OF MARKET GARDENING}

garden methods. For strawberries this alternate system is well adapted, because they are only retained for a few years on one plot, and, more than most fruit crops, they are benefited by having fresh land. Root crops can also be alternated with other vegetables in a similar way; while bush fruits, such as gooseberries or currants, succeed remarkably when planted upon land previously cropped with vegetables. Many exhausting crops can be folluwed by flowers with advantage, as too rich a soil is apt to induce excessive leaf growth.

\section{Economy in Production}

Several matters in connection with commercial horticulture do not receive the attention they merit, and one of the most important of these is economy in production. This does not mean a blind reduction of expenses to the lowest level, which may really defeat the best objects in view, but a constant endeavour to secure efficiency, to avoid waste of labour or material, to increase the output of the power employed, or to improve the quality of the products. These results are partly dependent upon the employment of the most skilful labour at fair wages, and upon the supervision exercised; but they are also largely influenced by the knowledge, experience, and judgment of the directing power. Many instances could be given where a falsely named economy, founded upon insufficient or inaccurate knowledge, has produced far worse financial results than the defects it was intended to remove. On the other hand, some of the most successful growers for market have, at times, incurred expenditure in the organisation or development of their business which appeared excessive to the unenterprising, though it resulted in gains out of all proportion to the outlay. Keen observation and sound personal knowledge must furnish the key to success in such matters, and it is wise 


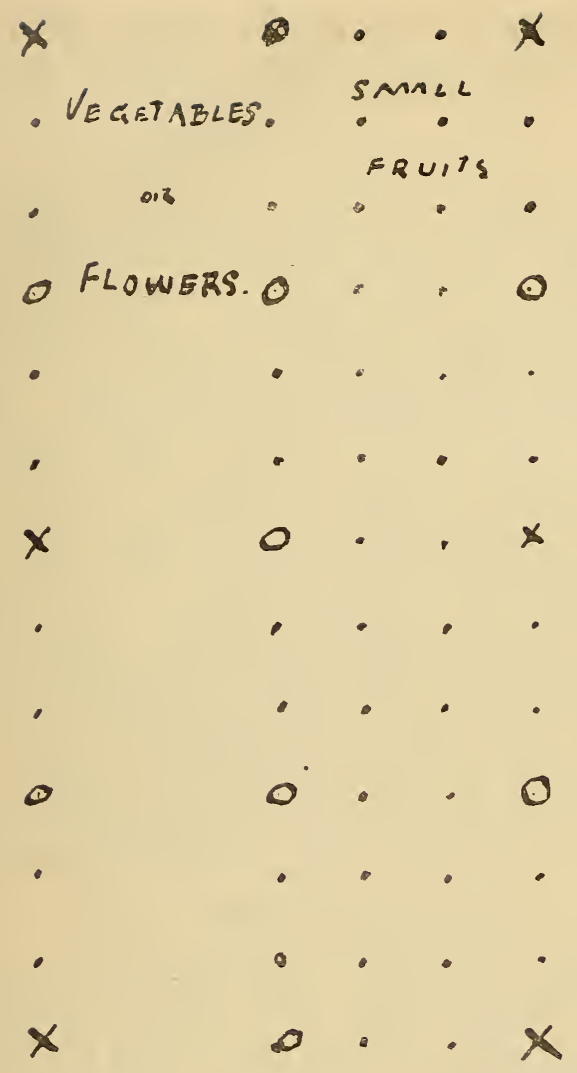

Diagram 5.-To Illustrate the Arrangement of Mixed Fruit Plantations, with alternate Spaces for Vegetables or Flowers.

Standard Apples ( $\mathrm{X}$ ), 30 feet by 30 feet. Standard or half-standard Plums, or bush Apples $(\odot)$ at 15 feet apart. Gooseberries or Currants $(\cdot)$ at 5 feet.

$[$ Scale, 2 inches $=30$ feet. 


\section{THE BOOK OF MARKET GARDENING}

to remember that though the proverb states, "In the multitude of counsellors there is safety," the safety is often on the side of the advisers only.

\section{The Use of Fertilisers}

One point that is either neglected entirely, or if recognised is too often not utilised to the fullest extent, is in regard to the use of chemical or artificial manures in addition to natural manures. When the position of the market ground permits the carting of produce to market, the vehicles returning loaded with stable manure, the supplies are plentiful and the cost small. A grower therefore does not feel disposed to incur additional expenditure in purchasing artificials. In some of these cases, however, a judicious occasional dressing of special fertilisers produces good results, though their value is especially found when the supply of natural manure only suffices for small dressings. Applications of carefully chosen fertilisers as sources of nitrogen, potash, or phosphoric acid, are then of considerable advantage, as many have proved by experience. Under heavily manured land, lime is also frequently beneficial.

Interesting information in this direction, particularly as regards vegetables, has been afforded by the experiments conducted by Dr Bernard Dyer and Mr Shrivell on a farm near Tonbridge, in Kent. In our own experience we have had instances where artificials alone have either failed to produce any appreciable effect upon certain soils and crops, or the result has even been unfavourable; but in soils which have had abundance of natural manure, or in addition to moderate dressings of either stable or farmyard manure, the effects have been conspicuous

\section{Insects and Diseases}

The judicious use and prompt application of insecticides or fungicides to plants attacked by pests or diseases 
is another subject which does not receive adequate attention in many commercial centres. There is too much of the inclination to receive such evils with folded hands as something inevitable or irremediable. Yet, both in the direction of prevention and cure, great advance has been made in recent years. It is true that success has not attended all efforts, but the investigation of the life history of some insects, or the minute forms of parasitic fungi, is difficult and tedious, though that must precede any systematic attempt at dealing with our enemies. Again, some of those who have employed the substances recommended have not exercised the promptness, discretion, or caution that is needed, with the result that the desired object has not been attained, or the plants have been seriously injured. The knapsack sprayers and other machines now in the market permit the work to be done in an efficient and economical manner, while the majority of the substances employed are obtainable at moderate prices. Preparations of Paris Green, tobacco, quassia, soft soap, and petroleum are those most largely used as insecticides; copper sulphate constituting the principal basis of effective fungicides, though plenty of special mixtures are sold that have proved well fitted for their respective purposes.

\section{Cultivation under Glass}

The department of market gardening concerned with the production of crops under glass is one of the most astonishing developments of modern times. In such centres as the Worthing district on the Sussex coast, or north of London from Edmonton to Broxbourne, at Swanley in Kent, as well as in many other localities, a great acreage is under glass, and the produce in the shape of fruits, plants, or flowers is enormous. To deal with such a gigantic business, a special treatise would be needed of considerable proportions; here our 


\section{$3^{8}$ THE BOOK OF MARKET GARDENING}

only object is to indicate its importance as a part of market gardening generally.

How materially the possession of glass-houses aids the resources of a cultivator is proved by the small size of the holdings from which a living can be made when the efforts of the land-worker are supplemented by a few suitable structures. Where the proximity to a market or town affords the opportunity, many men with from half an acre to an acre of land and a few hundred feet run of glass-houses have created a business and secured a respectable living, which their means would have otherwise rendered impossible. Not only is work provided at times when the weather and season would cause enforced idleness on the open land, but a continual supply of produce available for sale is also afforded. Further, whether on large or small holdings, the addition of glass-houses helps to ensure the grower against the disasters which at times overtake out-of-doors crops. Though the occupants of such structures are not exempt from attacks and failures, it is rare that heavy losses in both directions would occur at the same time.

The market man does not require, and cannot afford either to buy or erect, the elaborate structures which are seen in the private gardens of wealthy persons. The simplest and plainest of houses consistent with reasonable durability and adaptation to the purpose in view are needed, such indeed as many an intelligent man with an elementary knowledge of carpentry and building can put up for himself, with the assistance of a handy helper. All the materials are cheap-bricks, wood, and glass are obtainable at low rates, and the most serious outlay of all, the artificial heating with hot-water apparatus, can for many purposes be dispensed with, at all events when starting on a small scale.

The assistance rendered to plants in our climate early 
in the year by the protection of glass and the storage of the sun's rays is surprising to the inexperienced. From the seller's point of view it is important to have his produce in the markets as early as possible, and with many crops, if a week or two can be gained in advance of outdoor produce in bulk, the prices are often more remunerative than where a much heavier expenditure has been incurred for heating apparatus and fuel to secure their crops extra early. In this way wooden frames with movable glass lights, hand frames or lights of various forms, bell-glasses, and the French "cloches," are also utilised to good purpose, both for the protection of tender plants placed out of doors, and for forwarding their development. Thousands of tons of grapes, cucumbers, and tomatoes have been grown for market in England in unheated glass houses; the chief difficulty has been the utilisation of such houses in the winter months. With the help of moderate heating power they are available for many purposes, and with the improved forms of economical boilers now obtainable the expenditure is judicious if the means are at command. In the southern parts of the kingdom, and places at a distance from the coal-fields, the cost of fuel is a heavy item, whatever form is used, but it is less serious for growers in a position to buy in quantities during the summer months, or who can secure contracts for coke supply over a long period.

Span-roof houses are generally preferred, and they are erected now with much more spacious dimensions as regards width and height than formerly, with the rafters farther apart, and consequently larger sheets of glass are used. The objects are obvious; a larger body of air is enclosed, and there is freer exposure to the sun's influence, while greater roof space is provided for anything trained inside. If walls are available of sufficient height, and with a southerly aspect, lean-to houses, or those 


\section{THE BOOK OF MARKET GARDENING}

termed three-quarter spans, can be cheaply erected, and will prove useful for early produce, often without artificial heating arrangements.

Forcing fruits or flowers for the winter, or early in the year, is a difficult, expensive, and uncertain business, severely testing the skill of the most experienced growers, especially in town districts, with all the disadvantages of a smoke-laden atmosphere, dense fogs, and diminished light to contend against. Some succeed in a satisfactory degree, but they also have heavy losses to face at times, and it is not a branch of the business beginners should venture upon.

Another form of forcing by which sheds are utilised for securing early Rhubarb, Sea-kale, or Asparagus, is, however, worthy of attention; the expenses are not large, the demand is considerable and fairly constant. There is more room for extension in methods of this kind than in forcing crops under glass for the earliest markets, though competitors already in the field are numerous, and some have engaged in the work on a large scale.

The value of even temporary protection in the direction of preserving many crops from injury, and thus avoiding heavy losses, is often shown. Here is one example which occurred in the early autumn of I905. In a market garden district where some hundreds of acres were planted with early flowering Chrysanthemums for cutting, the whole crop was rendered quite unsaleable by two or three sudden sharp frosts. A short distance away in a similar situation a grower who had a large acreage under these plants adopted a simple means of protection, by means of slight wooden uprights and cross pieces at intervals, across which tiffany or similar light material was stretched at night. The cost in material and labour was an insignificant percentage on the total value of the crop, and the whole of the flowers 


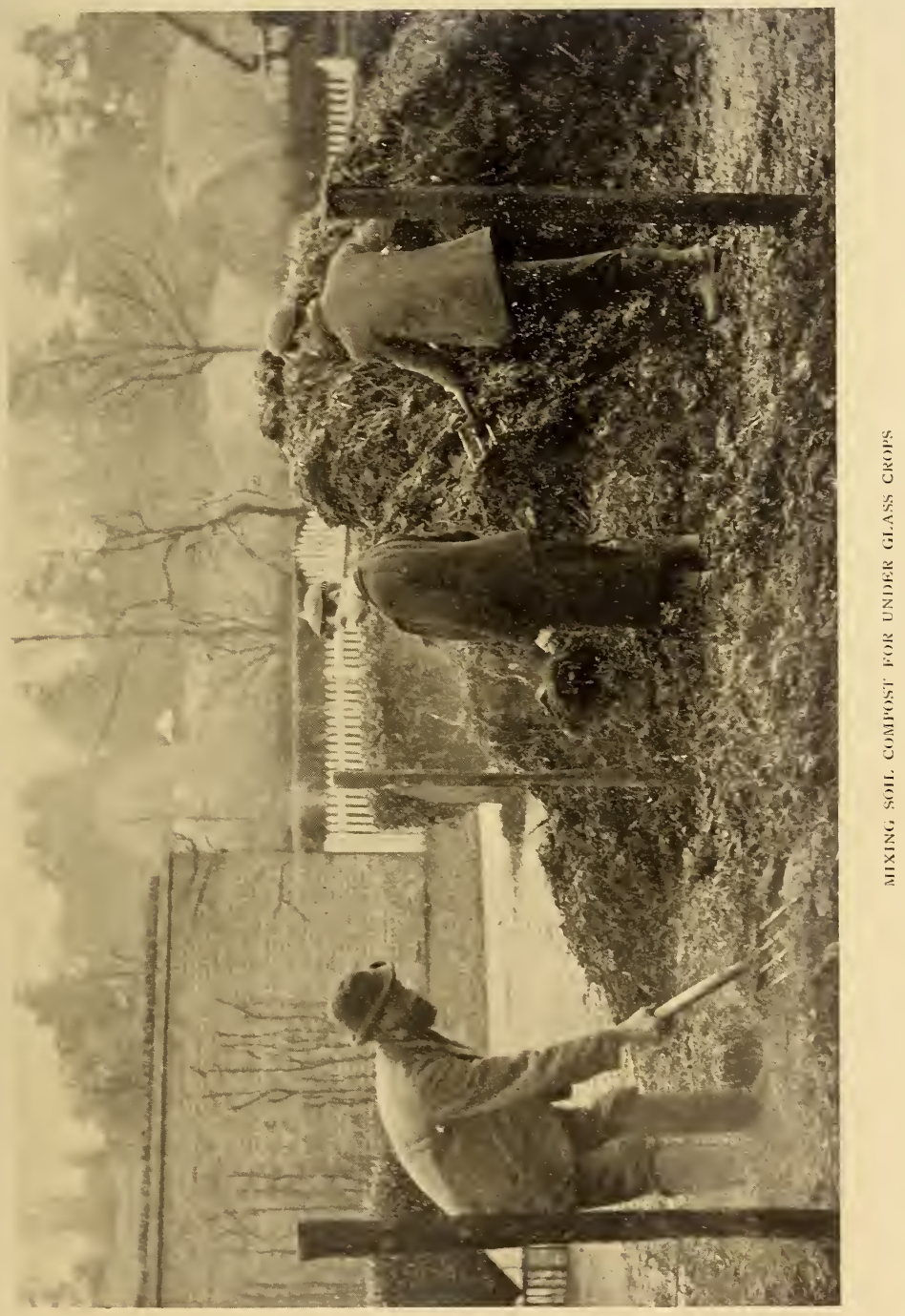



were saved and sold. If no frost had come the cost incurred would have been a small deduction from the gross receipts; but the risk of loss without such aid was a great matter, and proved in the first case very serious to the growers affected.

One matter in connection with cultivation under glass requires attention, and that is the provision of adequate and suitable water-supplies. On a small place it is not a serious affair, but upon a large one it assumes rather alarming proportions. Thus Mr Peter Kay of the Claigmar Vineyard, Finchley, has adopted a plan by which he estimates that some $£ 600$ per annum is saved. By the construction of reservoirs and pumping apparatus, the rain is systematically stored and utilised. The average rainfall at Finchley is about 25 inches a year, which is equivalent to 562,500 gallons per acre; and as the glass-houses cover 34 acres of land, the total amount of rain falling upon that area would be something like I9 million gallons per annum. The reservoir is constructed to hold one-fourth of this, namely five million gallons, or the three months' average. Mr Kay gave the particulars of his experiment before the Royal Horticultural Society, September 25, 1900, and the paper appeared in that Society's Journal. That much water is wasted through insufficient provision for storing the rain is an unquestionable fact, and it applies to many places where the water-supply is very unsatisfactory; yet if it were only remembered that an inch of rain means about 22,500 gallons per acre, some method of catching and storing this valuable supply would be devised wherever there are many buildings or glass-houses and quantities of water are in demand. In the absence of sufficient roof space it has been suggested that a definite area of land should be covered or cemented and the rain conducted into pipes and tanks. Any waste or sterile portion of land could be used for such a purpose : 


\section{THE BOOK OF MARKET GARDENING}

we know of one case where an experiment of the kind proved satisfactory, and much less expensive than sinking wells in that particular instance.

Where running streams or ponds supplied by springs are at command it may be worth the expense of raising the water by mechanical means instead of depending upon the laborious and costly method of carting. Hydraulic rams can be used when a sufficient fall is obtainable, but there are several excellent forms of lightly constructed iron windmill pumps that are both cheap and serviceable in this work, and they are adapted for use anywhere. Whether spring, river, or rain water is the source of supply, ample tank space must be provided for storage and exposure of the water to atmospheric influences. To ensure the raising of the temperature the tanks should be wide and somewhat shallow, in preference to those that are narrow and deep.

The buildings required upon a market-garden holding will vary with the extent and the character of the business conducted. In most cases roomy sheds for sorting and packing purposes are essential; if fruits are grown largely, especially late apples and pears, storing arrangements must be provided. For the first-named object, cheap boarded buildings, with ample windows, will suffice, or corrugated iron sheds are obtainable in various sizes and shapes at moderate prices prepared for erection on any site. Some firms quote prices including railway carriage, and completing the building in accordance with specifications and plans which are supplied free. Besides the provision for packing, space is needed for keeping empty boxes and baskets under cover, also some special accommodation is required when these are made upon the premises. It is advisable to have some sheds open in the front, and of sufficient height to permit a loaded cart or waggon being drawn under the roof in wet weather. In storing fruits extra care is necessary 
to provide buildings with thicker walls of some nonconducting material, so that an even temperature can be maintained. Double wooden walls packed with sawdust or formed entirely of woven straw, or heather, have proved satisfactory, and excavations in the side of banks (especially in light soils) bricked up inside have also answered the required purpose.

The simplest and most efficacious method of storing apples and pears is by fitting the inside of the fruit room with sliding shelves constructed of stout lath or thin wood in strips, shallow trays being formed that will hold from half a bushel to a bushel of fruit.

Storage space is also requisite for some roots that cannot be conveniently clamped out in the open; bulbs, tubers, etc., for another season's planting similarly need dry quarters safe from frost. The stabling for horses, cart sheds, and various other buildings must be provided in all large establishments.

\section{A Summary of Cultural Essentials}

A market gardener who wishes to succeed in his business must be in all respects a skilful cultivator, and should have gained his practical experience by working through all departments. But it is, not the object of this treatise to deal with the details of the various crops and their requirements, as these are fully discussed in other books of this series. It will suffice here if we briefly summarise the essentials that must not be ignored, and upon the due observance of which most of the instructions and suggestions in this volume depend for their efficient application.

\section{Outdoor Cultivation}

I. Cleanliness. It does not pay to grow weeds. The destruction of all, but especially those with creep- 


\section{THE BOOK OF MARKET GARDENING}

ing roots, or abundant, easily-dispersed seeds, must be followed up vigorously.

2. Persistent Cultivation, i.e. the stirring, breaking, and deepening of soils, whenever the weather conditions permit such operations with safety. The deepening to be preferably effected by the gradual improvement of lower layers, and mixing with the upper portions, not by bringing up large quantities at once. When the subsoil is harsh or unfavourable, bringing it to the surface results in a total deterioration of the whole depth.

3. Maintaining the fertility. Constantly adding artificial and organic manure in proportion to the character of the soil and the crops removed, so that the essential elements may always be present in abundance, the physical condition being improved as regards aeration, warmth, and the chemical actions in the soil assisted by sufficient quantities of humus, i.e. decaying vegetable matter chiefly.

4. Protecting crops from insects and diseases. Prompt adoption of measures for the destruction of insects, and the use of remedies for, or preventives against diseases. Equal or even greater attention is needed under glass, but more efficient means are available in the form of fumigators, which cannot be used out of doors with advantage.

\section{Under Glass Cultivation}

All the essential conditions are under the absolute control of the grower, except sun-heat and sun-light, but with such artificial arrangements the utmost care and the closest supervision are needed to guard against injurious excess or deficit.

I. Temperature. The conservation of heat is mainly dependent upon sound roofs and thorough glazing. The maintenance of the requisitive temperature neces- 
sitates well arranged and efficient heating apparatus, suitable fuel, and skilful stoking. Extremes and sudden alternations of high and low temperatures should always be avoided. Plants seriously checked in leaf, growth, flower, or fruit development are often permanently injured, and their value, or that of the produce, greatly reduced.

2. Ventilation. Adequate and easily worked means of ventilation is important. A gradual increase of ventilation is a safe way of decreasing temperature, and hardening plants for sale or use. Aeration is also necessary to the welfare of many plants. Excessive ventilation in highly heated houses is one of the causes of injurious checks noted in the preceding paragraph.

3. Supplies of Water. A skilful gardener must have mastered the use of the water-can. It is an essential portion of his art in under-glass work. Plants grown in glass-houses are subjected to rapid evaporation, and those in pots have limited soil stores of moisture to draw upon. Constant attention is therefore requisite to keep the balance. In an atmosphere saturated with moisture the evaporation is proportionately reduced, but while essential to some plants that condition would be fatal to others, though between the extremes there are many stages that are helpful in preserving plant-health.

4. Sun-light and Sun-beat. To benefit to the fullest extent by these influences early in the season, wide glass sheets, the reduction of rafters to the minimum consistent with stability, and a sharply angled roof facing south are essential. To these may be added the necessity for keeping the glass clean, both inside and outside the house, the latter being of urgent importance in town districts where the deposits from smoke-laden air are abundant.

Insects and diseases are mentioned in preceding paragraphs. 


\section{IMPORTANT DETAILS IN COMMERCIAL GARDENING}

MANY varied circumstances and details exercise a material influence upon success in commercial gardening, and every man who wishes to make substantial progress must give them his best attention, or he soon finds in the keen competition of the age that he is left in the rear. He must be a close observer as well as a good cultivator, and should be prepared to take the fullest advantage of all observations which indicate a reasonable chance of profit. Enterprise will often enable a man to find a fresh crop, or a more paying outlet for his produce, while another man is lamenting over quantities that remain on hand unsold, or who dolefully reckons up his losses on the low prices returned for goods sent to overstocked markets.

In the production of garden crops for sale on a large scale it is quite unavoidable that at times the rush and pressure will lead to rough-and-ready methods of working; but if the general organisation is good, such instances will be the exceptions; where there is no well-considered system, however, "rough-and-ready" becomes the rule with disastrous results. In earlier days, when competition was less severe than it is in present times, some industrious growers who could turn out large crops of fairly well-grown produce were able to secure returns showing considerable profits, because their expenses in some directions were less than they are now. In these days mere bulk is not sufficient, a higher 46 
quality is demanded; the produce must be presented to the buyer in the best condition, and no effort should be spared to ensure this if lasting reputation and sound trade are desired. In this connection therefore we will review some of the chief subjects which affect the results.

\section{Selection of Kinds and Varieties}

Quite apart from the larger question of the special crops a market gardener has to decide upon as most likely to repay him for his labour and outlay, is the secondary but still important selection of kinds and varieties. For instance, it may be considered that fruits offer the best prospect of profit in a particular soil and situation, and attention will, in consequence, be concentrated upon these, though other crops will be grown besides. But the matter is not settled there ; consideration must be given to the point of which kind of fruit is the most promising, as apples, pears, and plums, cherries, small fruits, etc., and when that is disposed of the selection of the varieties requires careful attention, for a large share of success is usually dependent upon this. If varieties most suitable to the soil and district are obtained, and these also are adapted to the growers' special requirements, skilful cultivation ought then to yield the best results that can be possibly secured from land devoted to commercial gardening. The foremost growers have long recognised this in whatever department of horticulture they may work; the seedsmen and raisers of new fruits, flowers, and vegetables have proved its truth repeatedly; yet there are in many districts men who are struggling to extract a living from the land who practically disregard it. They prefer to keep to the "good old sorts" because they have seen several socalled novelties proved to be failures. Yet there are few of such men who have not also seen some of their 


\section{THE BOOK OF MARKET GARDENING}

more persevering and observant rivals reap substantial rewards from the discovery of varieties which for certain qualities have enabled them to command a ready sale, while the others have been wringing their hands or grieving about the decadence of trade.

It might be thought needless to dwell upon this, but experience shows that the neglect of selection is too general, especially amongst the smaller growers, who should be particularly concerned in utilising every chance which might increase their returns. Obviously, it would be folly to discard proved sorts in favour of every variety brought into notice as a novelty. Still, a close watch should be kept for any improvement that gives promise of real value, and it pays any grower to test for himself a limited number of the best. The money value of a substantial advance upon varieties in general cultivation to a grower who is successful in procuring a large supply before others have found out its qualities, often means the making of a business. To every man who has had any experience in growing, buying, or selling, garden produce of all kinds, the knowledge must come that it is only possible to get " out of the rut" by raising something that is better in quality, more attractive, earlier, or cheaper, than the goods offered by his near or distant rivals. If this fact be not recognised, and the knowledge acted upon consistently and constantly, no competitor in the race of modern business-life can hope to gain a forward place.

There is too much "looking over the hedge," i.e. imitation rather than originality. A man notices that his neighbour has some crop which he grows largely and well; it is cleared away regularly with little waste or unsold remainders, and all the results seem very satisfactory, as the producer does not complain about ruinously low prices, or does so with all the evidence of prosperity about him that belies his grumbling. The 
watcher immediately sets about imitating his neighbour, and congratulates himself upon his smartness when he also has secured a stack of the gold-producing variety. Then, too often, he discovers that while he has been "watching," others have been doing the same thing, and where a few had a profitable market, the many bring about a state of affairs in which the prices scarcely pay the cost of production and carriage. Beyond that he also finds that the man who had the real "smartness" was the one who secured the first command of the market, and who by the time the "watcher" is preparing to imitate him is on the look-out for something to take the place of the crop or variety which has rendered him such good service.

\section{VARIETY Trials}

A business man cannot indulge in "fads"; that is not the originality which is requisite. Neither can he be a scientific experimenter on a large scale unless he is prepared to pay for his amusement. But it is in the power of every grower to be a practical experimenter, and one of the departments to which he can profitably turn his attention is the testing and comparison of varieties. Occasionally, under special circumstances, it may even pay him to become a raiser of varieties for his own use, though in a general way it answers better to let the large seedsmen or wholesale dealer perform this work. Hundreds of market men in the principal centres grow their own selections of Tomatoes, Cucumbers, and many vegetable crops, but they find it exceedingly difficult to prevent deterioration, and sometimes this proves a serious matter when the crop is grown extensively. For instance, in one district where Cabbages are cultivated for the early spring markets on a large area of land, it is customary for the growers to save

D 


\section{THE BOOK OF MARKET GARDENING}

their own seed every season. Before cutting is commenced, those Cabbages which are to be saved for seed are marked with sticks, the best and earliest heads being always selected. But in the rush of marketing the crop the sticks are frequently shifted or knocked down, with the result that, unless most careful supervision is exercised, seed of an inferior type is obtained, which may lower the standard of a large crop.

Notwithstanding such mischances, however, every grower should keep close observation upon his own stock, as both seedlings and "sports" may appear that will pay well for increase, and in such a case, if the novelty is of sterling value, the cultivator is sure for the time being, at least, that he holds the whole of the stock. If of exceptional merit, it may prove a substantial asset, and may pay to distribute in the trade.

The chief and most readily available sources of novelties for market growers are the large seed raisers in the United Kingdom and elsewhere, who devote considerable capital and land to the highly important work of producing improvements in cultivated plants. Under the right conditions the business is a lucrative one, but it is none the less work of such great public value that it is deserving of generous recognition when it is conducted on the right lines. It is impossible that all novelties can prove to be of special value. That must be largely a matter for individual growers to determine in accordance with their requirements. But there is no question that the firms with any reputation to lose take the greatest care to avoid misrepresentation of the qualities ascribed to productions sent out as novelties. This is not a passing opinion, but is founded upon an intimate knowledge of the methods adopted by the largest firms in the country and on the Continent. For that reason it is strongly recommended to all market growers not merely to give a close inspection 


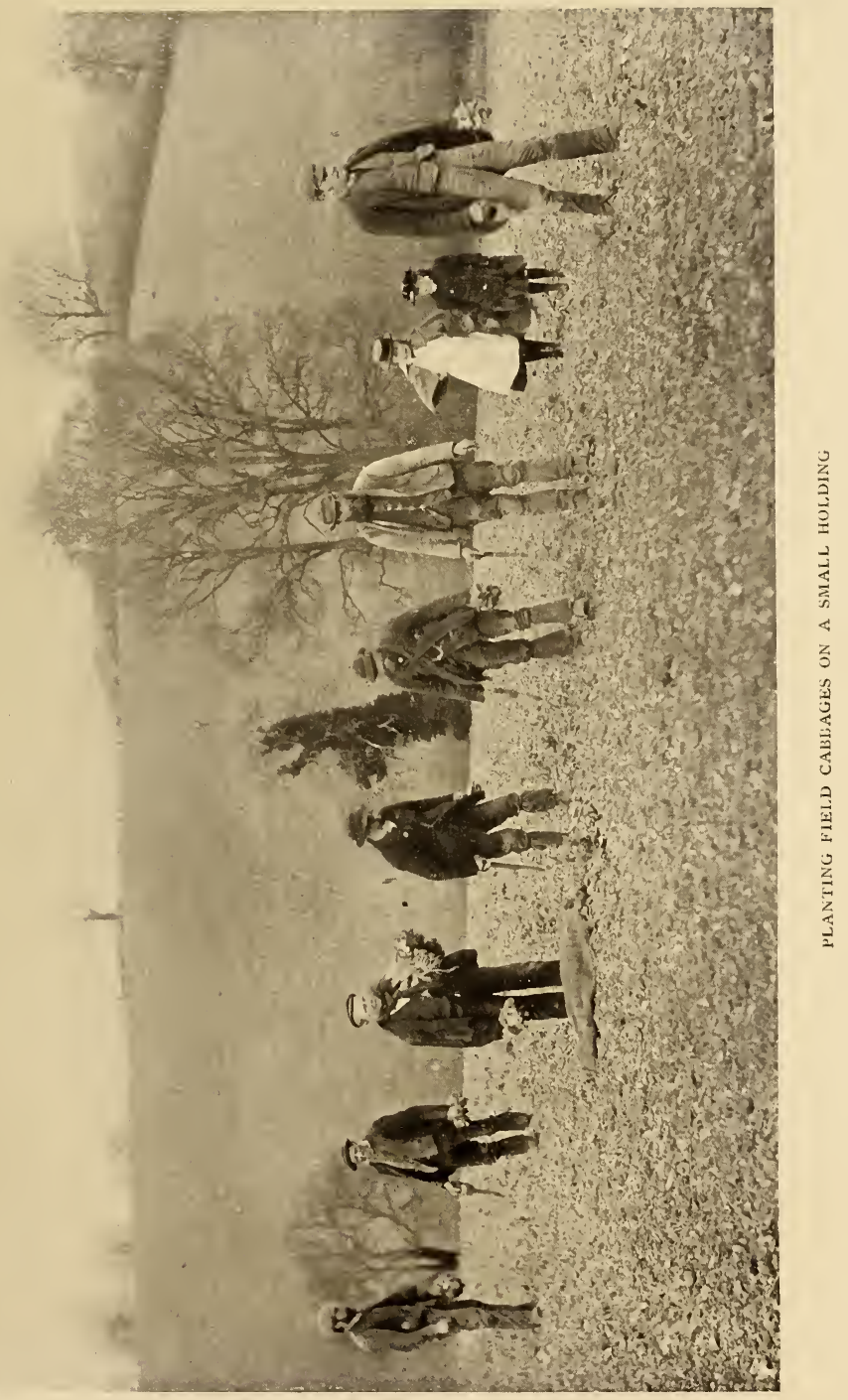



to the catalogues, but to endeavour to see the novelties growing, or at exhibitions, and then found upon these observations a trial for themselves.

The official trials of the Royal Horticultural Society, the exhibits at the fortnightly meetings of the Fruit, Vegetable, and Floral Committees of this body, and the trial grounds conducted by some of the County Councils, afford abundant object-lessons of the greatest value. The utmost advantage should be taken of every source of information, including the numerous excellent periodicals devoted to horticulture, which contain much useful information respecting all novelties as they appear.

The characteristics of new varieties which especially appeal to the market grower and to the public may be briefly reviewed under the following heads, viz., Earliness, Productiveness, Constitution and Duration, Appearance and Quality.

Earliness.-In favourable situations, and by skilful cultivation, it is possible to obtain some outdoor crops much earlier than is usual, and the pecuniary advantage of these first supplies is well understood. But it is not always recognised how greatly the work may be assisted by growing the early selections of standard crops, vegetables in particular, which are being continually raised and distributed. If a week, or even a few days, can be gained in the time a crop is ready for market, it often means all the difference between a substantial return with a good margin of profit and a result which barely pays expenditure. In our variable climate there must be a limit within which such earliness can be considered reasonably safe; it is useless incurring the cost of producing an early crop that runs a serious risk of being cut off by frost. With the earliest garden produce there will always be some uncertainty as to results, but it is the same here as in other investments-if the profits are large the danger of loss must also be reckoned in the 


\section{THE BOOK OF MARKET GARDENING}

account. Perhaps no crop better illustrates the demand for earliness than peas, for within the past fifty years large numbers of varieties have been raised and sent out with special qualifications, amongst which earliness has taken a prominent place. Yet every year some addition to the lists is made which is said to be a few days earlier than the older forms. If the season and weather would have permitted we should have been able to gather peas out-of-doors in January by now. Still the inducement is great, for it is within my own experience, as well as of many other growers, that a difference of a week has meant Ioo per cent. difference in the price realised. As an old grower quaintly puts it, in one week he can procure "more for pods" than he can in the next week "for peas."

Extra late varieties which come in after the bulk of supplies is exhausted, also command good prices in some seasons; but if the main crops are abundant or prolonged they do not give much satisfaction, and generally there is more uncertainty about the demand than in the case of early varieties. This especially applies to vegetables, but in the case of fruits, late varieties, with good keeping qualities, may often be reserved until a first-class market is secured. There is another point in favour of late varieties generally, and that is they are usually of higher quality than the very early ones.

Productiveness. - The commercial value of a new variety which possesses increased cropping qualities is considerable. It means the extension of the producing capabilities of land materially when a large acreage is allotted to a particular crop. Therefore it is a property that must be regarded with marked favour by any grower for profit. Increased fertility in pod and fruit-bearing plants is commonly attended by a diminution in size, but that is not a disadvantage within certain limits. A large crop of medium produce will usually yield a better result 
than a small amount of large size. But in the extreme, i.e. undue smallness through heavy cropping, returns are often very unsatisfactory for the producer. Experience and good judgment are, in consequence, needed to place the true value upon a variety which is claimed to possess an unusual development of the productive character. Still, it never pays a market man to grow "shy" forms of anything, however good the quality may be, as there is the same risk of loss from weather influences and the same cost in cultivation. It is always possible, on the other hand, by the aid of the right manures, by the highest culture, or by judicious thinning, to increase the size of produce if there be a sufficiently good crop to pay for the outlay.

Constitution and Duration.-The hardiness of a variety and the period during which it continues in use are also properties which demand consideration in all sections. As regards the first the difference is often conspicuous in forms of plants so closely allied that without determining the fact it could never be expected. The chief reason which has led to the extensive growth of the Pershore Plum in Worcestershire is the well-proved constitution, i.e. hardiness and fertility of the variety, in contrast with others during a series of years. In consequence the tree has been planted largely in various positions, and the weight of evidence is, that although admittedly of inferior quality as a garden plum, the average returns are too good to allow its being discarded in favour of others, for a crop may often be had when other varieties are almost fruitless. Similar results are found with many plants which come within the scope of the commercial gardener, and in any case a hardy constitution, that is usually also resistant to insect pests and fungus diseases, is a most valuable character for raisers to improve and growers to secure.

The duration of the season or yielding period of a 


\section{THE BOOK OF MARKET GARDENING}

fruit or vegetable is equally of importance, but applies to a more limited number of kinds, as there are many which are cleared at one gathering only. Where successional produce can be had from the same plants, it is evident there must be a larger return for the labour spent upon it and the land occupied. Connected with this may also be considered the "keeping" properties of certain varieties, which is shown more particularly in fruits and Potatoes, though it is seen, too, in many flowers grown for cutting. In any produce not required for immediate use, a lasting character is of substantial help to the grower, as it enables him to place it on the market in the best condition or to avoid any gluts.

Appearance and Quality. - Although these have been placed last in the list of characters in market plants, that is not their position in the order of importance, but taken in conjunction with some of the other properties enumerated they should rank high. The good appearance of any production for sale is not merely of great value, it is almost essential to securing the best prices, and no market grower can afford to disregard it. The majority of buyers judge by the eye alone, and what is pleasant to look upon will always command a wider market than imperfect, distorted, or disfigured produce. In many respects the popular judgment is correct : compare, for instance, the coarse, corrugated old forms of tomatoes with the smooth, even fruits in general favour at the present time. Every housewife can give unanswerable arguments in favour of an evenshaped potato with shallow "eyes" as against the rough, distorted tuber with "eyes" like pits. Equally, too, amongst apples for cooking, the heavily-ridged fruits with deep stalks and "eyes" are discarded in favour of the evenly-formed fruits where the waste in peeling is reduced to the minimum. Unfortunately, appearance and quality are not always synonymous; some varieties, 
both of fruits and vegetables, are very deceptive in this respect, and it is the chief reason that has led to the doubt with which experienced growers regard finelooking exhibition novelties. If the quality of any variety required for eating is really bad, it is not worthy of cultivation, however tempting its appearance may be, and no grower who desires a good reputation and a permanent business should waste his labour over such a crop. The general public do not, however, require the highest excellence such as a connoisseur would expect and insist upon. The majority of buyers are more concerned with securing what they need at a moderate price, and they are content with average quality, provided the other conditions are satisfactory. For good average produce there is an enormous outlet in the large cities, but for that of exceptionally high quality, the market is restricted, though the prices secured may be more remunerative. It practically resolves itself into this: the grower who has an extensive area under cultivation must rely upon the multitude for the sale of the bulk of his produce, and it must therefore be cheap even though the quality be not of the highest. But the market-man who has a small piece of land to depend upon should aim at raising the best quality and securing the top prices. If the small man has to compete with the large grower in the same quality of produce, it is obvious that the former will be placed at a great disadvantage: In the limited number of cases where appearance, quality, and quantity are combined, the ideal approach to perfection is realised if the best cultivation be also provided.

The question of the market value attaching to size in garden productions requires a few remarks under this head. Excessive size is so often associated with coarseness and inferior quality, that it is not surprising there is considerable prejudice against such varieties in the 


\section{${ }_{5}^{6}$ THE BOOK OF MARKET GARDENING}

better markets. At the same time, within reasonable limits, size commands a money value which growers cannot afford to overlook. For example, in the West of London fruiterers' shops, extra large fruits of Cox's Orange Pippin Apples may be seen at 6d. each, equal to about $2 \mathrm{~s}$. per $\mathrm{lb}$., and small fruits of the same variety similarly well coloured, and quite as good in quality, are sold at $6 \mathrm{~d}$. per $1 \mathrm{~b}$. Again, another illustration is afforded in a cabbage-growing district where small varieties of the Ellam's Early type have been almost entirely discarded in favour of selections of the larger Offenham. The demand for early cabbages is great, but the larger heads command the best prices, although the smaller ones of the above named have often more solid hearts and in many cases a greater proportion of eatable substance. As regards cooking apples also, large fruits secure a much better market than small ones, especially early in the season, provided they are not coarse or ill-formed. Therefore in the selection of varieties the property of size cannot be altogether overlooked, though it must not be followed throughout as an invariable rule that the largest produce pays the best.

Colour exercises some influence upon prices, especially in fruits, brightly coloured Apples in particular realising a much more ready sale than those of dull tints. Consequently a variety which possesses a good constitution and fertility with richly coloured fruits, whether new or old, is worthy of attention. Pears are mostly deficient in bright colours, except shades of yellow, but the few which do display more tempting tints are always market favourites. Strawberries, Raspberries, Red Currants, and Plums are all rendered more saleable by bright, rich, and clear colours, and this also applies to Tomatoes with equal force.

In most vegetables the only colour which has a selling 
value is green, and how valuable this may be is proved in the case of Peas, for the varieties which show the deepest tints of green in pod and seed are always in demand. With dwarf and runner Beans, the forms with brightest green pods are also the favourites with purchasers. Under this head may be considered the negation of colour, i.e. pure white, which is important in blanched vegetables, such as Sea-kale and White Celery, or Cauliflowers and Broccoli. Varieties which naturally approach the condition required most readily and clearly should have the preference.

Amongst market flowers, colours are all important in conjunction with durability. Bright, clear, well defined tints are in better demand than mixed or dull hues, and though taste varies at times with regard to the colours most in request, yet the chief general favour is extended to the primary colours and gradations of these rather than to mixtures. A few exceptions occur, amongst which Roses may perhaps be placed, as crimson and magenta shades are admired in them that would scarcely be admitted in other flowers, but even with them clearness and brightness are essential. Pure white always has a high commercial value amongst flowers, and any addition to the list of those suitable for cutting or for decoration is sure to command attention.

In the preceding notes the object has been to indicate the points upon which the market grower should concentrate his attention in making selection of varieties for sale. The variation of cultivated plants is so great that the range is a wide one, but interesting as the whole subject is to the student, the market grower is only concerned with the forms which possess a money value. Public taste is not always quite the same, nor are the requirements in all districts and markets alike, but these are matters which every producer must determine for himself in accordance with the direction he intends to 


\section{$5^{8}$ THE BOOK OF MARKET GARDENING}

take for the disposal of his goods. It is especially desired to emphasise the advantage of keeping a close watch on all novelties as they appear that are likely to affect the particular branch of business being developed. Take every precaution that observation and trial can provide to make sure of the character of a novelty before launching largely into it; but do not go to the other extreme and wait until it is seen that scores of growers are reaping substantial profits, because by that time the most remunerative prices will be falling. Another point worthy of remembrance is that as soon as any particular variety or crop is being overdone and the markets glutted, it is well to turn attention to something else, at any rate for a time. It not unfrequently happens that many growers will discontinue the cultivation, and if the plant possesses any real merit a demand will again arise for it. Should it, however, be a case where the public taste has changed or some substitute has been found that is preferred, it may be generally advisable to drop it entirely. Some judgment is necessary to determine if it is only a temporary or a permanent change, as this may depend upon a variety of circumstances, but it is a rare occurrence that the whole demand ceases at once, so the chief point is to reduce the stock proportionately. 


\section{PREPARING PRODUCE FOR SALE}

THE utmost care and skill expended upon cultivation can easily be (and often are) largely discounted by neglect in the methods of preparing the produce for sale. This is all the more deplorable when every detail has been closely studied up to a certain point, and then when the critical period is reached for presenting what has been grown to the consumers in the best possible way, it is practically left to its fate. Where inferior varieties are grown under the worst conditions, it is not surprising that a series of mistakes is completed by sending the produce to market in a slovenly manner. But from the experienced and able grower something different is reasonably expected. For years salesmen in the largest centres have endeavoured to impress upon growers the advantages derivable from greater attention to this matter, and many have been wise enough to profit by the advice given. As a result there has been a steady improvement amongst all the most up to date producers; that there is still abundance of room for further advance is only too evident to those familiar with the British markets. Our foreign and Colonial rivals contribute abundant examples of the care they have proved to be profitable, but though their methods excite admiration, some home growers are frequently content to stop at that, and continue unchanged the rough style of marketing which has prevailed in the past.

\section{Gathering and Collecting Crops}

The time and method of gathering produce from the land will exert a material influence upon the selling 


\section{6o THE BOOK OF MARKET GARDENING}

results. The special requirements of particular crops must be referred to under Fruit, Vegetables, and Flowers, but there are some general rules which apply in all cases. The first of these is that all practicable care should be exercised in the work, without going to any fantastic extremes which would increase the cost out of proportion to the benefit gained. It would seem almost needless to make a rule of such an obvious requisite, yet we have seen some most grievous and disastrous

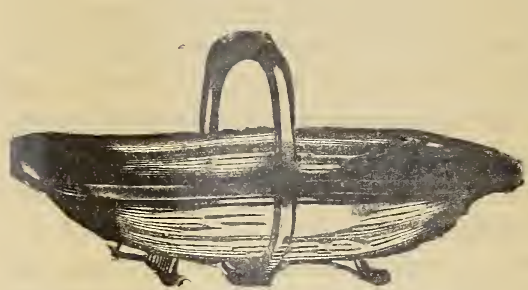

Sussex Truck Basket. (Osman \& Co.) mistakes made in the matter, and it is evident also from the condition in which many consignments reach the markets that similar errors are more frequent than they should be.

Not only should garden produce be in its best state as regards the period of development, but the freshness, cleanly condition, and care in handling demand due attention. With all vegetables and the softer fruits, freshness is an essential of the greatest importance; if it is considered what a long and trying ordeal they have to be subjected to in conveyance by road and rail, and in the markets or shops, before they arrive at the consumer's house, this would never be ignored. The best grown produce in a stale and flaccid state, in contrast with second-rate crops in a fresh and bright condition, is placed at a serious disadvantage, and the majority of purchasers will take the latter in preference. We have seen large and valuable consignments sold to hawkers at the lowest prices entirely on account of stale condition when they reached the markets. Of course in some of these instances the fault rests with the railway 
companies, or may arise from accidents out of the grower's control, but in a large proportion it is mainly due to the producer's neglect or bad system. The difference in the state of all the softer produce when gathered in early morning, as compared with that of similar crops collected later in the day under a hot sun, or in a drying wind, is conspicuous long before the consumer is reached. The ideal arrangement is to gather early and have the produce on sale the same morning, and where this can be realised the grower has overcome an enormous impediment in the road to success. Under the usual roundabout methods of marketing this can only be carried out within a moderate distance of the selling centre; if a long journey by train is an unavoidable part of the programme, it is rare that the goods can be on sale until the following morning. When transmitted by passenger train, or by special arrangements for such fruits as Strawberries, long distances can be reached the same day and sales effected under the right conditions, provided the consignments are of sufficient value to pay for the expense.

Amongst ordinary crops, which constitute the bulk of market consignments throughout the spring, summer, and autumn months, the majority are gathered in the afternoon or evening of the day preceding that when they are to be sold. In the hottest weather all soft, young, and tender green vegetables or salads are then in a semi-exhausted state, which results in a flabby appearance that is far from inviting. Some advantage is gained if such crops can be gathered quite late in the evening, when they have had time to partially recover from the effects of the day's heat, but with few exceptions the early morning has everything in its favour. Instances have occurred in my experience where early gathered consignments of the same crop have been sold in the next morning's market together 


\section{THE BOOK OF MARKET GARDENING}

with those collected some hours later, and the results were conspicuously in favour of the first named, despite the longer period which had elapsed from the time of removal from the ground.

Freshness is therefore of the highest importance, but it must not be secured by neglect of other considerations. For instance, it is not advisable to gather crops in a wet state, particularly if they have to remain packed in boxes or baskets during a long journey. In the warmer part of the year, soft fruit or vegetable produce heats rapidly, and the decomposition induced soon renders it unfit for sale or consumption. But it is not only the wet state arising from rain which has to be avoided, but in clear weather on some heavy, cold soils the dews have quite as much effect in early morning. When the produce is to be sold the same morning or during the early part of the day, this may be really helpful; but if the packages have to remain unopened until the following day, it is a disadvantage and should be avoided where possible.

Cleanliness is another important consideration in the gathering, apart from any attention that may be given afterwards. The inclusion of rubbish of any kind, decayed or defective leaves, and soil-spattered samples, all assist in lowering the value of the other portion of the produce. As regards fruits, too, if the defective or diseased specimens that possess no saleable value are excluded at the time of gathering it reduces the after labour of sorting, and does not damage the better samples, as contact with damaged fruit is apt to do.

Care in handling garden produce applies more especially to fruits which are most easily injured by rough treatment, the slightest bruise even in hard Apples and Pears soon manifesting the effect in disfiguring marks and decayed tissue. Such defects quickly become visible, and fine fruits may be reduced to the price of third-class 
samples by the carelessness of gatherers. But vegetables also pay for the due exercise of care in the gathering, green produce in particular like Cabbages, Savoys, Kale, Lettuces, and Endive, have a sorry appearance when a number of their leaves are broken or damaged. It is easy to lower the market value of a crop seriously in this way, and early Cabbages especially show the evil effects of rough gathering. Potatoes cannot be treated with the same tenderness as dessert Pears or Plums, but there is no reason why they should not be secured with more care than is frequently extended to them. It seems to be a prevalent idea that it is impossible to bruise a Potato by any amount of roughness, yet it can be and is done much too often, while purchasers fancy the discoloured blotches they find on peeling the tubers for cooking are due to disease. Experienced exhibitors at shows know full well the value of care in lifting and preparing Potatoes for competition, and though a market grower who has many acres of tubers to lift cannot expend the same labour on the task, yet he can do something in the direction with profit to himself. Much the same applies to root crops generally; within reasonable limits they pay for all the care bestowed upon them, in removing them from the ground under the best conditions and in avoiding injury as far as possible.

The operation of cleansing after a crop is taken from the land is principally requisite for roots such as Potatoes, Carrots, Parsnips, Turnips or Radishes, as well as those earthed up for blanching like Celery or Sea-kale. As regards the four first named, when the soil is not of a very adhesive character, and it is in a fairly dry state, all that may be needful will be the removal of the soil by hand, or by sifting in the course of sorting, in the case of Potatoes. A large amount of soil adhering to any roots sent for sale has not only a disfiguring effect, it lowers the value materially, and those over-sharp 


\section{THE BOOK OF MARKET GARDENING}

individuals who might imagine they would gain in the weight are labouring under a mistake. Any one familiar with the markets knows the value attached by purchasers, whether dealers or consumers, to clean root crops, and it is one of the special advantages of soils which are not unduly heavy, that the crops turn out clean in the course of lifting without necessitating much afterattention.

Cleansing pays in every case, but the actual subjection of a crop to a washing process is not practicable under all circumstances, though it is essential to the proper marketing of some produce. For example, Radishes nearly always require a preparatory washing, and there is no question that Carrots and Turnips are equally improved in appearance and value. The same remark applies to Celery, which should always be sent to the best markets in a clean condition.

Wherever there is a good supply of water-and this is essential in all the best market gardens-the provision of an arrangement for the systematic washing of crops that require it is neither expensive nor difficult. A series of large shallow tubs or tanks which can be readily and quickly filled or emptied and a connecting pipe with large taps for the supply, with large plugs at the base for outlet, will answer the purpose, while if it is desired to save the water, a channel may be constructed to convey it to a tank at a lower level. If the washing of crops is attempted on a large scale it is no use half doing the work; do it as thoroughly as possible, and have the roots or other produce cleansed, not merely smudged over, they are almost better left in their natural state. This is one reason why several tubs are needed, so that after the washing, rinsing in fresh water will complete the operation. This seems a small detail for a large undertaking, but these small matters tell on ultimate success, as every successful business man has proved. 


\section{PREPARING PRODUCE FOR SALE 65}

Fruit gathering must be regulated by the purpose for which it is required, and though the preceding remarks have a general application, the particular object in view will determine the time at which the work should be done. Fruits to be sold in a ripe condition should have reached their full development as regards size, but must not be in the last stage of ripeness when the tissues are becoming soft. In hot weather, when such rapidly ripening fruits as strawberries are collected, this matter demands the closest attention and the judgment derived from experience. A small proportion of overripe fruits which become crushed on the journey to market is quite sufficient to damage a large quantity of

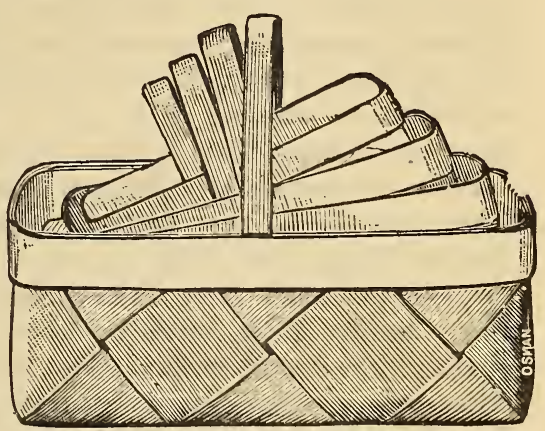

Swedish Chip Fruit-Basket.

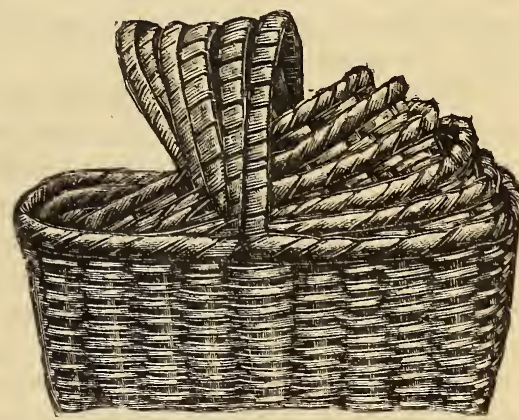

Fruit and Flower Basket.

(Messrs Osman \& Co., I 32-134 Commercial Street, E.)

berries and spoil their sale. Due attention to frequent gathering will ensure the collection of fruits before they reach this stage and a material saving will be effected. Of all fruits which growers have to market in a ripe 


\section{THE BOOK OF MARKET GARDENING}

condition, none is more difficult to deal with satisfactorily than the Strawberry, for besides being fully developed, it must have the best colour possible, which it may only attain a short time before it is dead ripe. While it is extremely undesirable that the fruits should be gathered when hard, green, or white, with a minimum of colour, it is on the whole safer to take them under-ripe than err in the other direction. They need to be sufficiently firm to travel safely, yet should appear in the market in their most tempting guise for the purchaser, and that is where the inexperienced or careless producer often fails. Some varieties are much more easily dealt with in this respect than others, notably the well-known Sir Joseph Paxton, which possesses an important character of a market-man's Strawberry in its firmness of flesh, and the fruit can in consequence be gathered with safety in a much later stage than the soft-fleshed varieties, admirable though they be in other ways.

These remarks particularly apply to fruits intended for consumption in a fresh state, and some modification is needed where the Strawberries are to be converted into jam. It is then advisable to be able to gather as large a quantity as possible at a time, therefore they are taken when the bulk is in the best condition, which is after the earliest and finest fruits have been consigned to market. For the best quality preserves it is quite as undesirable to have the fruit in an over-ripe and smashed state as it is to have it hard and unripe, that is, where "whole fruit" jam is the speciality. If it is all to be pulped, inequality in the ripening is of little moment, provided the majority of the fruits are ripe and of good colour.

Similar methods are adopted with Raspberries, which form another very critical soft fruit crop to gather in the best condition. If it is desirable to gather Strawberries in a dry state, it is absolutely essential to secure 
Raspberries in that condition, for they are the most perishable outdoor fruits a grower has to deal with in a ripe state. Both are picked with the stalks by preference for ordinary market work, but sometimes they are gathered without the stalks for preservers, though occasionally these prefer to have that work performed in their own factories.

Ripe. Gooseberries demand careful handling and prompt gathering before they are too advanced. Heavy rain after a dry time is apt to lead to serious losses in burst fruits when the last stage of ripening is reached, so judgment and observation are requisite to minimise risks. Ripe Plums are also liable to much damage by cracking in wet weather, and some varieties, like Early Orleans, are very subject to this defect. All the choicest varieties for dessert should be gathered with the utmost care, and just before they are fully ripe, which also applies to most stone fruits, as Cherries, Apricots, and Peaches. Plums for preserving on a large scale are sometimes gathered when not more than half ripe and partly coloured. This is particularly the case with the Pershore Plum, of which many tons are sent from Worcestershire to jam-makers in various districts, in a state that the inexperienced would consider much too unripe for the purpose.

Pears in most cases have to be gathered considerably before they are fully ripe, in fact, many profitable market Pears would be useless for sale if left to ripen on the trees. There is one great advantage about these fruits, and that is, provided they are not gathered too early, their best qualities of flavour and aroma are developed almost as well as when on the trees. The large consignments of Pears from France and California prove the truth of this statement, for all of these, but especially those from America, are gathered considerably in advance of their ripening period. By growing the 
right varieties, by careful selection, and by the best packing, good prices are realised in our markets for excellent fruits. The utmost care is needed in gathering Pears that have to be packed or kept for some time before they are exposed for sale, as the slightest bruise is soon developed either into an objectionable spot, or the still more disastrous commencement of decay. Varieties employed for cooking purposes are not so easily damaged in the gathering or in transit, but they are worthy of the little trouble involved in the avoidance of bruises. They can be taken from the trees at any time when fully developed.

Apples constitute an important crop, covering a long season of supply, and the varieties equally meet the two great divisions of popular demand, namely, for cooking and eating. Every preceding remark concerning care in the gathering applies to these fruits with equal force, but, unfortunately, this essential attention is frequently neglected, or such quantities of damaged fruits would not be seen in the British markets from home growers. All early Apples should be gathered as soon as they have reached their average size and the eating varieties are coloured. But well-developed samples are needed for cooking purposes, and though, if supplies are short, growers often gather their earliest fruits when little more than half their full size, it is a question if much is gained by the practice unless the prices are exceedingly high. If the object is to relieve young trees of their crop in order that good growth may be made, it is another matter, and the course is a wise one to take. When also such varieties as Lord Grosvenor set a large number of fruits that are too thickly placed on the branches to develop properly, thinning becomes necessary, and the fruits thus removed are often saleable, if not too small, while those left on the trees will advance rapidly to good size. 


\section{PREPARING PRODUCE FOR SALE 69}

Colour is so great a help in the sale of dessert Apples, that the fruits should always be left as long as possible to acquire this character. Most of the earliest varieties need to be gathered quickly, as they soon deteriorate in quality, becoming "dry," "woolly," or flavourless, if too far advanced. The mid-season and late varieties can be gathered well before they are at their best, if of full size, as they often improve greatly in flavour, and even in colour, if they are stored or packed under the right conditions. The best varieties of Apples, well grown, give good returns for every attention paid to them in the gathering, and other details preparatory for sale.

Similar general principles apply to fruits grown under glass, such as Grapes, Peaches, Nectarines, Figs, and Melons, as well as to Tomatoes and Cucumbers; all must be gathered somewhat in advance of their final stage if they have to be conveyed a distance to the selling centre. But they must not be taken before certain essential characters are developed; thus, with all Grapes, the possession of a dense "bloom" is all-important, and adds materially to the value of the best samples; large berries are also of substantial value, together with freshness, and as near an approach to ripeness as is consistent with safe carriage.

In Peaches and Nectarines, size and colour carry money value, but the fruits must on no account be dead ripe, or they will be useless for sale. Figs, too, are very perishable, and must be picked immediately they are full-grown. Melons require careful judgment to get them in the right condition, for they should be well coloured, yet if gathered a few hours too late they may be almost rotten by the time they are cut on the consumer's table. They are better removed from the plants as they reach full size, and marketed in succession, as they do not all mature at the same time. With Tomatoes, colour 


\section{THE BOOK OF MARKET GARDENING}

is of urgent importance, and the grower has to secure this with the requisite size, and yet avoid that degree of ripeness when the fruits become soft to the touch. Moderately firm, brightly-coloured, even-shaped, and medium-sized fruits are those which pay the tomato grower best, and he must select the time of gathering in accordance with these characters.

Cucumbers of the dark-skinned type should have a good "bloom" on the surface when gathered, but vith the lighter green forms of the Telegraph type the points are full average size and even shape, which also apply to the others as well. In any case a Cucumber should be really green, not yellow or blanched, it must be quickly grown, and as fresh as possible.

Whenever fruits are not gathered direct into the baskets or boxes in which they are to be sent to market, special baskets should be provided for the purpose. The most convenient form is that with a handle over the centre, so that it can be readily carried or suspended as required. It should be shallow, the depth depending upon the kind of fruit and its size; the bottom and sides should be well padded with some elastic material, which must be covered with a substance having a smooth surface, so that the fruits placed in it may not be rubbed; it should be readily removable for cleaning as necessary. In dealing with all the choicest and most tender fruits this trouble is well repaid, especially when crops are short and prices high.

Flowers grown for cutting all require to be gathered before they are fully expanded, and many are best cut when in the bud stage, or, in any case, when they are not more than half open. If properly shaded from the sun, and transferred at once to a cool, rather dark shed, or one with a northern aspect, the stems being placed in vessels of water, most flowers will keep well for some hours, and be in excellent condition for packing even 


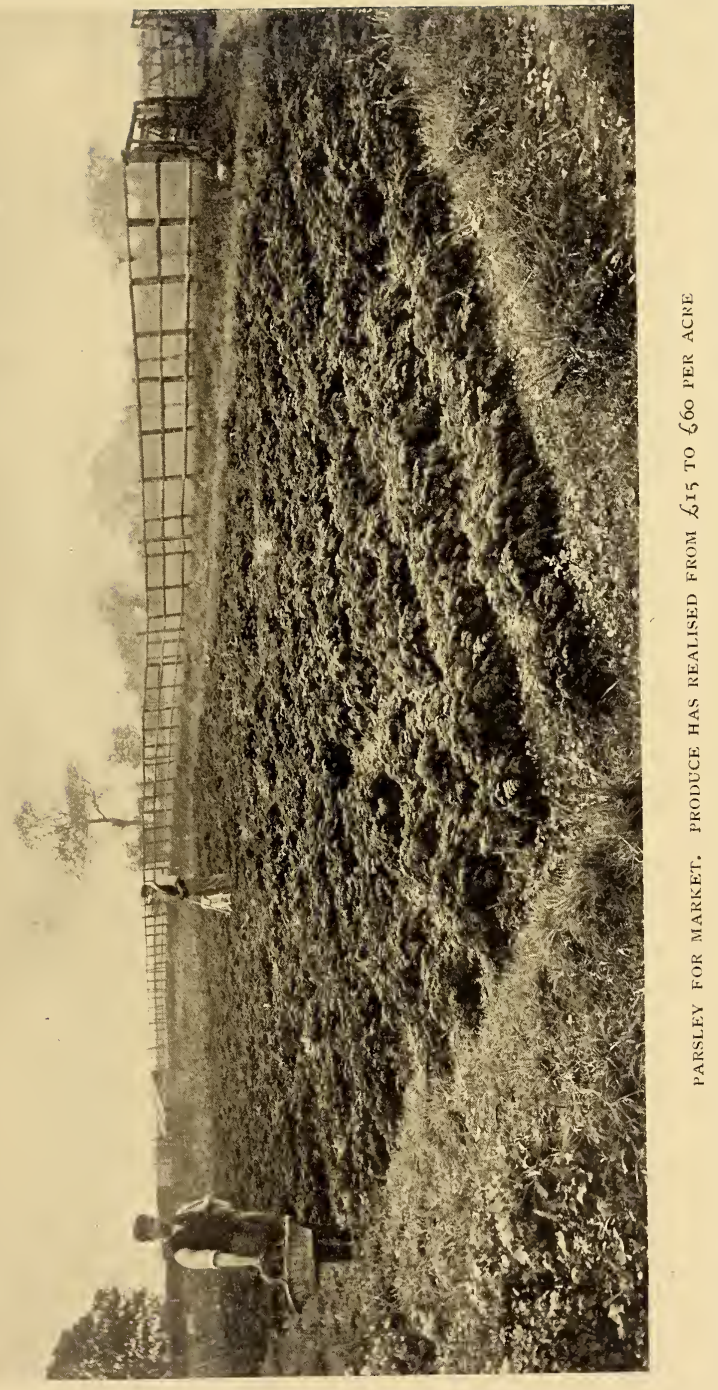





\section{PREPARING PRODUCE FOR SALE $7 \mathbf{I}$}

in the hottest weather. The advantage of gathering flowers in early morning or late evening, as already pointed out, must be borne in mind, for the main object should be to secure them in as fresh a condition as possible, and to keep them so until they reach the buyers. For delicate floral structures the shortest period is a severe trial, even under the best of circumstances, during the summer months. The lasting qualities of flowers vary greatly in different kinds and in varieties of the same species, a character which is well exemplified in Roses, some of the most beautiful of which are so fugacious that they cannot be included in the market grower's list. The least durable of those cultivated are gathered in a proportionately early stage, and this enables the sender to have a quantity ready about the same time in an equal state. With many flowers that are gathered early in their development, it may sometimes be feared that they will not all be sufficiently opened, and to avoid this the stalks can be placed in tepid water for a time, which assists the expansion greatly. In dull, cool, or damp weather, flowers can be gathered and kept with little trouble, though it is necessary to avoid packing them in a wet state, especially some in which decay commences quickly. Wallflowers, for instance, in tight bunches packed closely, will often turn out with an offensive smell if very wet when gathered. If flowers are wet at the time they are cut, they should be placed loosely in small bunches in the packing-shed, so that excessive moisture may drain off or be evaporated from the petals. Full or double flowers like Roses, Chrysanthemums, Dahlias, Carnations, the double forms of Narcissi and Daffodils, retain a good deal of water amongst their petals and florets, but the greater part is easily shaken out if the blooms are young and firm. 


\section{THE BOOK OF MARKET GARDENING}

Flowers forced under glass, usually in a humid atmosphere, wilt very quickly if unduly exposed after gathering. As a rule they are better packed as soon as possible without removal to a shed where the air is dry and cold. When early forcing is conducted on an extensive scale, including bulbs, shrubs, and other plants which are subjected to high temperature, special provision in the shape of heated packing sheds will be necessary, but even then it is not safe to expose the flowers long before preparing them for market.

Some flowers are apt to lose their petals, or the whole corolla, very soon after gathering; and for all those of special value gumming becomes essential before they are packed. This is an operation which requires some practice to perform efficiently without rendering the work conspicuous or disfiguring to the flowers. Where there are many petals it is more difficult to carry out thoroughly and quickly than when these are united into one corolla, as the object is to secure the petals to the calyx, and one drop of gum properly applied will usually effect the desired purpose in the latter case, though several may be needed for the many-petalled flowers. Where numbers of flowers have to be prepared in this way it is a tedious process, but experience soon teaches the quickest and best method of applying the gum. In some cases it is more efficient if dropped inside the flower at the base, and a skilled hand will make one application suffice, or it may be needful to gum both inside and outside the corolla. A small machine oil-can with a long fine tube in which the emission of gum can be regulated by the thumb at the base is useful, and a serviceable gum can be readily prepared from powdered shellac dissolved in spirits of wine, sufficient of the former being used to obtain the requisite adhesive power, but not too much to prevent it running freely from the can. Several ex- 
cellent forms of gum are also prepared by dealers in florists' sundries, and can be obtained cheaply when the trouble of home manufacture is not desired.

The wiring which is now so general in floral work is usually left to the retail florist, and would not require attention in a market business unless a retail trade is also conducted.

Flowers are cut with long stems wherever practicable, that is in every case where this can be done without taking an undue portion of the producing plant, but it is advisable to avoid cutting into hard growth if possible, though with forced shrubs and other woody plants that cannot be helped. Where the flowers are borne in clusters, but are mostly employed singly in floral arrangement, as with Stephanotis and Tuberoses for example, long stems are not required, because the flowers are wired individually after removal from the cluster. If cut with fresh soft growth only attached, the majority of flowers absorb water more readily through their stems, and in consequence retain their freshness better or can be more quickly revived. 


\section{GRADING FOR PROFIT}

\section{Packages and Materials}

THE full significance of the term "grading," and the advantages derivable from its consistent practice in a methodical manner, are still unrecognised by many producers who otherwise manifest much ability in the conduct of their business. Yet all our competitors in other lands who export largely to this country are alive to the importance of grading, and they secure a material share of their profits by the keen attention devoted to the subject. Why neglect should prevail here it is difficult to understand or explain, for if the labour required can be supplied in addition to the freightage of thousands of miles' carriage over sea and land, besides all salesmen's charges, it ought to be possible to obtain a margin of profit close to the home markets. Where this is not done it is through some lack of judgment or from the work being performed in an imperfect manner. We have never known an instance where a crop was of uneven quality that sorting into two or even three grades did not yield a better total result in money return than if all were marketed together without separation. Imperfectly carried out, any attempts at sorting are certainly wasted labour, but there is no substantial reason why it should be done in this manner; wilful neglect and ignorance of simple matters ought to have no place in present day businesses.

Grading can be most effectually practised with fruits, and if carried out in a systematic manner the expense is 


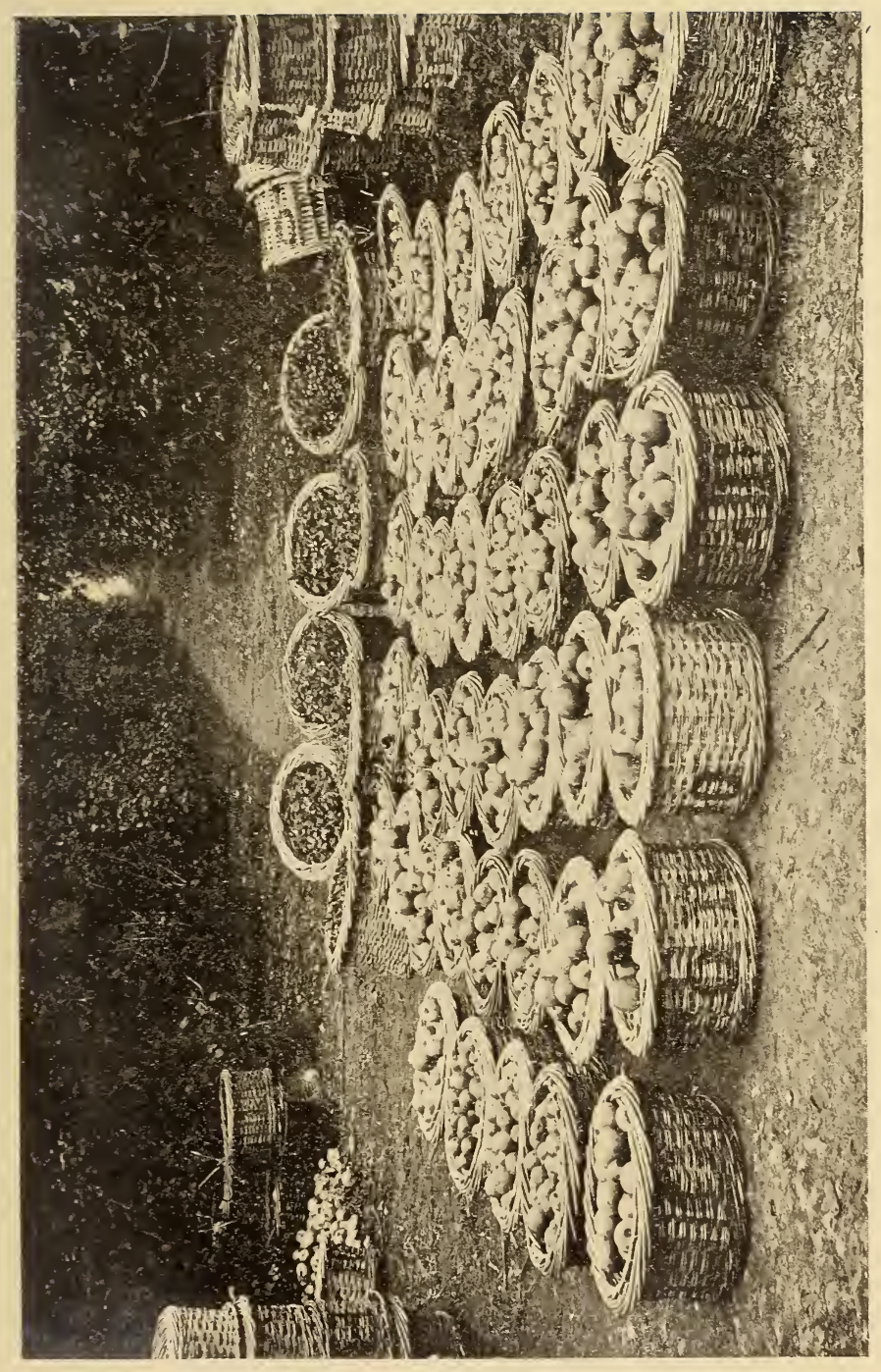

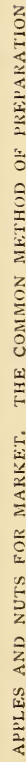



so small that any gain in advanced prices for the produce must show a profit to the grower. The simplest form it can assume is the exclusion of defective, damaged, or small samples, which can be effected at the time of gathering. It commonly happens that a small proportion of such fruits included with the better ones lowers the value of a consignment very seriously, as growers would realise more generally if they sometimes took the place of buyers in the markets. Even though the excluded specimens are unsaleable, the gain is yet on the side of the grader, unless the whole crop is bad in quality. If there are any good fruits, they are worth separating from the inferior ones, and a special outlet may be found for the poorer samples if they will not pay for carriage to a market, and they seldom will do so. However even and good a crop may be, it is nearly always possible to make two grades, the first and second quality, and in many cases three can be separated with advantage. This is especially the case with Apples, which show considerable range in their degrees of merit.

It is not only size which has to be regarded in grading, but colour also demands its share of attention. Mediumsized fruits, highly coloured, will often rank before larger samples that are deficient in the latter character. But if the qualities are well balanced, the larger fruits as a rule will command the higher prices within certain limits. No hard and fast rules can be laid down for guidance in the selection, as the standard will not only differ in distinct varieties, but in other plantations or even on other trees in the same orchard, as well as in different seasons. The chief points to be observed are that there should be a well-marked difference between the grades, and that each should be uniform in itself. These are very important, however, and apply to all garden produce that may be subjected to the process of grading for markets. 


\section{THE BOOK OF MARKET GARDENING}

Pears, Plums, Cherries, Peaches, Strawberries, Raspberries, Gooseberries, Currants, Grapes, Figs, Tomatoes, and Cucumbers all admit of grading if only in two qualities; while the majority of vegetables, particularly those producing pods, or roots and tubers, can be similarly sorted with equal profit. Though the bulk of a sample is reduced by the removal of the second and third-rate produce, it often happens that the returns are increased in all grades by the course taken. The selling value of a mixed sample is based upon the inferior specimens it contains, and not upon the best; besides, when in contrast with finer fruits or vegetables in one box or basket the poorer samples are seen to the worst advantage and do not command the price they would do when constituting a separate grade.

The Board of Agriculture now issues a weekly return of market prices of farm and garden produce, and in this actual selling prices of the latter are given for nine markets -namely,London, Bristol,Evesham, Birmingham, Wolverhampton, Leeds, Manchester, Liverpool, and Glasgow. Fruits and vegetables are included in these returns, the leading varieties of apples, pears, and potatoes being named separately. The prices are given for two qualities in nearly every case, and a comparison of these returns affords some interesting facts with regard to the quality range of prices for the same varieties, in the same markets, at similar periods. In few cases is the difference between first and second less than 20 per cent. increase on the lower value; in many it varies from 30 to 50 per cent., and in some instances it is even 100 per cent. Of course these do not represent grades of one crop or from one grower, and it is probable that some of those sales are recorded concerning consignments that have never been sorted at all, but they serve to illustrate the subject here referred to, namely, the variation in price that is caused by differences in quality. 
Beyond what sorting can be done at the time of gathering fruits for immediate sale, there will always be much in a large establishment that will require a special arrangement for the work of grading. For apples a few large growers and dealers have adopted a machine that is constructed to carry out the grading with great rapidity and with sufficient thoroughness for all such crops in bulk, except perhaps the choicest and ripest samples. One large fruit-merchant speaks favourably of the machine, its work, and the cost ; but if really efficient it could only be pecuniarily satisfactory where the supplies are both extensive and continuous over a long period. Such appliances are therefore better suited for the dealer or salesman than for the grower, who rarely in this country has such enormous crops as would render their employment necessary or profitable.

Packing sheds of the best type, light and spacious, with central tables upon which the fruits can be turned out for the sorting, are in consequence best adapted to the requirements of the majority of home growers. Sheds are a necessity, and the provision of the additional convenience for fruit-grading is a comparatively small matter. Ordinary long wooden tables of the simplest construction, cheap but strong, can be easily adapted to the purpose by fitting them with rims to prevent the fruits rolling off. Large trays that can be moved about as required are also very convenient, as no alteration of the tables is then needed, and they can be stored away when the sorting season is over. They should be higher at the back than the front, the bottom also sloping slightly in the same way; they may be any width, provided they are not too heavy; but the depth (from back to front) must be regulated to the grader's work, 3 feet in depth being the maximum, and in an ordinary way about 2 feet to $2 \frac{1}{2}$ feet is the most serviceable for fruit generally. The construction of such trays 


\section{THE BOOK OF MARKET GARDENING}

is so simple that any handy man can do the work on the premises under direction without having to call in the services of a carpenter.

In all grading, where the fruit is brought into a shed and turned out on tables or trays, it is obvious that the additional handling required for the sorting and packing will subject the fruit to more risk of injury; therefore the greatest care must be exercised, and the closest supervision given, to ensure that such damage is reduced to the lowest point. The men or women entrusted with the task must be selected with judgment, and suitable encouragement given to those who devote the best thought to their work combined with the needful quickness. Some special fitness is essential, and those who take an interest in it can soon be trained to sort with all the accuracy and care desired.

As a matter of precaution, the surface of the trays or tables may be covered with a soft material to lessen the danger of bruising, but it should have a smooth surface, not one that is likely to rub the fruits or leave any lint upon them. It must, further, be affixed in such a manner that it can be readily removed, for if fruits are damp, or they have, as with some varieties of apples, a "greasy" skin, the surface is soon clogged, only serving to smudge and spoil other fruits. It should also be of a washable character, so that it can be replaced when cleansed.

The same principles of sorting apply to flowers as to fruits and vegetables, namely, first, the separation of different grades, and second keeping each grade as uniform in quality as possible. It often happens that it is not necessary to send the different grades to the same market: the man who knows the character of the demand at different centres can regulate matters accordingly: what would rank as second-rate in one market may take first place in another. It is the same when 
supplying direct to the consumer: one desires the best of its kind that can be procured, and is prepared to pay any reasonable price; another requires a cheap article, and is not so concerned about high quality provided he is not offered a lot of rubbish. Grading enables the producer to meet both classes: he pleases his customers, utilises his goods to the best advantage, and conducts his business upon a firm and satisfactory basis. It is both honest and economical, and no one can give the matter a fair and thorough trial without being convinced, as we have long been from extended practical experience, that judicious grading is one of the essentials of successful market gardening which demands the attention of every up-to-date grower.

\section{Packing Garden Produce}

Market growers who are situated within a short road distance of the centres they supply are in a position to cart the greater portion of their produce without the expenditure of much labour upon packing. But the number so placed, and who can depend upon the local demands to absorb all they grow, are comparatively small : the majority have to look far and wide for their markets; due protection for their produce in transit consequently requires the best attention. For all the choicer fruits, flowers, and vegetables, the ordeal is a severe one: first, there is the journey by road to the station, which in some districts is alone a great trial, the removal to trucks or waggons, and a period of some hours in the train, with the added joltings of sundry shunting operations; the transference at the terminal station again to carts or vans, the unloading at the market, and the final loading into the retail fruiterer's or greengrocer's conveyances. It is astonishing that after going through such a process of "preparation" for the 


\section{THE BOOK OF MARKET GARDENING}

consumer, tender fruits are fit to look at or to eat when they reach their journey's end, yet a large proportion of British garden produce has to go through this programme as a regular part of the business that is to some extent unavoidable under present conditions. Ought it to be necessary to point out that the utmost care in packing is an absolute essential if the grower expects his goods to arrive in even decent condition? It seems almost like insulting the intelligence of practical men to question the matter at all, yet a visit to any of the markets when the consignments are opened is a revelation, and would supply an answer, unexpected but true, namely, that packing is much too frequently and too generally neglected.

In conjunction with a cumbrous and antiquated system of marketing, this neglect is one of the causes of low prices and the resulting dissatisfaction, with disputes between sender and salesman. It is a defect that can be removed or at least greatly reduced, and it should no more be tolerated in a market garden business than it would be in any other where goods of a less perishable character are dealt with. What is the use in giving the best skill to cultivation if every effort is to be heavily discounted at the last by the neglect of so simple a matter as packing, with due regard to providing for safe arrival at the journey's end?

Baskets.-By far the major part of home-grown fruits and vegetables is conveyed to market in baskets, and though some of these are of awkward shapes or sizes, and by no means up to date as regards general convenience, yet for many crops there are several points in their favour. When well made they are strong and durable; in proportion to their size the best are light, and therefore do not add much to the cost of carriage; while the ventilation provided is beneficial to some crops conveyed in bulk. Taking the durability into consideration, a 
properly constructed basket is also cheap, though the first outlay is considerable if they have to be purchased. So great indeed is the expense that many have been led to shirk it by using the cheapest productions, often irregular in size, and easily damaged, with proportionate risk to the contents. Recognising this, the largest salesmen and dealers have endeavoured to ensure something like uniformity in the packages of their numerous clients by providing baskets for all who consign goods to them in sufficient quantity. The only expense to the grower is usually the payment of the railway charges on the empties, a very small matter, though there is a heavy surcharge for lost or damaged baskets.

Established market gardeners who have land available for the purpose adopt a more satisfactory method: they grow the willows and make their own baskets on the premises. One grower who has several hundred acres under close cultivation, with fruits and vegetables, has employed three basket-makers continuously for some years; but he also acts as salesman for other smaller growers, and further his baskets have attained some reputation, and when he has a surplus stock they are readily sold at remunerative prices. The land where the Willows and Osiers are grown is not adapted for any other purpose in its present state, and the cost of draining to bring it under ordinary cultivation would be heavy. Many who are similarly situated might well adopt this plan, as if care is taken in the selection of the right varieties of Willows there is always sufficient demand for good stock to ensure a ready and profitable sale. A leaflet issued by the Board of Agriculture (No. $3^{6}$ ) gives some valuable information upon this point.

The form of basket most generally in use is the round type of various dimensions as the bushel or " sieve" and some modification like the half-bushel, the half-sieve, and the peck. These are made with stout rims and the 


\section{THE BOOK OF MARKET GARDENING}

bottom raised in the centre, so that they can be placed one upon another when filled; but all produce packed in them requires to be covered with some protective material on the surface. Even with this care, however, the top layers are liable to injury, as with all lidless baskets where the contents are packed above the rim. There is also an unfortunate tendency to "top-dress" in packing such baskets, i.e. surfacing with better samples than the bulk. This is a species of dishonesty which is apt to recoil upon the packer, for if the upper layer becomes damaged or disturbed the difference is at once observed, and the value is lowered proportionately, besides doing a lasting injury to the grower's reputation. Except for the coarsest, hardest fruits, or the least delicate vegetables, these open baskets are objectionable in several ways; but it is difficult to convince those who are accustomed to using them that they are faulty. Such baskets have been employed by the growers in the London district for many years, and it is only in a few cases where improved forms or other modes of packing have been substituted. Yet even when a good covering is provided, the contents of such baskets are very inadequately protected from either damage or loss; and though the material used is of insignificant value in small quantities, in large establishments it becomes a considerable item, in addition to the labour of application. Occasionally sheets of old newspaper are thought sufficient, with the result that three parts are torn off before the market is reached, both labour and material being wasted. Again, some will dispense with all covering, and we have seen large consignments of ripe strawberries, raspberries, plums, and gooseberries forwarded in open pecks or half-sieves on a long road and rail journey, exposed to dust and contamination of all kinds, to be converted into "choice" preserves when they arrived at their destination, some twelve hours after they left the ground. 


\section{GRADING FOR PROFIT}

A different form of basket is extensively used in some districts, notably in Worcestershire and adjoining
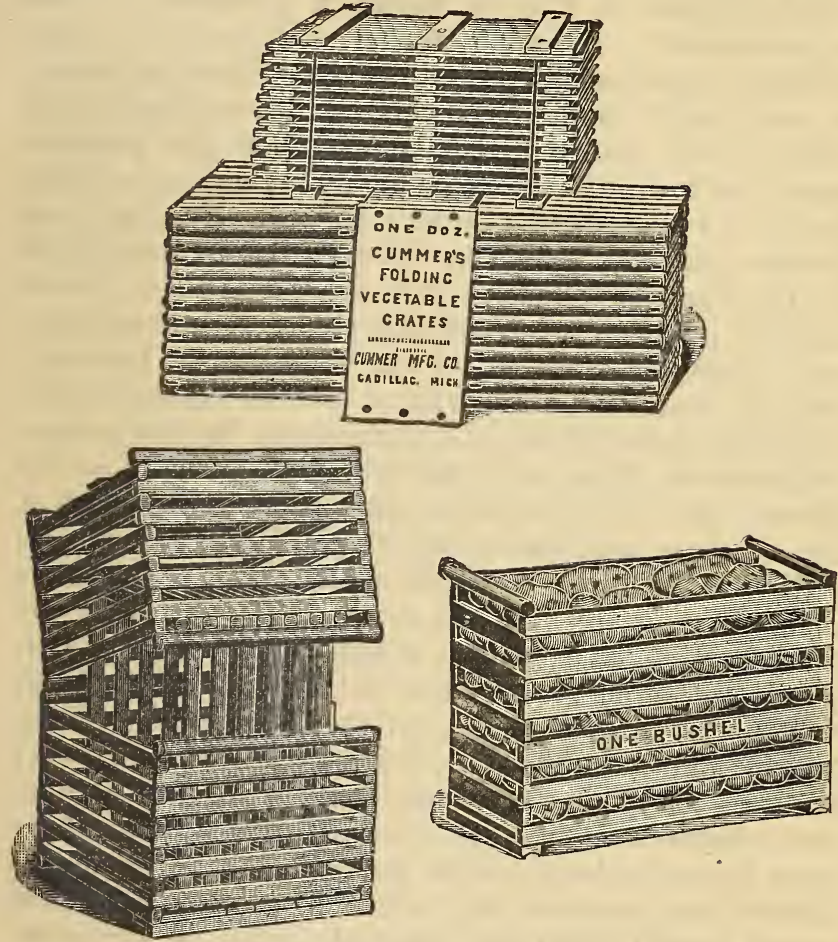

Patent Folding Wooden Crates for Fruit and Vegetabies,

To hold $\frac{1}{2}$ bushel to $\mathrm{I} \frac{1}{2}$ bushel.

(The British Basket Co., Ltd., Crownpoint Street, Glasgow.)

counties, namely the pot, though it is rarely seen in the Metropolitan counties. It is a tall square basket, and is usually supplied with handles at the ends; it is strongly made, very durable, and convenient for removing produce 


\section{THE BOOK OF MARKET GARDENING}

on the ground. For hard unripe fruits, and rough heavy vegetables it is to some extent suitable, but for anything that is ripe or tender it possesses all the objections of the round baskets, with some others specially appertaining to itself. The full size pot, which is that chiefly employed, holds 72 lbs. of plums, and when these are approaching ripeness the pressure upon the lower layers is enough to damage any soft fruit. In one district alone, between Evesham and Pershore, in some seasons hundreds of tons are despatched by train in this manner. But the pot is used for all kinds of garden produce besides plums, and though it is well fitted for crops like Peas, Beans, early Potatoes, Brussels Sprouts, and herbs, it is also employed for Cauliflowers or Cabbages, together with flowers such as Wallflowers, Pinks, and Daffodils. With regard to the flowers the weight is out of proportion to the value of the contents, and thus expenses are increased unnecessarily; while for Cabbages the space is too small, and the result is they are crowded in so tightly that they are much broken and damaged. A smaller size termed a halfpot is free from some of the bad features of the large one, but it is seldom used to the same extent. "Both are, of course, without lids, and the contents must either be covered as with the round baskets, or left open to the weather and the dust. Locally, these baskets have been in use so long and so generally, that it would be difficult to introduce any other form, and objections raised against them are regarded as due to strangers' prejudice, though a few of the leading growers are substituting smaller baskets for choice fruits.

Increasing favour is being extended to flat square baskets furnished with lids, which can be had in various sizes from most of the larger makers. They are adapted for all garden produce except flowers; they are more readily packed than the round baskets, and can be stacked 
on the top of each other without injuring the contents. Against them it is urged, first, that they are expensive; secondly, that the larger sizes are not so strong as the round baskets, and they are therefore more liable to damage; thirdly, that in rough market usage the lids are apt to be separated and lost. The cost can be reduced by ordering large quantities at a time, and well in advance of the season when they will be needed; or a still greater reduction can be effected if the baskets are made on the growers' premises from home-grown willows. Sufficient strength can be ensured in the manufacture if the defects are duly pointed out, and the lids may be firmly secured with cane hinges (or even with wire), so that the risk of loss is very small. We have tried flat baskets of the kind described for some years, in comparison with open ones of the round or square types, and greatly prefer them for most produce where it is advisable to employ baskets.

Handle baskets with lids that slip over the handle are now much used for grapes, tomatoes, choice plums, and other fruits of value; but they are rather expensive, being well made of the best white willow, and they must, therefore, be always booked or charged when sent. They are both neat and convenient, and help the sale of produce by their appearance. The same may be said of the so-called "baby baskets," used for the best homegrown grapes, as in these shallow tray-like forms the fruit is seen to the best advantage when well packed and secured; the bunches can also be placed in the fruiterer's windows without handling until sold to the consumer.

Crates are largely used in the southern markets for Cabbages, Cauliflowers, Kale, and similar vegetables: they are from 3 to 4 feet high, of varying width, tapering somewhat to the base, as lightly constructed as possible consistent with the requisite strength. They should 


\section{THE BOOK OF MARKET GARDENING}

contain at least five dozen of the first named, which constitute the "Tally" of the London markets.

"Chip" baskets of moderate size are in considerable demand, and being cheap are useful for soft fruits like strawberries in quantities of 4 to $6 \mathrm{lbs}$. Chip punnets of

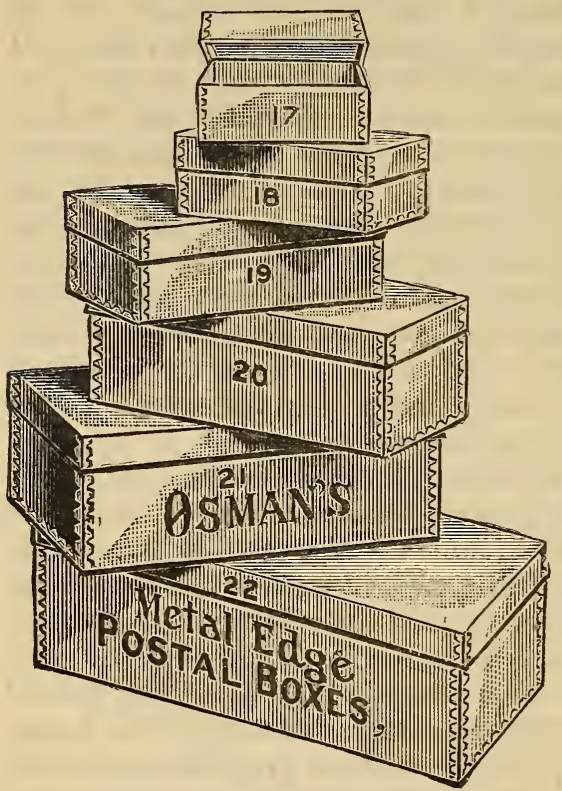

Parcel Post Boxes. Cardboard. various forms and sizes are also employed extensively for choice ripe fruits : they may be had in sizes to take from half a pound to $2 \mathrm{lbs}$. of strawberries, but the I lb. size is most in demand, either shallow or deep. These are also used for small or "Button" Mushrooms extensively.

Boxes.-Continental, American, and Colonial exporters of fruits have employed boxes for many years, but the use of such packages has advanced very slowly in Great Britain until quite recently. Some growers have recognised the advantages attendant upon the use of boxes, provided these could be non-returnable. The chief difficulty has been to produce a box sufficiently strong to convey the contents safely, and yet cheap enough to include in the price without materially decreasing the 
growers' profits. 'That this can be done has been abundantly demonstrated, more especially for fruits in small quantities; but they are also admirably adapted for flowers, and the lighter vegetables or salads. A wonderful business has been developed in direct communication between the producer and consumer in some districts, notably around Wisbech, mainly by the assistance rendered at starting by the Great Eastern Railway Company. Boxes of various sizes are provided at moderate prices, and the Company at first undertook to collect these when packed with farm and garden produce, as well as to convey or deliver them at an inclusive rate from all stations on the line to London, regardless of distance but dependent upon weight. Other companies have followed the lead, and provide boxes of similar size, the following being those most in demand with the prices:-

Inches, Inches, Inches, Price.
length. width. depth.

No. I, - $10 \frac{3}{4} \times 7 \frac{1}{2} \times 3=2$ d. each.

, 2, . I $3 \times 9 \times 4 \frac{1}{2}=2 \frac{1}{2} \mathrm{~d}$.,

, 3 , I $5 \frac{1}{4} \times 10 \frac{3}{4} \times 5=3 \mathrm{~d}$., ,

, 4, . I $6 \frac{3}{4} \times 1 \mathrm{I} \frac{1}{2} \times 5 \frac{1}{2}=3 \frac{1}{2} \mathrm{~d}$. ,,

, 5, - $18 \frac{1}{2} \times 13 \times 6=4 \frac{1}{2} \mathrm{~d}$. , ,

, 6, . $2 \mathrm{I} \frac{3}{4} \times \mathrm{I} 4 \times 7=5 \frac{1}{2} \mathrm{~d}$. ,"

These boxes are intended for use once only, and the following conditions are attached, viz.-

"That the boxes be secured by nails, not by rope or cord."

"That the produce be conveyed at owner's risk, and the carriage prepaid."

"That no box shall be of greater weight than 60 lbs."

The charge is $4 \mathrm{~d}$. for $20 \mathrm{lbs}$. and $\mathrm{Id}$. for every $5 \mathrm{lbs}$. up to $60 \mathrm{lbs}$., including delivery within the usual limits, but the collection is not undertaken now. 


\section{THE BOOK OF MARKET GARDENING}

We have used these boxes extensively:for some years, and have proved them to be very satisfactory, the smaller sizes for fruits, and the larger ones for flowers or light vegetables of a choice character. The stipulation that nails only shall be employed is objectionable, and we have not found that the companies are very strict about enforcing the regulation, provided the lids are nailed on (and this is necessary); but tying with stout string also is a protection that has proved advisable. Nos. I and 2 are the least liable to be damaged, being comparatively stronger than the others, and when the produce is well packed they can be safely sent long distances, provided ordinary care be exercised by the railway servants.

Numerous firms of box-makers throughout the country make a special feature of their business in the production of boxes for farmers and market gardeners, so that such packages can be obtained in any desired size and strength at moderate prices. But where the amount of produce is very large growers have found it profitable to make their own boxes, either by employing men in wet time and during the winter months, or by utilising some of the up-to-date machinery constructed for box-making. Much can be said in favour of the former method, as there is nothing elaborate in the construction of the boxes usually required. Any intelligent handy man can soon master the few details, and it is a great advantage both to employer and man to have regular work available at all bad times. This, of course, especially applies where the crops are chiefly grown in the open ground; when there is a large area under glass the labour is not affected to the same extent by weather conditions, and the employment of machinery is then advisable if it can be kept in use sufficiently. Excellent and ingenious machines are now sold by several firms, which can turn out large numbers of well-made boxes in a few hours. 
In districts where there are numbers of small growers, a larger producer would find a sale for a considerable proportion of the boxes he could turn out beyond his own requirements, provided they were cheap enough. In such a case the outlay upon machinery would be a safe investment, and might prove a substantial aid to his business if judiciously worked.

The essentials in the production of boxes that are to be of real service to market growers are as follows :-

I. They must be as light as possible consistent with a reasonable strength; it is useless to rely upon flimsy makes-they will only result in endless trouble and repeated loss of goods. On the other hand, if heavy thick wood is employed, the weight will be prohibitive.

2. The cost must be low, and in proportion to the value and quality of the produce they are to convey, especially if they are to be non-returnable. For instance, it would be folly to give a box costing sixpence with goods that are only worth one shilling. When boxes are to be returned, and are made stronger to fit them for an average number of journeys, the larger cost per box amounts to much less per journey, provided the empties do not have to be returned singly. We have used home-made, strong half-bushel and smaller size boxes, the actual cost of which, including return in bulk, did not average one penny per journey. It is obvious that in such cases the relative value of the produce is of less consequence than when the box is used once only.

3. Boxes should be made the means of advertising the grower, and they should therefore be labelled or branded with his name, and preferably also with the name of the place, and of the variety (when fruit is sent in them), as well as the quality or grade.

4. If the boxes are returnable the lids should be secured with strong hinges, as their loss is a frequent 


\section{$9 \circ$ THE BOOK OF MARKET GARDENING}

source of annoyance and expense; when non-returnable this is not important.

Convenient as boxes unquestionably are, and much as there is in their favour, they must be mainly relied upon for direct conveyance to consumers or retailers, at all events for the present. Salesmen in general have a prejudice against dealing with British garden produce in boxes, although so large a part of their business is founded upon imported fruits in similar packages. We have repeatedly endeavoured to induce salesmen to take first-class fruits in boxes and have always been met with objections. If they have taken them it has been almost under protest, and with a "don't blame me for results" kind of expression that has not been encouraging. Notwithstanding this, however, when genuine efforts have been made to give them a fair trial, well-selected, graded fruits have yielded much better returns than similar fruits sent in baskets in the ordinary way, and that is what concerns the grower. One experienced salesman in a northern market assured us that he has had to turn produce out of boxes into baskets to enable him to secure a sale for fruits as British grown. He says the custom is so general, and so firmly established, to regard fruits in boxes as of foreign origin, that he failed to convince his customers to the contrary. There is no reason why such prejudice should prevail, and properly branding the boxes would remove the difficulty. We have abundant proof that the demand for boxes is extending, and if salesmen do not awaken to the fact they will find that increased facilities for direct communication with the consumers, and the development of co-operation amongst producers, will eventually deprive them of part of their business.

Card-board boxes of excellent design are now manufactured in great numbers for art flowers and florists' productions; they are light and strong, being well 
adapted for parcel-post trade, in which they are extensively employed. These are sold at such a cheap rate that it is scarcely worth while to make them at home, still machines are now available that render the task an easy and expeditious one. They can be had stamped with the trader's name and address and an indication of the nature of the contents. Much improvement has been effected in these boxes of recent years; the insides are covered with a smooth, non-porous lining which aids materially in preserving flavours in a fresh state after they are packed.

Thin metal boxes have also been advocated for similar produce, but while they offer some advantages in the preservation of flowers or fruits in transit they have several objectionable features, notably the weight and the liability to damage; besides this, in proportion to their size they are expensive. Such boxes with partitions to enclose special fruits like peaches have not proved satisfactory in general business, though they are sometimes used privately. A method adopted by some of the Californian growers for the conveyance of plums to this country consists in having small metal boxes which fit into larger shallow wooden cases, and it appears to offer some advantages, as the fruits are not in bulk, and the effects of one or two damaged fruits are confined to a small area.

Barrels, though chiefly used by American and Canadian fruit growers for apples, are not likely to be generally employed in that way here. They are occasionally used for roots such as Potatoes, Turnips, Carrots, and Horseradish, but only for inferior grades of the second and third named, as the best are bunched. Tubs of smaller size are employed for later gatherings of soft fruits that will not pay for sorting, and which are conveyed direct to jam-makers for conversion into pulp. This is often only an excuse for disposing of a quantity of damaged 


\section{THE BOOK OF MARKET GARDENING}

fruit, and it must be remembered that the closest supervision is exercised in jam-factories as regards the quality of such consignments, and prompt destruction follows upon condemnation.

Sacks and bags of varied sizes and materials have many uses ; they are manufactured in enormous quantities, and can be bought cheaply on a large scale from the

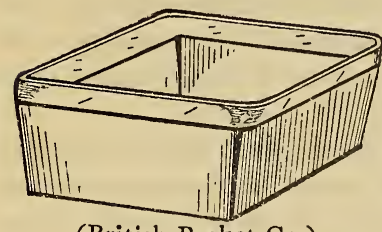

(British Basket Co.)

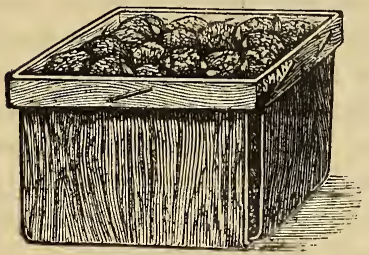

(Osman \& Co.)

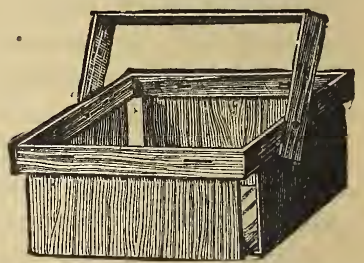

(Osman \& Co.)

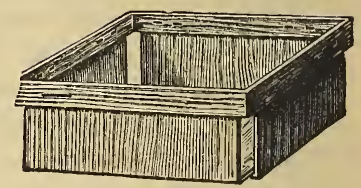

(Osman \& Co.)

Chip Punnets for Fruits.

makers. But the smaller, lighter bags may be profitably made as winter or bad-weather work in many establishments of moderate extent. We have tested this matter and found it to answer well, taking into account the utilisation of labour that would either be unprofitably employed or stopped entirely. In my gold-medal essay on packing fruit and vegetables for small holders the details of sizes, material, and methods are dealt with fully. If a good system is organised the work is simple and readily mastered, sufficiently at least for all ordinary purposes. Small bags for light produce are best made from Hessian canvas, which, if of good quality, is both 
strong and durable. A convenient width for cutting up is 6 feet, and this costs about $6 \mathrm{~d}$. a yard run, or $3 \mathrm{~d}$. per square yard. Useful bags can be made at from $2 \mathrm{~d}$. to $6 \mathrm{~d}$. each, according to the size, that can be employed for small quantities of roots or hard, unripe fruit. Bags should never under any circumstances be used for produce that is easily damaged.

Potatoes require strong and specially made bags or sacks; the former are usually formed to hold I cwt., and the latter $I_{2} \frac{1}{2} \mathrm{cwts}$. or three bushels. The two-bushel bags are more extensively used now than formerly on the score of convenience, and bags of similar size are utilised for the heavier roots, such as turnips and carrots. Bags are almost exclusively employed for imported nuts, but generally the small sizes are preferred; British grown walnuts, hazel-nuts, and filberts are marketed in a similar way, though they are also sent in baskets.

\section{Packing Materials}

An important aid to the best packing is afforded by the choice of the right materials, and a small quantity of that fitted for the work used in a judicious manner will do far more to effect the purpose in view than a large amount of a cheaper but defective substance. The only object in using such aids should be to ensure firmness in the contents of the package, and to prevent damage, though in the case of some produce a suitable substance may be rendered the means of maintaining freshness as well. Beyond this, too, materials of an ornamental character are sometimes desirable, particularly in small packages, for the sake of increasing their attractions to purchasers. What might be termed the artistic side of packing receives little attention amongst British growers, though the majority of importers to this country have realised its value to the fullest extent. It is sufficiently 


\section{THE BOOK OF MARKET GARDENING}

difficult here to induce those concerned to study the utilitarian side alone, namely, the due protection of their goods.

An ideal packing material should possess some measure of elasticity, otherwise it is liable to be a source of trouble rather than an advantage. If there be a shrinkage after the package is completed the space left allows a movement of the contents which almost invariably results in some degrees of injury. It must be entirely free from any strong odour, or fruits especially are unfavourably affected; for the same reason it should not be of a very perishable nature, as if decay commences quickly, even in an incipient degree, an enclosed package is rendered offensive. Substances that are either unduly dry and absorbent, or too retentive of moisture, should be avoided, as well as fancy products at excessive prices. Efficiency with reasonable economy must be the rule in this as in all other operations of the commercial gardener.

Nothing at present available comes so near the ideal as the best forms of "wood-wool," as the extremely fine wood-shavings are termed, the production of which has become quite an industry by the aid of improved machinery and methods. This is obtainable in many different degrees of fineness and quality, and at varying prices, but some manufacturers have made great progress in recent years, providing more suitable wood and turning out a much better article than was the case a few years ago. At first it was thought wood-wool would never be of much real use in the horticultural world, owing to the strong resinous smell it possessed for one thing, and its coarseness for another; but though these objections still apply to some of the common grades, they have been effectually removed from all the best brands.

At one large manufactory in the east of London 
large quantities are produced, and we have seen thousands of waggon-loads of hundredweight bales despatched thence to many districts, for this substance is employed for many purposes besides packing fruits. The four grades in most general use vary in price from 4 s. 9 d. to 6 s. 9d. per cwt., and we greatly prefer the last on account of its fineness, whiteness, and odourless character. All the grades are said to be cut from white "pulp-wood," the lightest timber in use for the work, that generally employed being heavy "fire-wood" which affects the weight considerably. Some makers turn out a quantity of a very fine quality termed Aspen-wood-wool, which is more expensive than the above named but extremely light. Some which we have used for years has not weighed more on the average than I 2 ozs. to I $\mathrm{lb}$. per bushel. The cost and weight are therefore insignificant additions to any package, while the advantage is considerable.

Even when the most expensive brands are employed, such as that which under the name of "Continental White Wood-wool" is sold as high as 40s. per cwt., the substance is so extremely light and fine that abundance is allowed for an ordinary sized package at the cost of $\frac{1}{4} \mathrm{~d}$. An experienced fruit-growing friend in Kent claims to have sent over 10,000 peaches packed in this grade within a short period, without having one fruit damaged, a record that also speaks well for his judgment in gathering the fruits and his skill in packing. Cotton-wool or wadding is not in so much favour, as the wood-wool has proved more efficient in its elasticity. This property wadding possesses in a very small degree, and it is apt to become "dead" or compressed, so that the contents of the package are loosened, however much care may be exercised in the filling. When employed at all it should be used in the sheets as bought with the smooth side outwards, but as a general rule it is prefer- 


\section{THE BOOK OF MARKET GARDENING}

able to separate the articles packed from the wool by sheets of tissue paper. Apart from the defect mentioned it is very absorbent of moisture, and if loosened out the fibres readily adhere to anything with which they may be in direct contact. It is obtainable in two qualities, the grey, which is the cheaper and answers the same purpose but is not so pleasing in appearence; and the white or bleached, which is in more request where cotton wool is in use for any purpose. The sheets are usually 18 inches wide, and are sold by the dozen yards.

Paper-shavings, shredded paper, and similar productions are used as packing materials to a limited extent, but they are chiefly employed in different colours for ornamental effect, and if a little taste is brought to bear upon the matter they are valuable aids to the sale of small boxes of fruits that are placed direct in the fruiterers' windows. The same remark applies to narrow margins of loose paper for small boxes, like those containing early cherries, apricots, etc., from Continental growers. But as reliable packing materials all paper products alone are not so satisfactory as woodwool.

Moss in a dried and dyed state is chiefly used for ornament; it is not an efficient packing material for most fruits, it is expensive, and the tinted sorts have an artificial appearance. Fresh, green, clean moss can be employed for some choice flowers to good purpose, but its principal use is for packing small plants turned out of their pots. When the soil is shaken from the roots to save cost in carriage damp moss is the best substance that can be had to prevent the plants suffering from evaporation in transit. This is especially the case as regards short journeys by post or train, for long distances, as with exported or imported plants it is found risky to enclose a quantity of damp moss. Under 
the right conditions of gathering and packing many flowers travel well without such assistance.

As an ordinary covering for open baskets various materials are utilised, such as straw, hay, grass, and the stems or haulm of the crop gathered, as Pea, Bean, and Potato tops. Where it is available Bracken Fern is used, and this with good soft straw is the most efficient of what may be termed "make-shift" substances. Hay is soft, but often smells too strong, and is expensive; grass is not always available, and is objectionable in its quick decay; the haulm of crops is obviously only at command when the supply is finished, further it is often not so clean as might be desired.

Certain substances are used for packing imported produce that might occasionally be employed here, though not for the same goods. For example, Buckwheat husk is extensively used for packing bulbs in Holland, and it serves the purpose well in preventing damage while at the same time being dry but nonabsorbent. Where obtainable at a cheap rate it would be useful for ripened roots. Cork dust is largely used in packing Almeria grapes in tubs, and they travel well as a rule, but it is a very thick skinned variety, and the removal of the cork on arrival causes dealers and fruiterers a great amount of trouble. It is a question if the substance could be imported to this country cheap enough to be of any service for other purposes, certainly it should not be used for fruits.

Paper is chiefly used in packing fruits to protect them from the material relied upon for safety or as a top-covering to exclude dust. The best forms of tissue-paper are well fitted for the first-named purpose and in the smaller boxes for the latter also. We prefer the white tissue for general purposes, but where ornament is an object it can be had in various colours, of which the pink and blue tinted grades are the most serviceable. A superior 


\section{THE BOOK OF MARKET GARDENING}

form with a very smooth surface is sold under the name of "Waxed tissue," and any of these kinds of paper can be had at particularly cheap rates by the ream of 480 sheets.

When it is thought desirable to surround an entire package with paper a different quality is needed, and nothing is better than some grade of brown paper which is sold as "wrapping." It is seldom necessary to take this course, however, as the small wooden and card-board boxes are sufficient in themselves. In the case of covering open baskets for protective purposes it is a waste of time and labour to use common thin paper, which is certain to be torn before a market is reached, as it gives the packages an untidy appearance. If the contents are not of sufficient value to pay for doing the work thoroughly, it is better to adopt some other method.

Tying materials comprise a variety of substances, each of which has some special purpose, but the market gardener's principal requirements are bunching vegetables, salads, or flowers, tying boxes or baskets, and securing the tops of open baskets. In bunching vegetables, willow shoots, specially selected for their pliability, in various grades are most generally employed, and in some market districts it constitutes quite a business, the bundles being exposed for sale like other produce in large heaps. Varied in size and strength, they are used largely for Radishes, for Asparagus, and for such roots as Carrots and Turnips, as well as for bunched Greens (Coleworts).

When boxes are tied in addition to being nailed, the regulations of the Railway Companies (noted on p. 87) must be remembered. In any case it does not apply to packages sent at the ordinary parcel rates at owner's risk. It is useless employing string or cord that is not sufficiently strong to ensure the safety of the boxes; 
though on the score of cheapness, growers are often tempted to use samples that are quite unfit for the purpose. Adequate strength is the first consideration, after that lightness and neatness, and then the question of price demands attention. But on the latter point the careful avoidance of waste will often provide all the difference between a low price and a much higher one. Exact measurement of the length required for each package, and cutting this off before the work of tying begins, ensures an economy that amounts to a considerable gain in a large business. For the small size boxes any ordinary stout string suffices, but for the larger sizes when packed with heavy fruits it is advisable to use cord. The best and cheapest we have tried is Manilla, in 2, 3, or 4 ply strengths, in proportion to what it is required to secure.

Large boxes of extra strength, on which the lids are firmly hinged, with some form of fastening in front that can be relied upon to serve its purpose, may not need cording. It is wise in such cases to provide either metal or rope handles at the sides in order that the boxes can be readily lifted. String is also used for hampers to secure the lids, and sometimes to tie on the covering of open baskets. But for the latter, sticks are mostly preferred, either stout willow, split hazel, or some other strong and flexible wood, crossed in the centre and passed through the sides.

In bunching flowers of all kinds only soft material that will not bruise the stems should be employed. Raffia stands pre-eminent for the purpose, as it is tough, soft, and pliable, it is also obtainable in excellent quality at moderate prices. A neat green-tinted material of similar texture termed Raffiatape has come into use for tying flowers to sticks more particularly; it is inconspicuous, and that is a recommendation in such work. Some soft kinds of string are useful for large and heavy 


\section{IOO THE BOOK OF MARKET GARDENING}

bunches of flowers, that termed "Fillis" being the sort we have found serviceable for several purposes.

Large dealers in the substances named are Messrs Corry \& Co., Ltd., Finsbury Street, E.C.; Wood \& Son, Wood Green, N.; and Messrs Osman \& Co., I32I34 Commercial Street, E. (See Illustrations.) 


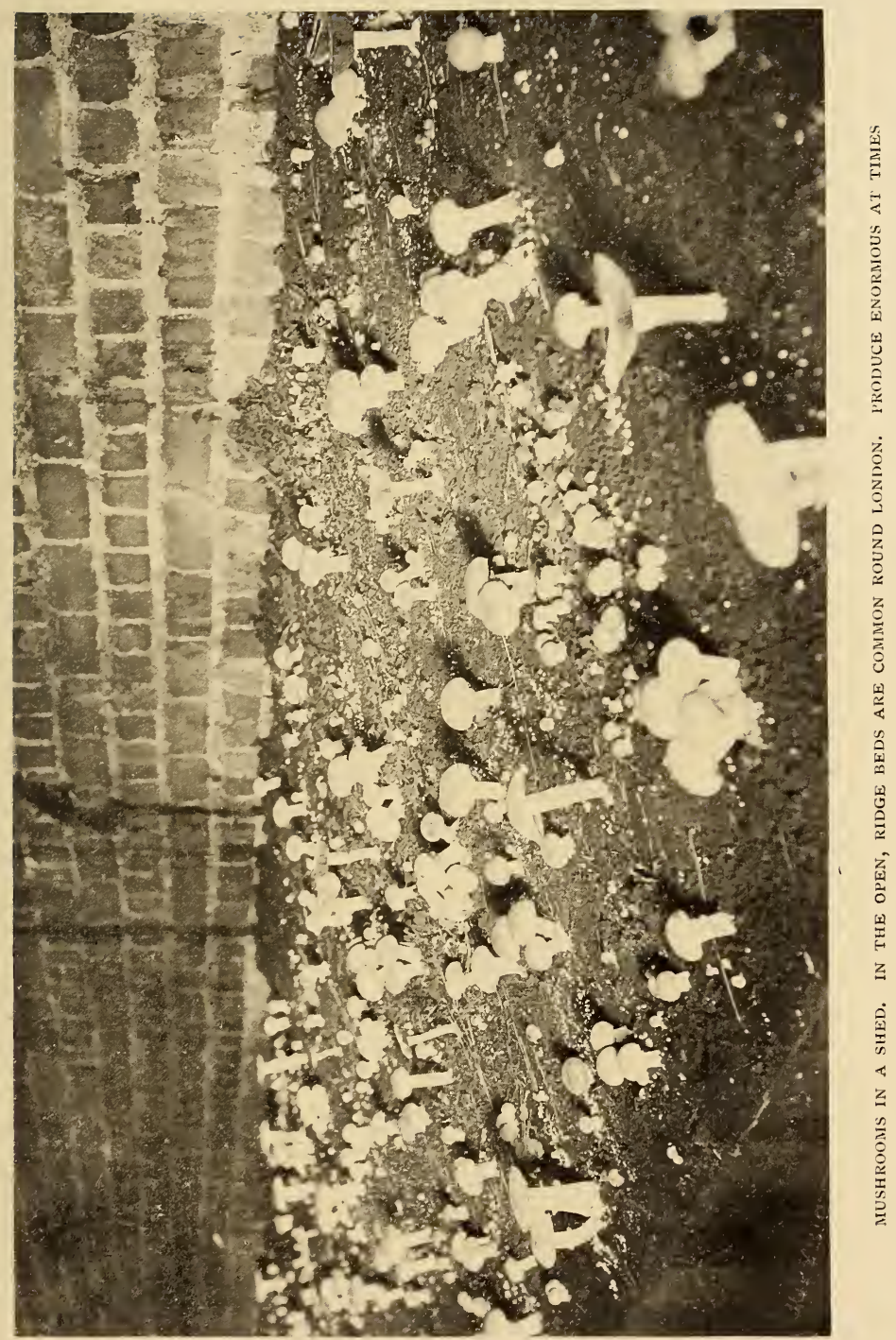





\section{METHODS OF PACKING}

Having at hand the requisite baskets or boxes, together with the materials it is decided to employ and the produce to be packed, there should be little difficulty about the methods. Provided that sound produce only is to be dealt with, the main consideration is to ensure firmness without crushing or bruising the contents of the package. The whole art of successful packing is expressed in those few words, and the manner in which the desired result is attained is of comparatively little consequence. The fresher and better the condition of all produce at the time of sale, the better the price, other characters being equal in merit.

\section{FruIts}

To ensure the desired result with the higher-grade fruits necessitates a certain amount of careful labour and attention. Every fruit must be placed in position singly; it is a poor practice to shoot a quantity into a box or basket and then shake it to ensure that all spaces are filled. The act itself is a source of damage to the fruit, and it is seldom that a firm package can be thus obtained. With practice and aptitude for the work, little more time is needed for packing fruits individually and properly than for the slip-shod, unsystematic styles. A comparative experiment or two will soon establish the money value of the extra care as far in advance of the additional cost it occasions. It must be clearly understood that these remarks in every case apply to the best classes of graded 


\section{THE BOOK OF MARKET GARDENING}

produce, and not to excluded or refuse fruits, which frequently will not pay for carriage in any form.

The protection of fruits in boxes should be chiefly provided at the bottom, top, and sides, while sometimes it may be desirable to protect the fruits individually. Thus for the small size boxes that will hold a dozen good dessert Apples of the Cox's Orange type in a single layer, the bottom is covered with the finest wood-wool, sufficiently thick to prevent contact with the wood. Over this is placed a sheet of tissue-paper, cut to the requisite size to fold over on the top when the package is completed. The Apples are placed in, close together, and wool is added at the sides as necessary to render all firm; another layer of wool is placed on the top over the paper before securing the lid, and boxes packed in this manner have been sent hundreds of miles without the slightest injury to the contents. When the fruits are rather smaller but highly coloured, a piece of tissue-paper, folded several times into a strip a little less in width than the height of the Apple, is wrapped round each fruit as it is placed in position, and this method we have always adopted with choice ripe Plums. Sometimes, in place of the tissue-paper wrapping, rather more wood-wool may be used, and drawn up in ridges between the rows of fruits; in that case and in all others where the substance named is in direct contact with the fruits, it should be shaken quite clear of dust or small particles that might adhere to their surface.

An example of the care which Californian and other foreign growers consider to be worth expending upon the best fruits is afforded by the system often adopted of wrapping each Plum, Pear, or other fruit in a small square of soft paper. This is stamped with the name of the grower, and occasionally with that of the variety. It serves as an advertisement, and while protecting the contents, also indicates to the buyer the character of the 
fruit. If a seller appears to set no value upon what he is offering, it is not surprising that the buyer, who may be quite ignorant of its real merit, places the same low estimate upon it.

Shallow boxes are preferable for all choice fruits, and those named are best in single layers, or at most two layers, while ripe Peaches, Nectarines, and Apricots should never be in more than one layer, and even then need the utmost care to ensure safety.

The deeper and larger boxes that are used for culinary Apples or unripe Pears and Plums are dealt with in a similar way as regards the protection supplied at the bottom, top, and sides; but the last can sometimes be dispensed with if paper is employed, and close packing is adopted. When very fine samples are being packed, it is advisable to separate the layers by sheets of paper and a covering of wood-wool. In these and similar matters the packer must exercise his own judgment and discretion as the cases arise; the general methods and the principles upon which it is advisable to work are what we wish to indicate.

Ripe Strawberries can be safely packed in the smallest size railway boxes previously mentioned; but it is useless attempting to send the soft varieties in that way, or any fruits that are over-ripe at the time of gathering. Each box will hold about $3 \mathrm{lb}$. of selected fruits, and for these we have never used any other packing than strawberry leaves and the best tissue-paper. As regards the leaves, however, they are always specially selected for their softness and deep green colour, in which characters a few varieties excel. These are worth growing for their foliage alone where much Strawberry packing is done in punnets or small boxes.

Near to a centre where there is a good demand for the best Strawberries early in the season, the most profitable mode of disposal is in punnets, the shallow 


\section{IO4 THE BOOK OF MARKET GARDENING}

round form, holding about I lb., being usually preferred, as showing the fruit to the best advantage. The square chip punnets, with or without handles, are convenient for packing, but as a rule they do not sell so readily as the others. Round punnets, neatly set off with leaves at the sides and well selected Strawberries tastefully arranged, are very tempting, and if presented in good form invariably bring good prices, but much care is required in the carriage. For this method of packing Strawberries, shallow trays are needed that will just take six punnets, but these must be made firm with some material at the ends or sides, as if there is much shaking in transit the appearance is soon spoiled. Sometimes cases are used into which the trays are passed like drawers, and this offers some advantages in the direction of safety; but the cases are heavy for moving about, and an accident means disaster to the whole consignment.

When punnets of ripe fruits have to be sent a long distance by train, the results are apt to be unsatisfactory. Owing to this fact there are some districts in which Strawberries are largely grown, but at a distance from populous towns, where punnets have been entirely discarded in favour of small boxes or baskets that take from $3 \mathrm{lb}$. to $6 \mathrm{lb}$. each. It is claimed that the net profits are greater in this method, taking the frequent losses by damage, the extra labour, and cost of carriage into consideration. Under such circumstances this conclusion is no doubt correct, but we have increased the acreage return of a Strawberry crop so materially by the utilisation of the best early fruits for sale in punnets, that whenever buyers can be found within a reasonable distance the system is too important to be disregarded.

In arranging Strawberries in punnets, the appearance is greatly improved by placing the fruits so that the points are in one direction, and with the bright side 
upwards. The berries should be as nearly equal in merit as possible, but the best formed and brightest fruits may always be used to finish off with. This is only a fair displaying of goods to the best advantage; it is not to be confounded with the method by which a top layer of good fruit is employed to conceal a larger proportion of inferior quality. Such practices with any fruits or garden produce cannot be too strongly condemned, not merely in the interest of the purchasers, but also in that of growers. Special details have been given with regard to Strawberry packing, because they illustrate the methods best adapted for all soft fruits in small quantities of high quality. Ripe Raspberries, when of good size and rich colour, sell readily in punnets, though it is usually left to the retail fruiterers to sort the fruit for that purpose. There is no reason why growers should not reap a share of the advantage when they are conveniently situated for doing a trade direct with consumers. The white or yellow varieties of Raspberries are well fitted for sale in punnets or small boxes, though the demand is more limited than for the red type.

Red and White Currants look well in punnets when the berries and bunches are large, the colour bright in the former and clear in the latter. They must be fully ripe, and only long bunches should be used, the small ones and single berries, however fine, being excluded. This also applies to Black Currants, though they are not so much used for dessert purposes.

The finest ripe Gooseberries of any colour, provided it be bright or clear, are sold retail in punnets, often at prices considerably in advance of those obtained for fruits of the same quality by weight or measure. Small or medium fruits are useless for this purpose, even though they may be highly flavoured. Comparatively few of the general public are familiar with the choice 


\section{6 THE BOOK OF MARKET GARDENING}

varieties of Gooseberries, but all can understand a large ripe fruit of attractive appearance.

The small boxes already mentioned have been utilised for Currants and Gooseberries, as well as for Strawberries and Raspberries, with satisfactory results, pro-

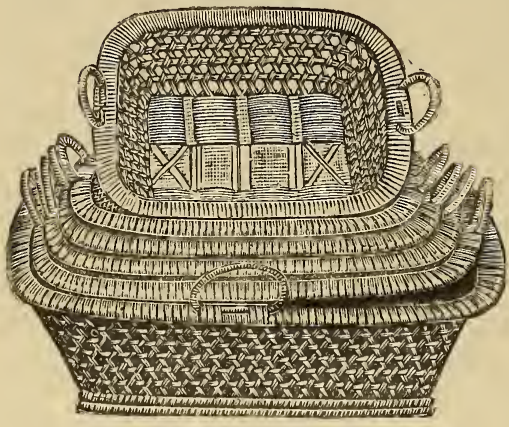

Square Willow Baby-Baskets.

(Osman \& Co.) vided the fruits were of sufficiently good quality to pay for the trouble of packing. The smallest size in use holds about $4 \mathrm{lb}$. of Currants or three quarts of Gooseberries, and lining the box with paper is usually sufficient, making sure that the whole is firm when the lid is fixed on. Vine leaves or Strawberry leaves are useful for finishing off the top, and the fruits should be filled in evenly so that no large spaces are left, all damaged or over-ripe fruits being rigidly excluded.

When forwarded in bulk, the peck baskets commonly employed have much in their favour; the tops being contracted to form a narrow mouth, serve to protect the contents and are also convenient for covering with paper, which is tied securely round the rim. They will take I2 lb. of Strawberries and other small fruits, or about I4 lb. of Plums, and as these fruits in such quantity are liable to be overheated in closed boxes, the spaces in the wicker-work of the baskets provide for a degree of ventilation which keeps that in check. There is apt to be some irregularity in the size and weight of these baskets, except those from the best makers, and this defect often causes the sender 
trouble in weighing, and leads to disputes with the consignee or buyer. In well-made boxes the irregularity is so small that it can usually be disregarded.

Cherries and Plums are packed in all of the methods described, but they are especially adapted for small boxes, and good bright fruits have an excellent appearance when well arranged, with a neat finish of white paper. The finest early Cherries imported from the Continent come in tasteful boxes and they tempt buyers, though the quality of the fruit as regards flavour leaves much to be desired. In this, as in so many other instances, earliness combined with good appearance is certain to command a market. The best later dessert varieties of both Cherries and Plums can well be made up into punnets, especially in seasons of scarcity.

Large crops are often sent to market in peck, halfsiene, or bushel baskets, and in the Plum district of Worcestershire the pot basket previously mentioned is extensively employed. For unripe Plums or any common variety like the Pershore, such large baskets are admirable, and some manufacturers of jam have all their Plums consigned in this manner. But the grower who wishes to make the best prices does not go to the jam-makers while he can find another market for good fruit in smaller quantities, though in the case of "gluts" or over-stocked local markets, these large consumers are very useful friends.

Packing Grapes for sale is in many places a most important operation: in the Channel Islands, in the Worthing district of Sussex, and in several localities around the Metropolis, the production of Grapes for market is a huge business, and hundreds of tons of this fruit are sent by road and rail during a large part of the year to the leading centres. The competition is extremely keen, and the prices obtainable are much lower than they were twenty years ago; consequently, 


\section{IO8 THE BOOK OF MARKET GARDENING}

it is only by the best cultivation, and by marketing the produce in the best possible condition, that profitable returns can be realised.

Next to fine berries and compact bunches, the "bloom" on Grapes is of considerable selling value as regards all the best qualities, and every care should be exercised to ensure its preservation. In fact, mediumsize berries and bunches bearing a dense bloom will often take a higher place than larger samples imperfectly

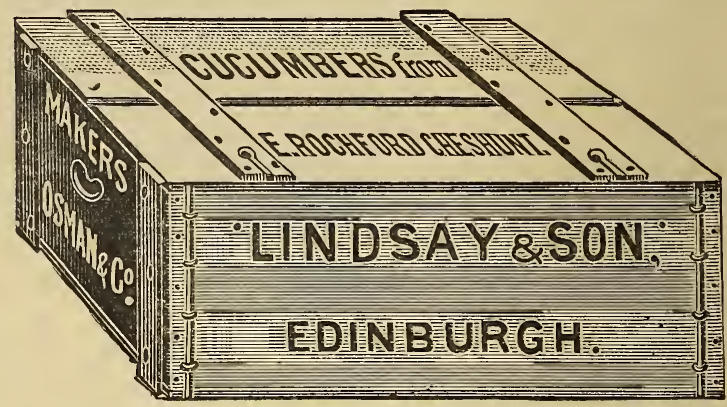

Box for Cucumbers. (Osman \& Co.)

coloured, or with the bloom rubbed off by careless handling or bad packing. The chief points are to secure firmness, and to avoid having any covering material directly in contact with the fruit, and for its convenience in aiding these objects the "Baby" basket has come into general use for the best Grapes. This is a shallow tray, sufficiently deep to protect the bunch fully at its widest part (the "shoulders"), and it can be had in various lengths, from 8 inches to 18 inches, and in shape either oval, oblong, or square. The best qualities are neat, light, and strong, being usually sold in "nests" or sets of 4 to 6 , averaging for the ordinary sizes about Is. each. They are furnished with small 
handles at each end, so that they can be readily lifted in or out of a larger basket or box without touching the grapes. The baskets can thus be placed direct in fruiterers' windows without unpacking, and the fruit is seen to the best advantage in all respects. Such packages must be charged or returned in every case.

The method of packing is simple, but requires some practice to perform in a satisfactory manner. The bottom and sides of the basket may be covered with the finest wood-wool, over which must be placed a sheet of the stoutest smooth tissue-paper. Upon this the bunches are laid with the points to the centre and the stalk at the sides, where they are secured by string. When closely packed as only the skilled hand can do the work, without crushing or rubbing, no other tying is needed, as the bunches fix each other, but they must be laid direct in their places, and not shifted several times, or the results will be deplorable in bloom damage. The basket is then placed in another only just large enough to take it, and it must be secured to this firmly at each end so that there may be no danger of moving on the journey. Sometimes string is crossed backwards and forwards over the inner basket, for further security, and a sheet of paper placed over all as a protection from dust. The outer basket must be strong and furnished with a good lid, upon the upper side of which large conspicuous labels are placed to prevent any danger of the package being turned upside down. Grapes of inferior quality to be sold at low prices are packed in shallow boxes or baskets, with care to prevent crushing, but in such cases it is not possible to protect the bloom very much.

Melons travel well in baskets or boxes when plenty of wood-wool is used to secure firmness, and covered with tissue paper. But they should lie in single layers, and the lids must close on to the packing, so that the fruits will not be bruised by any movement in transit. 


\section{IO THE BOOK OF MARKET GARDENING}

Figs are best in small shallow boxes that will hold from I 2 to $I 8$ in a single layer with sufficient packing material to keep them firm. Large numbers are sent from South Europe, and from the Sussex fig-gardens (West Tarring), to the London and other markets packed in this way. The gathering must, however, as already remarked, be well in advance of the ripening.

Cucumbers can be conveniently packed in shallow wooden trays that will take (with the packing) a dozen to eighteen full-size fruits. As regards the early forced cucumbers, we have found this plan to be far the best, as the fruits are all in single layers, and they travel more safely than when in bulk. The fruit is easily rubbed, bruised, or scratched, unless due care be exercised, and any such defects detract seriously from its value at a time when good prices must be had to bring the grower any profit. Wood-wool covered with paper makes a good bedding. When more abundant and cheaper several dozens can be packed in one basket or box, but it is never advisable to have many layers.

Tomatoes are packed in a great many ways, baskets, boxes, and crates being employed for home-grown and imported produce. All the finest samples and early fruits should be packed in layers, either in shallow boxes or baskets that will hold a single layer each, or packing material with paper must be used to separate the layers. The fruits require much care, as one or two damaged specimens in a package will materially lessen the value of the whole. Over-ripe samples should never be packed with others, however fine and bright they may be; it is only courting disaster. As with all other fruits, firmness is the great consideration, and woodwool with paper affords the most efficient means of securing this end. 


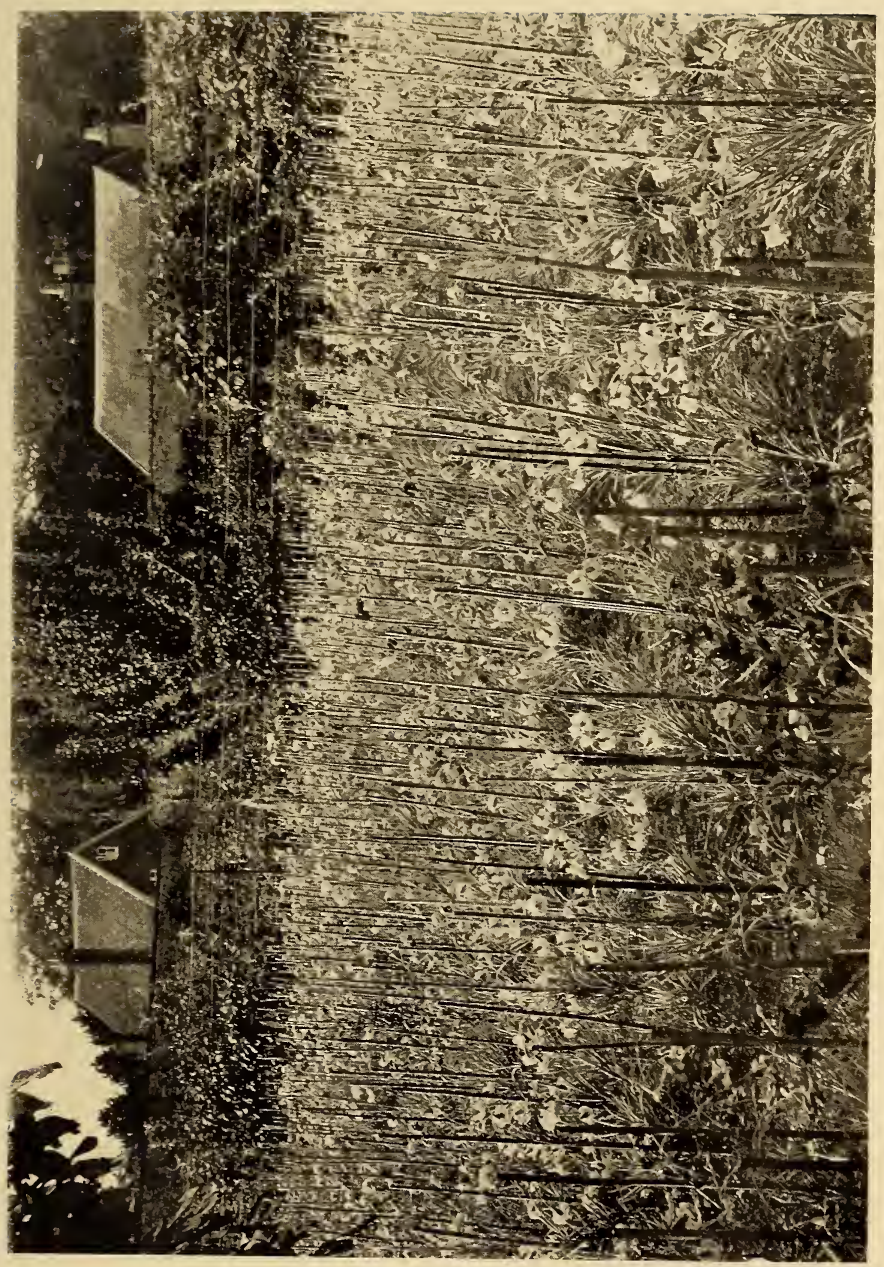





\section{VegetABlEs-Bunching}

An important aid in the preparation of certain vegetables, salads, etc., for sale is a careful and tasteful method of bunching. As regards some crops, it is essential as the only recognised means by which they can be placed on the markets to any advantage. The requisite labour therefore, though a considerable item in the expenditure, can only be regarded as an unavoidable necessity. The better the work is done, the more likely are the returns to be substantial, consequently it is worthy of every reasonable attention.

Where Radishes are extensively grown for the early markets, the work of bunching provides employment for a large number of women and girls, who become extremely smart at it, combining quickness with neat methods. The Turnip-rooted varieties are usually made up into round bunches, each about as much as a large handful, two to three dozen roots, and secured by thin willow twigs selected and prepared for the work. The large rooted sorts, which are more largely grown in some districts than the other type, particularly for the earliest crops, are made up into flatter bunches with the roots spreading out fan-like. When the variety is of bright colour, and the roots are well washed, such bunches have an ornamental appearance. The work is usually paid for by number-that is the score, the hundred, the gross, or in some districts by the great score, i.e. one hundred and twenty.

Turnips and Carrots in all the best and earliest qualities are put up in bunches with advantage, the number varying with the size of the roots and the season, from one to two dozen roots each. These are almost always secured with stout flexible willows, and the roots should not only be even in size throughout, but they must be arranged so that the roots are on 


\section{2 THE BOOK OF MARKET GARDENING}

a level, and not huddled together in an irregular manner.

Onions are made up into bunches and "ropes," but the latter mode is not so generally practised now as formerly; at one time in the Onion-growing districts of Bedfordshire it constituted quite an important occupation. It is also a convenient method for marketing the crop, and the Onions keep well when the "ropes" can be suspended in a suitable place. The method is especially adapted for good medium-sized roots with small "necks," the greater part of the top being removed, and the Onions are bound on with string to a foundation of cord, reeds, straw, or anything similar that will keep sufficiently firm for the purpose. They are tied on in succession, so that the "necks" are covered and a compact, even "rope" is formed a yard or more in length, bearing in four rows about a peck of Onions.

Ordinary bunches of large ripe Onions are not satisfactory, as however well they may be tied, the tops are apt to break away and some of the roots become lost or loose. But for the early spring or salad onions, this method is the best that can be employed, and the bunching of these crops is as extensively carried on early in the season as it is with Radishes. Usually for market purposes a small handful is tied with matting, and some certain number of these are formed into a bunch spread out rather flat; but the retailers divide these into the original size, or make up some of their own to suit their trade. A large proportion of the larger and later Turnips, Carrots, and Onions are sold loose by measure or weight, in baskets or bags, the only packing needed being care in the exclusion of defective specimens, and providing that all spaces are filled.

Bunches of the larger roots are best packed in crates, 
unless they are conveyed by road, when they can often be loaded direct into the waggons. The bunches of salading are packed in large baskets or light boxes, but the former are chiefly used either without or with lids.

Leeks are almost invariably bunched for market, and when extra fine, long, even, and well blanched, they have an admirable appearance for shop display. The size of the bunch or bundle varies greatly according to the demand of the market to which they are consigned. A few of the best quality may be tied together, or of a second grade larger bunches, including a dozen or more, are formed, somewhat on the style of the large Carrot bunch, i.e. flat with the base slightly spreading, soft willows being used for the tying.

All the finest Celery heads or "sticks" are made up into bundles for market, though they are rarely retailed in that manner except for large establishments. From eight to sixteen or twenty "sticks" may be sold in a bundle, the finest in single layers, and the more moderate size in double layers, making a flat even arrangement, the root ends close together, and the top slightly spreading. Stout willows or osiers are used for securing these bundles, generally one band near the base and another about three parts of the length nearer the top. The heads should have all been trimmed and cleansed first, and are placed in the bundle, so that the flat side is outermost, as the solidity and "heart" of the "stick" can then be partly seen.

Asparagus of all grades is sold in bundles, generally of Ioo stems, but sometimes in 50 or 25 , as half or quarter bundles. In the Evesham Asparagus district small bundles of 20 stems each are first tied with Raffia, being placed in a small cradle-like frame so that the heads are all quite even; then 6 of these primary bundles are tied into a large flat one by a single willow band; thus 4 small bundles constitutes the centre or founda$\mathrm{H}$ 


\section{4 THE BOOK OF MARKET GARDENING}

tion of the market bundle and one at each end completes it. Many thousands of such bundles are sent from the Vale of Evesham every year. Though often consigned in open baskets, Asparagus is much safer and better when packed in flat-lidded baskets or hampers, with some soft green material which will help to retain the "grass" in a fresh state. It is customary to send a large quantity of the "grass" to market with the base of the stems uneven and jagged as cut from the beds, but the appearance is greatly improved if these are cut evenly across after the bundle is tied, and a less surface is also exposed for evaporation. The French growers employ a little machine for making the bundles even, as this is furnished with a knife by which the ends are cut at the same time. Practice is needed in tying Asparagus to the best advantage, but some women and girls become very expert at the work.

Sea-kale is made up into flat spreading bundles to display the hearts and stalks to the best advantage. The base of the stem or the upper part of the root is cut short, but partly to conceal this and give the bunch a better effect, it is placed in a slanting position in a plaited punnet sufficiently wide to hold it firmly, and the depth is regulated in proportion to the size of the rootstalk left on the plants. The bunch requires to be tied, and sometimes a little soft paper is wrapped round the base, while the punnet also needs securing. Placed in larger baskets, careful packing is needed to avoid injury to the sea-kale, which should also come out as clean as possible. Smooth surfaced tissue paper should be freely used, and all made firm with wood-wool not in contact with the produce.

For the earliest forced rhubarb, and all grades up to the latest, out-door produce bundling is the most usual and convenient way of preparing the crop for market. There is no fixed or standard size for these bundles : they 
are varied according to the season and price. The earliest will contain but few stalks, while the later ones will have two dozen or more, and weigh $6 \mathrm{lb}$. or over. The size is varied for the convenience of the retailer chiefly, and when the crop has reached its cheapest stage substantial bundles are expected by buyers. The stalks are pulled, not cut, and a large portion of the leaf blade is removed, otherwise awkward, heavy, and unsightly bundles are produced. The earliest and most tender stalks are tied with Raffia or soft string at the top and bottom of the bundles, but for the later hardier produce willows are employed. The bundles should be made flat and compact, the stalks being reversed alternately, so that the heads are equally placed. They must be tied firmly and securely, whatever means is adopted, for loose bundles or those which become untied in the course of their removal are practically wasted, as buyers will not be bothered with them. Early rhubarb is packed in hampers or crates, but the later is usually loaded direct into the wagons or other conveyances.

Young Cabbages, pulled early in the spring, before they have formed hearts, are made up into bunches and sold as greens ; Coleworts (or "Collards," as commonly termed) are treated similarly. The roots are shaken quite clear of soil and secured firmly by means of willow bands just below the first leaves, the number in a bundle being determined by the size of the plants, from 6 to 12 being usual.

Parsley for market sale is generally tied up in large bunches, and Watercress is dealt with in a similar manner, though both are frequently sold by the retailer in a loose state. Watercress is, however, often packed untied in flat hampers, and is made into bunches by the vendor who supplies the consumer.

Early forced Dwarf Kidney (or French) Beans are frequently tied up in bundles of 50 or 100 , being sorted 


\section{6 THE BOOK OF MARKET GARDENING}

into even-size pods for the purpose, and the bundles are then packed in hampers or boxes. Later out-of-doors supplies are placed direct into baskets or boxes, and with them as with Runners, Broad Beans and Peas no packing material is required beyond a sheet of paper as a covering. A trade has been developed by some growers in shelled peas, which are consigned in small boxes holding about 3 quarts each, direct to hotels, to shopkeepers, or private buyers. Where the labour of women and girls can be had cheaply, and a sufficient demand is secured, this work pays well. In large markets (like Covent Garden) it is carried out extensively by certain salesmen.

Mustard and Cress are packed in small punnets separately, and where this is extensively grown under glass the cutting and packing is an important business. Special punnets are employed, somewhat smaller than the I lb. plaited punnets used for Strawberries. Sufficient is cut with each sweep of a curved knife to fill a basket, and considerable practice is needed, both in the cutting and packing, to avoid waste and to secure an even and neatly filled punnet. The work must be done with great rapidity, too, where some thousands of punnets are despatched every morning in the season. The punnets are packed in baskets or boxes for travelling.

Other vegetables which are marketed in bulk and do not admit of being bunched are packed in the same way as the respective bundles, namely in baskets, boxes, crates, or bags, unless they can be placed direct into the waggons like Cabbages, Broccoli, Savoys, etc., for conveyance by road. The earlier and choicer salads and vegetables, such as Lettuces, Endive, Cauliflowers, are preferably packed in large flat baskets with lids. The later supplies of those named, together with cabbages and other green vegetables, are most conveniently packed in the large wicker crates we have previously described. 
With roots such as Potatoes, the coarser and inferior Carrots, Turnips, Parsnips, and Onions, bags or sacks are most commonly employed and no special packing is therefore required after the grading advised has been carefully carried out. As regards Beetroot, more attention is needed, for it is important to avoid breaking the roots or damaging the skin as far as possible. The majority of retailers boil the beet themselves as required for sale, and the loss of colour occasioned by the substance being injured seriously affects the value. When customers are supplied direct with hampers of salads or vegetables, the beet is boiled by the grower, and should then be wrapped in soft paper and packed with the greatest care.

Packing Cut Flowers.-Large quantities of cut flowers are sent for sale in boxes, either previously bunched where the flowers are adapted for that purpose, or otherwise they are packed as separare flowers or trusses. In many cases bunching is very important, and if performed with taste is helpful in the selling. Daffodils and the varieties of Narciss are excellent in this way, the flowers all turned to face in one direction, so that every flower is seen to advantage. Such blooms in bunches of a dozen are convenient to pack, and the quantity consigned is readily checked, both by seller and purchaser. Wallflowers are nearly always bunched by the grower, and some Chrysanthemums, particularly the early ones from out-doors, are treated in a similar manner. The finest examples of the latter are at all times bunched by the best growers, who supply salesmen that have a large connection amongst retail florists.

Roses are conveniently bunched, the number in each being partly dependent upon the choiceness of the variety, or the season when they are being sold. It is best in all cases to adopt a uniform system, and for the 


\section{8 THE BOOK OF MARKET GARDENING}

larger flowers of most kinds a dozen is a recognised number, though in some districts it is customary to allow thirteen to the dozen with everything so packed.

Violets are always bunched, and with their own foliage, but growers generally forward their supplies in large so-called "market bunches," which the retailers separate and make up in the usual button-hole size according to the abundance of the supply. Occasionally the producer prepares these smaller bunches, and they are again tied up in the larger size for packing. The requirements of customers or markets have to be considered in this respect with regard to all consignments.

Forced flowers like Lilies of the Valley, Roman Hyacinths, paper white Narciss, etc., are also commonly bunched, the first named especially, and with their own foliage. Early Tulips, when forced for cutting, are dealt with in the same manner, not mixed but in bunches of one colour or variety, and this applies to most flowers for market. Mixed bunches are seldom in demand, and it is preferable to send a small package of one sort than to attempt making up a larger one of several varieties. In the majority of cases the foliage of each sort is preferred with each particular flower, but sometimes this has to be supplied separately.

To summarise in regard to cut flowers that are bunched, the following are examples of those that are sold by the dozen bunches in some of the chief markets : Aster, Bouvardias, Chrysanthemums, Dahlias, Gaillardias, Gypsophilas, Lilies of the Valley, Mignonette, Marguerites, Montbretias, Statice, Violets, Wallflowers.

Examples of those sold per dozen blooms are Callas (Richardias), Carnations, Cattleyas, Cypripedium Eucharis, Gardenias, Gladiolus (Spikes), Odontoglossums, Pancratiums, Roses, Stephanotis (trusses), and Tuberoses, or when on their stems the last are sold by the bunch. Ornamental grasses, Everlasting Flowers, Physalis 
Franchetii, and Viburnum Opulus (Berries) are also sent in bunches by the dozen.

In connection with the cut-flower department the foliage sold separately in bunches must be considered, as similar methods of packing are adopted for most of that grown under glass. The following, for instance, are sent in dozen bunches: Crotons, Adiantum, Myrtle, and ferns of several kinds. Asparagus plumosus, Sprengeri, etc., usually in bunches, but the long growing form of the first named, is cut in lengths and sold by the "trail," which also applies to the "Smilax" of the markets (known in gardens as Myrsiphyllum asparagoides, or Asparagus medeoloides). Hardy foliage of many kinds is sold in bunches, particularly in the autumn, when the leaves are changing colour. Notable amongst these are Ampelopsis, Beech (Fagus sylvatica), Chestnut (Castanea vesca), Oaks of various sorts, but especially Quercus rubra, $Q$. coccinea, and $Q$. palustris. At other times the Mahonia (Berberis) foliage is in demand, and is sold in bunches like those already named, together with the Common Asparagus, and limited numbers of Carrot leaves when they are becoming tinged with red. Ivy is in demand of the small leaved, bronzed, and marbled forms, either in long " trails," in bundles, or by the dozen bunches.

Obviously the bunching of flowers greatly facilitates the packing and aids in their preservation when due care is exercised in both operations. Bunches of medium size can be packed with safety and with economy of space in larger boxes than bunches of greater proportions. With the judicious use of suitable paper little other material is required, but if any is used for the sake of firmness, or to avoid crushing, nothing of a porous or absorptive character should be allowed to come in direct contact with the flowers. From the time the package leaves the grower until the contents are on 
sale the object must be to reduce evaporation to the lowest point, and this can only be ensured by employing well-made boxes with closely fitting lids. This principle is equally applicable if the boxes be of metal, wood, or card-board, but it must be considered in conjunction with the advice previously given to cut all flowers under the best possible conditions. When flowers are bunched with their own foliage this provides a means of ensuring freshness in the contents of the box, as the leaves furnish some moisture, while at the same time protecting the blooms.

The exclusion of dust is an essential in packages of flowers. The blooms are always more or less damp at the time, and some exude a viscid substance in addition, so that every particle of dust which alights upon the petals will adhere to and disfigure them. This must be avoided by every care it is possible to take in the work of packing, and providing for their safe carriage. To the same end it is needful in the case of flowers with large anthers that shed their pollen quickly and profusely, to remove the anthers before packing, or indeed at the time of gathering. This attention is particularly requisite with the Lilies and white flowers generally, that have large, single, or bell-shaped corollas.

In the markets the majority of flowers are sold from the boxes as received, therefore it must be borne in mind that the flowers should be faced to the top. Thus when the lid is removed the nature of the contents can be at once seen without pulling them about and injuring them in the process. Not only should each box contain but one sort or kind of flower, but the quality must be uniform throughout; it is a mistake fatal to any good business to place a few extra fine bunches at the top to conceal inferior blooms below.

Packing Plants.-Millions of seedling plants or rooted cuttings for spring and summer bedding are raised and sold 



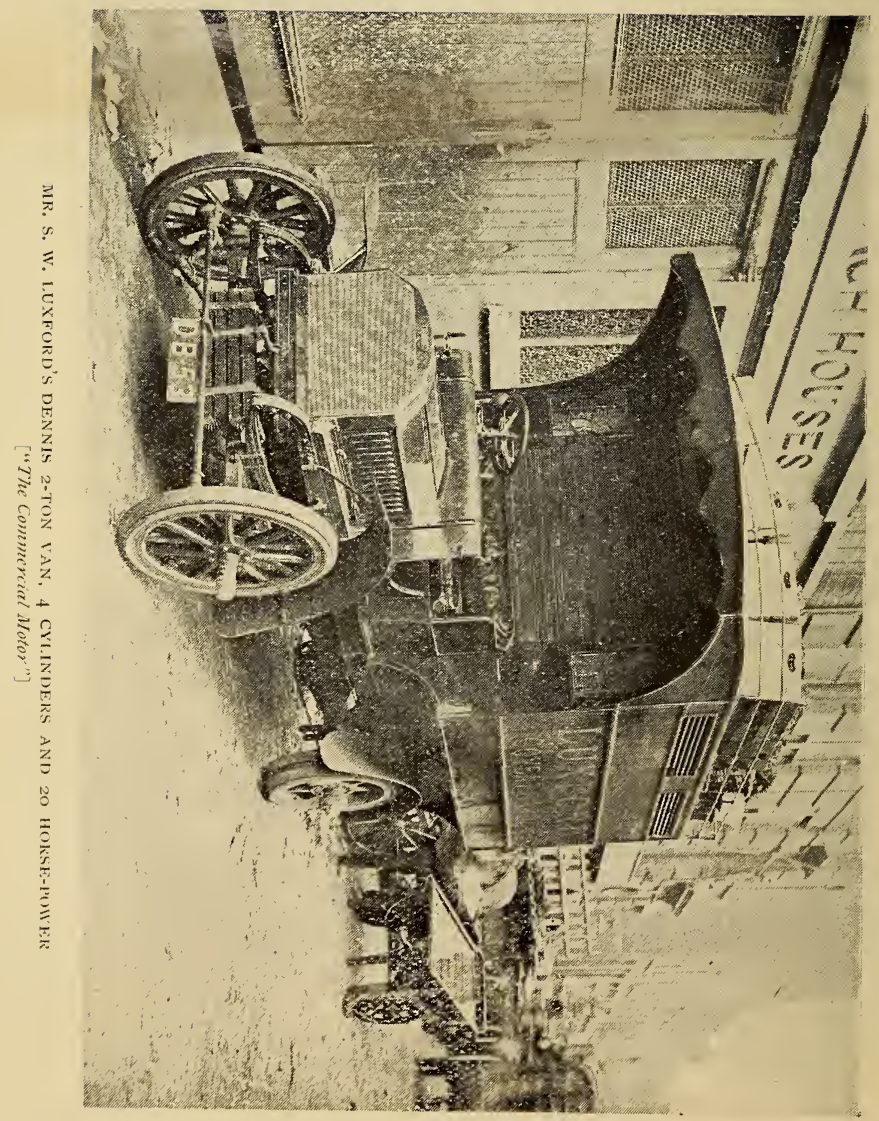


in the Metropolitan district in small shallow boxes or trays. A size which is used in large quantities is $14 \frac{1}{2}$ inches long by 9 inches wide and 2 inches deep; they are made of thin wood, just strong enough to carry the plants and soil until the former are put out in the borders. When bought by the thousand, these cost less than Id. each; by the gross, they are a fraction over that sum. Market men having an extensive trade in this direction occasionally employ their own machinery to produce supplies, but that can only pay where the machinery is utilised at other times during the year for general box-making. Small trays like those named will carry from two dozen to IO० or more young plants, according to their kind and strength. Cuttings are often rooted in such boxes and sold direct without any transference to other boxes, but seedlings are usually pricked out, though a few sorts are sowed thinly and sold as they stand. Only those who are familiar with certain market gardening districts in the home counties have the slightest idea of the magnitude of the business done with plants in this way. Apart from those sent to market, whenever the market growers are within convenient reach by road from popular centres, the costermongers dispose of enormous quantities; and as they pay cash for all they take it is a form of trade which often suits the grower well, though the prices are low.

When sent to market these trays of small plants have either to be packed in wooden crates fitted with moveable shelves, or the van itself must be so fitted. The two chief difficulties are to economise the space, as the value is low, and at the same time to pack firmly, so that none may be overturned in transit. Provision must be adequate for this work, as when the markets are very full a proportion of the load may have to be taken home again, though it does not pay to do that many times.

Plants grown in pots can be most conveniently packed 


\section{THE BOOK OF MARKET GARDENING}

in large trays or shallow boxes, as they can be rendered firmer for their journey, and are more readily placed in or removed from the vans. Straw, wood-shavings, or any similar material that may be available can be used for making the pots safe and firm in the trays.

The more valuable fine foliage plants, like Palms, Dracænas, Ferns and Crotons, usually pay for attention in tying up the leaves with matting and perhaps covering them with paper at the same time. The plants require less space, and the leaves or branches are protected from injury. The larger and choicer flowering plants in pots are worthy of similar care, especially when they have to be sent by rail or a long distance by road. Before packing plants in pots it must be seen that they are thoroughly watered, well in advance of the time they are required, so that superfluous water will have drained away, but leaving the soil moist. It is a great mistake to send pot plants to market in a dry state.

Where shrubs and trees, including hardy fruits, form a portion of the stock the best method of conveying them is in strong shallow wide baskets furnished with handles at the sides. The depth and width will be regulated by the size of the plants and their roots, also by convenience in removal, though, as deciduous trees or shrubs are packed without soil in the autumn and winter months, the weight is not a serious consideration as a rule. The roots are placed closely together with straw for protection from frost, and the whole is covered with mats; when the trees are large it is necessary to place sticks in the sides of the baskets, which are tied together at the tops to form a kind of cone over the plants, the branches of which have been previously drawn in to the main stems and secured by string. Mats are then sown round the sticks, and the package is complete. Sometimes a strong central stake is required to ensure the necessary rigidity; or, when 
trees 8 to Io feet high are being packed, the basket is dispensed with, the roots are packed with straw and covered with mats, which may be taken up the stems, and perhaps over the heads, if they are small enough to allow of its being done conveniently.

Roots of herbaceous or other hardy plants are packed in hampers or shallow boxes, every effort being made to reduce the weight as far as is consistent with the safety of the plants. Where the soil is inclined to be heavy and adhesive, such plants should never be lifted when that is in a wet state, if it is by any means avoidable. Large numbers of hardy plants are now kept in pots for the express purpose of ensuring ready packing at any time. Most bulbous plants are lifted and stored when growth is completed, so no special difficulty attaches to their being properly packed as required.

It is seldom that market gardeners are called upon to transmit plants, roots, bulbs, or seeds to foreign countries, but occasionally the demand may arise in special cases. The regulations concerning the importation of plants to the particular countries must be first ascertained, as these are very stringent in some of the colonies and foreign states. This is especially so with regard to vines and fruit trees, and applies to cuttings, buds, or scions for grafting, as well as to rooted plants. Forms have to be obtained, and a declaration made respecting the value and nature of the contents.

For the majority of plants of small size Wardian cases are largely employed, some preparation being needed to ensure that there is not an undue amount of moisture present when the cases are closed for their journey. Metal-lined boxes are used for plants in a dormant state, bulbs, or seeds, and for small consignments we have tried ordinary biscuit tins with the lids soldered on, in which the plants have travelled safely to South Africa and Australia. We have also received scions of fruit 


\section{24 THE BOOK OF MARKET GARDENING}

trees from India packed in thin rubber sheets or oiled linen, which have survived a long journey overland. In all such instances the ends of the shoots are inserted in hot sealing-wax, pitch, or some similar substance, to prevent evaporation. 


\section{THE DISTRIBUTION OF PRODUCE}

Selling land produce of all kinds to the best advantage is widely recognised as one of the most difficult parts of a cultivator's business. In fact it constitutes a business in itself, which requires the closest study and a considerable share of natural aptitude to ensure any substantial progress. There are far more men who fail in this than in the actual cultivation, for many details, apparently unimportant, affect the results in a serious manner. We have reviewed most of the essential preliminaries requisite to produce the best results, and we have now to consider the means by which produce can be distributed to consumers to secure the maximum returns at the minimum expense. Those are the objects which a commercial horticulturist must always have before him, and to their attainment he should direct his utmost energies. It is, however, a well-known fact that many skilled cultivators, in giving their best attention to the production of the crops, do not fully realise the importance of an equal concentration upon the marketing and selling.

The three essentials are quick conveyance; safety in transit, and the lowest expense that is consistent with safety and speed. The whole of the produce with which the market gardener is concerned is of a perishable nature, some, like the root crops, being much less so than others, but ripe fruits and flowers rank amongst the goods that are most seriously deteriorated in value by undue delay. This must therefore always be the first matter to occupy the attention of the vendor, as, failing that, all other care is of little avail. We have therefore to consider the 


\section{26 THE BOOK OF MARKET GARDENING}

methods of sale available and the means of conveyance at command, pointing out their respective advantages or defects.

Four systems of disposing of British-grown produce are followed either separately or in combination. These are-

I. Consignment to salesmen.

2. Consignment to market, the grower acting as his own salesman.

3. Consignment to the retailers, either shopkeepers or hawkers.

4. Delivery direct to the consumers.

Consignment to Market Salesmen.-Enormous quantities of garden crops are dealt with under the first-named method, for it offers advantages which have considerable weight with many growers. They can give their whole time to the cultivation and packing of their produce, and thus probably are able in many instances to obtain better results either in bulk or quality. There are plenty of reliable salesmen also who study the interests of their clients as far as they can consistently with the rapid clearance of the goods committed to their care, and who for their own reputation are anxious to secure the best returns. With all such men the grower is perfectly safe, as far as the system can ensure safety, and he has the personal relief of transferring the responsibility of the sale to another person. Salesmen with well-established businesses often have wide connections, which enable them to find outlets for goods that would require long experience for a grower to discover and utilise.

But there are disadvantages and defects in the system of which the unscrupulous are quick to take advantage, and the growers are in such cases the conscious or unconscious victims. In the first place, a salesman cannot depend upon one producer, and when he sends out an 


\section{THE DISTRIBUTION OF PRODUCE}

advice that the market rates rule high for any particular class of goods he communicates with others who are likely to have the stock in demand. As several salesmen have probably done the same, the result almost invariably is an all round disappointment, caused by the conspicuous difference between the selling prices and those advised. It is not surprising under such circumstances that growers complain, and are often inclined to make reflections which are not justified.

Again, under this system, a grower can have no control over the actual selling; he rarely knows who the purchaser is, and in the majority of cases the producer is unknown to the buyer, any extension of his business therefore rests in the hands of the salesman. If a difference arises, and another salesman is tried, or other markets sought, the grower has no connection to carry with him. This is quite apart from any questions respecting the actual prices realised for what is sold. Reliable salesmen never object to giving the fullest details that can be reasonably expected, but if every client required an account of all transactions, or to inspect the salesman's books, no business of the kind could be conducted with profit. It is often the case that large consignments of any particular produce may be sold to a dozen or more different persons at varying rates, and cash is received, so that keeping an account against the buyer is not required. The amount of each sale is put down to the credit of the sender, and the total rendered as usual. In many cash transactions the name of the purchaser is not known, unless there are baskets or boxes to be returned, when booking becomes a necessity as a check, though they would also be charged to strangers.

When sending fruit or vegetables in different grades, or in several varieties, we have found salesmen willing to keep the results separate as a guide to the grower. 


\section{28 THE BOOK OF MARKET GARDENING}

This is important, as it is soon found which quality yields the best return, and the future consignments may be regulated accordingly. Many salesmen make a speciality of some class of goods; some are particularly concerned with fruit, others with vegetables, and still others with flowers. A few will be found that have a connection for the highest qualities only, and they will not be troubled with inferior grades; while others again supply a different class of buyers in large quantities at cheap rates, and, in consequence, are not so well fitted for finding a good market for the best quality. All these are matters which demand the producer's attention and investigation.

Salesmen's charges vary from 5 per cent. to Io per cent. on the sales, perhaps the most usual being $7 \frac{1}{2}$ per cent., or Is. $6 \mathrm{~d}$. in the pound. It is the custom in some markets to charge a fixed commission per box or basket, regardless of the price obtained; when the prices are low this falls rather heavily upon the vendor, but when they are good he has the corresponding advantage. On the whole, it is more satisfactory to pay a percentage on the results. The higher rates of commission are charged when the salesmen supply the baskets required, otherwise a separate charge is made for their use. When it is considered that most salesmen will render a weekly account with their cheques, and that if they do not receive cash for the goods sold they take all the risk in collecting the debts, the charges cannot be regarded as unreasonable. At the same time the commission and all other deductions (like market charges) are made from the amount paid to the grower, and in a bad market these appear rather formidable.

Growers as Salesmen.-The second method of consignment is especially convenient when there are two or more partners in the business, when the grower has sons old enough to take part in the active work, or 


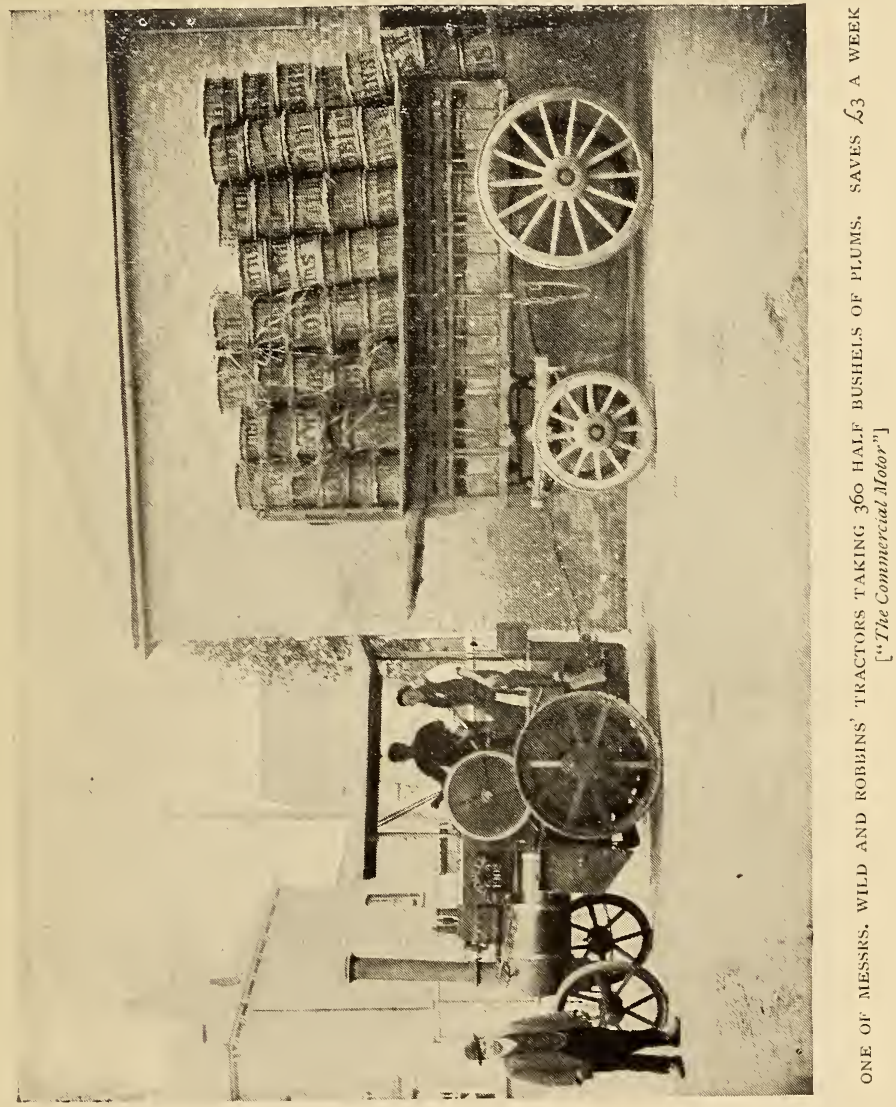



when the means at command permits the engagement of a responsible manager. In any of these circumstances the system offers many advantages to energetic men; it permits an absolute control over the whole business; the grower acquires an exact and first-hand knowledge of the market demands and the state of the trade; he is able to form a connection that is as valuable as a shop trade, and he sees in what direction he can advance with a prospect of success. He also knows the precise condition of the produce on arrival, and he is not disturbed with doubts as to whether the prices obtained are genuine or not. Against this must be set the expenses incurred, the extra work and anxiety, the booking and collecting of debts, with the risk of loss.

The usual practice is to take a stand or stall in some good market, and as the bulk of the trade is transacted in early morning it often necessitates an overnight journey with the expense of lodging, etc., unless the grower traveis with his produce by road, and that means perhaps a rough, all-night experience.

In the more important markets the competition for stands, especially those well placed, is very keen and applications may be on the books for months before a vacancy occurs. The authorities, too, are very particular in some markets respecting the position and credentials of the would-be stall-holders, so that whenever this method is to be adopted, arrangements must be made a considerable time in advance, or other means will have to be at command temporarily. The rent of market stands varies greatly; in some it is moderate and paid weekly or monthly, but in others it is paid every market day and amounts to a fairly heavy charge.

In favour of the system described, it must be said that within our own knowledge many growers have adopted it with a large measure of success, and have by its help 


\section{30 THE BOOK OF MARKET GARDENING}

founded prosperous businesses. Two of the most flourishing firms of market gardeners in the Midlands have followed it for two generations with exceptional advantage. In one case over 400 acres are under the closest cultivation, and not only do the members of the firm sell the whole of this produce, but they also act as agents for many others. Thus two departments are utilised in the support of their business.

One notable difficulty must be indicated, namely, that rarely can more than one or two markets be utilised in this manner: whereas, when consigning to other salesmen, the choice of a market need only be regulated by the existing demand for the goods offered. This is in a large measure overcome if a first-class centre is selected, as when a reputation has been gained, telephonic or telegraphic orders from widely separated towns can be dealt with as promptly as if consigning to the respective local markets.

Supplying Retailers.-A good connection amongst shopkeepers will render substantial help to any marketgrower, but it is of the greatest value to those in a small way, or at the commencement of their experience. It is then especially important to reduce expenses and intermediate profits to the lowest level, and dealing direct with the retailers is one convenient way of accomplishing this object. The method can be carried out to the fullest advantage where proximity to a town permits the conveyance of produce by road; but that necessarily provides only for moderate amounts of goods, and as the supplies increase, conveyance by rail must be relied upon for extension. The opportunities for developing a large trade in such a method must always be limited, but it is surprising that more is not done in this way in populous cities. In the Metropolis, for example, it is by no means uncommon to find greengrocers and fruiterers purchasing produce in the markets 


\section{THE DISTRIBUTION OF PRODUCE I 31}

which has been grown within a short distance of their own shops. We have thus known crops carted I4 miles, to and from a market, when about one mile would have taken them from the ground to the retailer. The extra expense incurred and the time wasted in such a round-about method are against the interests of the grower, and the condition of the produce (or the price) is certainly not improved for the benefit of the consumer.

Communication must be established with customers, and a regular system of delivery adopted to ensure a reliable trade in connection with shopkeepers, and well graded produce in moderate size packages is the best suited for the business. It is the uncertainty of the desired supplies and qualities being received when required which induces many shopkeepers to prefer the expense and labour of fetching their goods from market to the risk of being disappointed by the grower's failure to meet his wants. The question of current prices also gives rise to disputes in this system, and if either party is over-reaching or misinformed, difficulty is certain to arise. When a retailer goes to a market, if the price or quality in one case does not satisfy him, he tries other salesmen, until he procures what he needs. Producers who are anxious to develop a direct business should always keep this in mind, and with the exercise of discretion it is possible to gradually form a reliable and profitable trade.

Under some circumstances it may answer the grower's purpose to have one or more shops of his own, but considerable caution is needed in entering upon this department of business or the results may be disastrous. In the first place, a responsible person must always be in charge; other labour will be also needed, with probably horses and carts. The expenses are consequently heavy, and unless it has been proved that a good opening 


\section{32 THE BOOK OF MARKET GARDENING}

exists, the risk will be considerable. Besides this, a shop in a good district cannot be kept sufficiently stocked by any one grower, and it would be necessary to buy in the market at nearly all seasons of the year. However, if a florist's business is combined with fruit and greengrocery, a man who has a family of grown-up sons and daughters can, by the exercise of due thought, render the retail part of his business both useful and profitable.

A careful estimate should be made of all the expenses before starting upon it, and judicious economy must be exercised. It is preferable, as a rule, in such cases to avoid highly rented places, also those where a business has been created for which a large sum is required. The form of trade that has been carried on may be totally different from that it is intended to develop, and the capital sunk would thus be partly lost. Endeavour to make a cash trade with cheap articles in a populous district; or build up a high-class business in a more wealthy neighbourhood with the best quality produce obtainable. It is wise to choose one or other of these courses and follow it out consistently; they require very different methods of treatment, but the first gives the least amount of risk where the shop can be managed in a smart, up-to-date, energetic manner. One essential in successful shop management is that the advantages of tastefully aud effectively displaying the goods must be mastered. There is an artistic element of a most practical character in placing the goods before the public in the best possible manner, which should not be ignored even in the poorest districts. Just as in grading and packing, the extra labour demanded is insignificant in comparison with the gains.

One form of dealing with retailers is supplying the itinerant vendors known as costermongers and hawkers, a useful and generally an industrious class of men, with whom some growers transact a large business. They 


\section{THE DISTRIBUTION OF PRODUCE I 33}

invariably require the cheapest goods, but as they will often take produce that would barely pay for sending to market, they are by no means to be despised. In the great majority of instances they are prepared to pay cash for whatever they have, and if they are not, the growers must know his men thoroughly, or the risk in giving credit is too considerable to entertain.

Markets.-Markets vary greatly in their characters and requirements, which need to be carefully studied by all who utilise that means for disposing of their goods. Not only do they differ in the various towns, but in the largest cities, where more than one market is established for the sale of similar produce, the differences are often considerable. This is well exemplified in the Metropolis by a comparison of the markets at Stratford, Spitalfields, the Borough, and Covent Garden. It constitutes a part of the grower's business to make himself familiar with such differences and utilise the knowledge in his own interest.

Auction Sales.-Sale by auction is an important means of disposing of large quantities of fruits, but it is almost entirely confined in the Metropolis to imported produce, including fruits, flowers, and early salads or vegetables. In provincial towns the home-grown crops are often sold by auction, though generally in small quantities, which are bought up by agents or collecting salesmen. This is done at Evesham, where, during the busy season for fruits and vegetables, sales are held every day in two markets, and sometimes twice a day, i.e. in the early morning and the afternoon. It is convenient for small growers who can send their produce by road and avoid the expenses of rail transit.

It would be thought that such sales might be extended with advantage to growers, but in the chief centres it is urged against the method that British producers rarely consign one class of goods in sufficient quantity of a 


\section{34 THE BOOK OF MARKET GARDENING}

uniform quality to render it worth the trial. So long as better prices can be obtained for small consignments there is no need to trouble about the matter, but we have seen imported fruits sold by auction in bulk at prices considerably in advance of those being obtained in the same market for similar quality and varieties from home-growers sent in by the bushel or half sieve.

Consignment direct to Consumers. - Much can be said in the favour of any method which facilitates the direct communication between producers and consumers, because the immediate interests of both are concerned. When growers on the one hand are obtaining prices which leave a very small margin after all expenses are deducted, it is a common experience to find the consumers paying Ioo per cent. greater prices for similar produce. This difference is divided amongst those through whose hands it has passed, and is partly utilised in recouping the dealers for losses on perishable goods. But the grower also has equal or heavier losses to face from weather influences, or injuries to his crops by insects and disease, but he cannot command so large a percentage return on his outlay to provide against such contingencies. Middlemen cannot be entirely dispensed with for the reasons previously stated, but there is no question that thousands of growers might improve their condition and benefit the public by a systematic attempt to reach the consumer without intermediate agents. That it can be done has been proved in many trades, and it is being extended both in commercial horticulture and farming with marked success.

Two methods by which consumers can be reached direct are, first, delivery at the houses from the ground, and second, forwarding packages from a distance by train or post. The former is adapted for beginners in a moderate way, near large towns that can be readily worked by horse and cart or van. Many industrious 


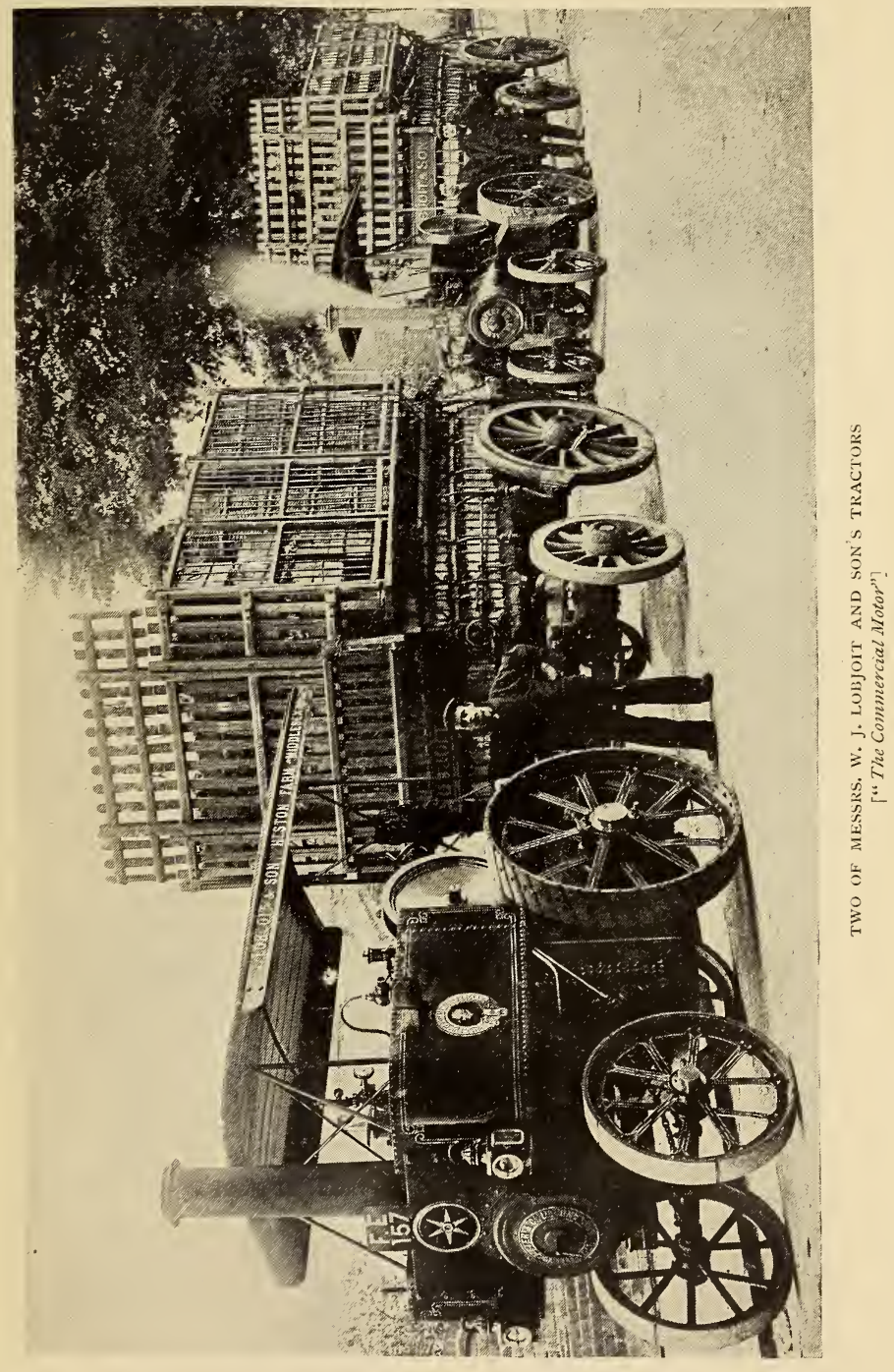





\section{THE DISTRIBUTION OF PRODUCE I 35}

men have succeeded in founding substantial connections on this basis which have subsequently developed into large businesses. If good produce at reasonable prices is brought regularly to the townspeople's doors, a certain trade can be ensured at all seasons, for the freshness of the goods offered should always impart a value to them apart from their actual quality.

It is little use trying to combine this form of trade with that in which the retailers are supplied by the grower. When shopkeepers find a man is also dealing direct with the consumers, including probably their own customers, it is hardly reasonable to expect them to continue the connection. The grower must decide which form will answer his purpose best, and proceed accordingly. Of course he may be able to include hotels and restaurants in his rounds, and if he succeed in securing the contracts for some of these, or for any large public establishment, he will be on the right road to ensure a market for all he can produce without any intermediate profits being deducted from his takings. The personal influence and aptitude of the seller will exercise a material effect upon the results, but the main points to depend upon are good quality with freshness in the produce and reasonable prices. It is necessary to be early with all fruits and vegetables in their respective seasons, as well as reaching the towns in good time on the days selected for the journeys. Further, the partiality of customers for special articles should be studied, and the characteristic requirements of a town or district must be fully considered. Endeavour to acquire a reputation for certain classes of produce, and maintain a sufficiently varied supply on all occasions, even though it necessitate purchasing for the purpose. If a customer can only be supplied with a portion of what is required, the probability is that other vendors will secure the whole order. 


\section{THE BOOK OF MARKET GARDENING}

Spacious light spring carts or vans are the best vehicles for the conveyance of garden produce to towns on a regular system. The vans should be fitted with a movable waterproof cover, or failing this, waterproof sheets must be carried for the protection of the goods. With a cover the vans can be utilised for many purposes when not required in the ordinary trade. Hawkers in the Metropolis employ a light spring barrow with a long body which can be purchased for a few pounds, but the majority are let on hire, some firms in the East End of London keeping over 300 in stock for the purpose.

Large numbers of market gardeners and small farmers are either too far from the towns to render delivery by road profitable, or these are so well supplied locally that there is little room for extension. In such cases small packages either as boxes or baskets become extremely serviceable, and a great business has sprung up in this direction. With suitable organisation and all the facilities the Railway Companies can afford when they give their attention to the matter, this form of trade may develop into enormous proportions with equal advantage to producer and consumer. There are difficulties attending it as in all other forms of business, but they are surmountable, and the efforts demanded to accomplish this are well repaid in the results. Where the Railway Companies deliver the packages to the houses of the consigners, all the sender has to do is to make his boxes or baskets as secure as possible and to convey them to his nearest station. The chief difficulty consists in finding customers that can be regularly supplied in this manner, and in securing payment. Some help is rendered by a few of the Railway Companies in the first matter by printing lists giving the names and addresses of producers on their system who undertake to supply small quantities of specified 


\section{THE DISTRIBUTION OF PRODUCE I 37}

articles. These lists are distributed gratuitously to all applicants, and they are advertised widely in Time Tables and other publications. This action has brought a considerable trade to some producers; and the latter can further aid themselves individually by the distribution of circulars in the towns that are most likely to suit their purpose. Judicious advertisements in papers with large circulations, or in those that appeal to certain classes of readers, also furnish assistance in the same direction. Bearing in mind the subjects we have discussed respecting selection and grading, with good packing, the formation of a sound business should only be a question of time. As regards payment, it is wise to adopt the plan of "cash with order" for all new or unknown customers; it is in fact preferable throughout; but if a well-known and regular customer desires to pay at stated periods, say fortnightly or monthly, it is a matter for consideration. Where the grower is paying carriage in advance, besides providing boxes, etc., it is only fair to expect immediate payment, and that is the only safe method on which such a business can be conducted.

Fruiterers in the larger cities, notably in the West End of London, occasionally make a feature of small boxes of the choicest British fruits, and when these or other dealers find there is a demand, an important opening is afforded for small packages. Some of the principal general stores have also taken up boxes of home-grown fruits, and when these can be sent in consignments of fifty to one hundred boxes each, several advantages are gained. One is that on some of the lines the total weight of a consignment to one person is charged for, and not on the packages separately. This makes a material difference in favour of the sender.

A branch of this direct consignment system which has only been partly developed by a few growers is the 


\section{38 THE BOOK OF MARKET GARDENING}

delivery of hampers of fruits and vegetables to families in towns, as often as may be required each week. It would be possible to extend this considerably, especially where farming is combined with market gardening, as other produce, such as butter, eggs, fowls, ducks, etc., can be included in the arrangements. We know some market gardeners who have followed this method for the past twelve years with substantial advantage to themselves, and satisfaction to those they have supplied.

Obviously several of the systems described could be worked in conjunction with each other, and it is essential that no opportunity be lost which offers the slightest chance of sufficient remuneration. After having incurred all the expenses of cultivation, it is little short of a calamity when the produce cannot be sold to good purpose, particularly when the demand is so great in all the centres of population. Usually it is found that one method must be depended upon for the chief bulk of the supplies; all the others come in as useful helps as the occasion demands.

Exportation of produce rarely concerns the homegrower, unless a portion of his business is devoted to the manufacture of preserves, either jams, jellies, or pickles. If means and experience have permitted the development of an up-to-date factory, and his productions have gained sufficient celebrity to be in demand in other countries, the export trade may be something considerable. But that will constitute a business in itself, which scarcely comes within the scope of a treatise like the present one. Similar remarks also apply if ordinary nursery stock is included in the produce of the holding, as occasionally exportation will be needed. 


\section{THE CONVEYANCE OF PRODUCE}

THE available modes of conveying land produce to the markets, or to the consumers, are worthy of a chapter, for in many ways there is evident room for improvement, and the growers' efforts are partly discounted by defects that should admit of remedies. Garden crops in the British Isles are largely conveyed by road and by rail, and to a much more limited extent by post. It is therefore with the two first methods that we are chiefly concerned, and these deserve our earnest attention.

\section{Conveyance by Road}

This old-time method of market gardeners situated around the large cities still presents many advantages where the distance is not too great. As compared with former periods, there has been marked improvement in the condition of the roads, which facilitates all kinds of traction, decreasing the strain upon horses and increasing the speed of conveyance. But against this advantage must be set the fact that growers have been forced out farther from the markets by the advance of population and the value acquired by the land for building purposes. Every few miles of road thus added to the journeys increase expense and difficulties, until at last the limit is reached as far as horse power is concerned. In the metropolitan district it has been the custom for generations to convey the garden produce to the central markets by two, three, or four-horse wagon loads on one day, and return with manure the following day. From the London stables the manure could be had for a 


\section{40 THE BOOK OF MARKET GARDENING}

nominal sum, indeed in some cases it has been obtainable without any actual outlay, on the undertaking that the yards should be regularly cleared. It is incalculable how many millions of tons of stable manure have been thus applied to land in the Thames Valley, and we have examined soil that has been under market garden cultivation for nearly 200 years, which was simply a mass of humus to the depth of nearly three feet. No system could have answered the grower's purpose better in every way, and it is easy to understand why even now it is pursued whenever the position of the ground permits. But manure cannot be obtained so cheaply as formerly. Dealers now buy it up for despatch by train to longer distances, and there is considerable competition at some seasons of the year for the available supplies. When manure is not required or not obtainable, the wagons are loaded with empty baskets or boxes, so that the expenses are confined to the horse and man labour requisite, together with the provision of suitable vehicles. The outlay is, however, a heavy item to take into consideration, for a full size market wagon, well and strongly built as it must be, is very expensive, and occasional repairs have to be provided for besides. If a market is only attended once or twice a week, it is possible to employ the horse labour on the land for part of each week, but if three market days are utilised, the whole labour of a team of horses is needed for the carting alone. In estimating probable expenses due allowance must be made for all these contingencies.

The London market wagon is a heavy vehicle with a long body, fitted with sides and rails, so that an enormous load of bulky vegetables, like cabbages or cauliflowers, can be packed on often to a height of 6 feet or more above the sides. Such wagons are mostly used for vegetables, but they are also employed for fruit in baskets or half-sieves, but lighter vans are 


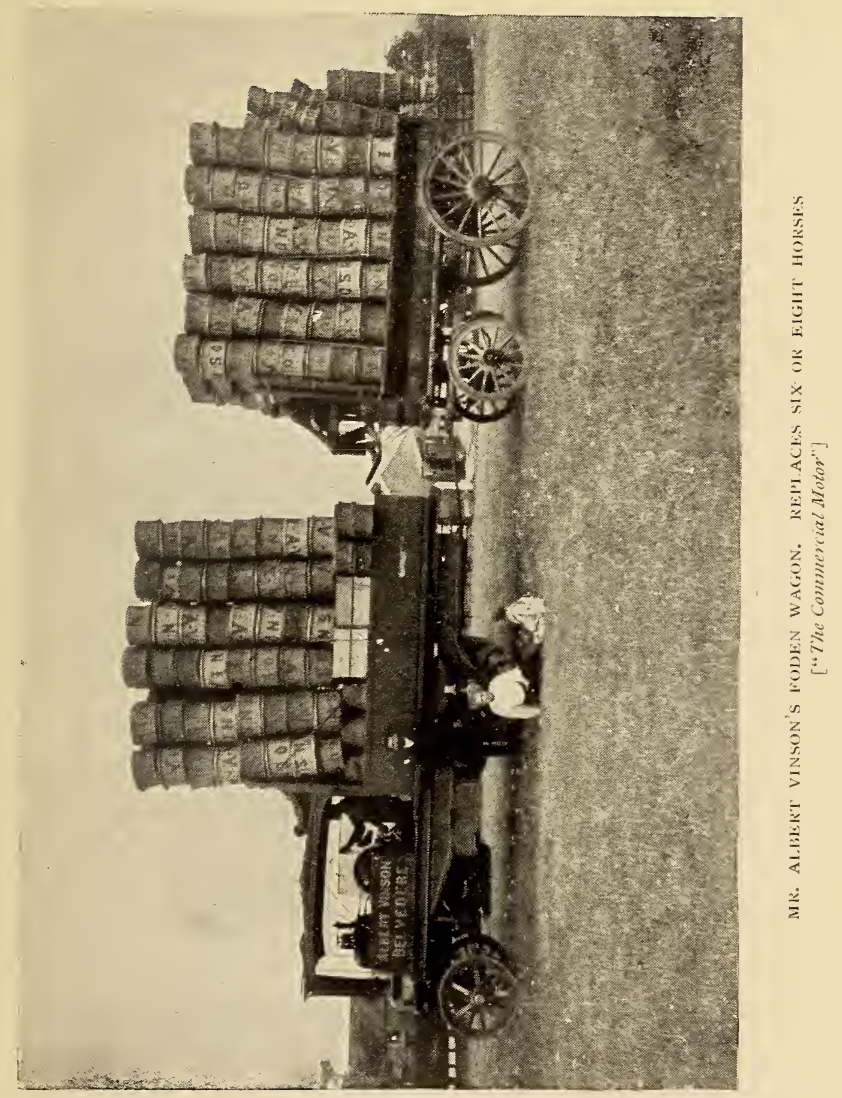





\section{THE CONVEYANCE OF PRODUCE I4I}

generally utilised for the choicer or soft fruits, in the style of that described for local selling in towns. On good roads, with the requisite horse-power, loads of two to three tons can be taken with safety on the larger wagons, but the pace is a slow one, and a ten or twelve miles' journey may take from four to five hours.

A vehicle extensively employed by market-gardeners in some districts is the lorry, which is both light and strong, usually consisting simply of a body on four wheels, without sides or rails. It is convenient for loading, but to the inexperienced it would seem difficult to pack a large load securely, yet this is performed with considerable skill by those accustomed to them. In no town can this form of lorry be seen more in evidence than in Evesham, particularly during the spring and summer. It is the favourite conveyance of the district, and the speed with which large one-horse loads are rushed up the roads, round the corners, and into the Great Western station-yard is astonishing, seeing that accidents are of rare occurrence. The whole affair is very suggestive of the hazardous way in which the cars are driven in the Irish towns, when it appears a certainty that at every corner some of the passengers will be projected into the road or on to the path. We have watched some hundreds of the Evesham lorries being driven at headlong speed, but never saw a single basket dislodged nor a collision of any consequence. They are often used for taking women and girls out to the gardens for piecework in the busy season, and the natives are both safe and comfortable, seated on pot baskets in the centre, though the "strangers" take a time to get accustomed to it. Similar lorries are in use amongst greengrocers and fruiterers in a few districts, and generally prove very serviceable; they are much cheaper than ordinary wagons, and lighter horses can be employed for them, with increased speed. 


\section{42 THE BOOK OF MARKET GARDENING}

Motors and Tractors. - Within the past few years the development of various forms of motor cars and traction wagons has led to many experiments in the application of such power to the needs of market-gardeners. The greater distance at which the producing grounds are now placed that supply the large centres has rendered some other system of carriage essential, unless the growers are to forsake the road for the rail. In addition to the advantage of loading back with manures or empties, as pointed out, there are several other matters which render the utilisation of roads desirable. One of the most important of these is the fact that a wagon is loaded with crops on the land, and they have not to be handled again until the market is reached; whereas, however near the station may be at the grower's end of the rail, horse-power must be employed for the conveyance to the line, with the loading up at the ground and the unloading into the companies' vans or wagons. 'This also has to be repeated at the station nearest to the market, with the result that the risks are more than doubled, because the work at the last-named will probably not be performed with anything like the same care as at starting. Delays of a serious character, also, take place in the delivery to the markets, perhaps at some critical time.

Consequently there are many reasons why market growers on good roads within twenty miles of a large centre should endeavour to utilise any motive power that offers a prospect of serving their purpose. Motors or tractors do not come within the scope of the smaller growers; the outlay is too great, and they have not sufficient produce covering a long period in the year to keep such machines in constant work. The case is quite different where a large area is under market garden cultivation, as it is possible to employ similar power on the land in partial or entire substitution for horse labour. 


\section{THE CONVEYANCE OF PRODUCE I 43}

Efforts have been made to provide machines that will perform both land and road work and to some extent this has been accomplished. But the best authorities agree that so far as development has proceeded up to the present it is more satisfactory to employ different machines for the two purposes. Substantial advance has been made in the improvement of the road motors, etc., and though some of the earlier forms have proved disappointing, yet there are many of the latest types being worked to the entire satisfaction of their owners. The extension has been much greater amongst large manufacturers in town than in the market garden industry, but an increasing attention is being paid to the matter by these producers, most of whom speak favourably of their results which have now passed the experimental stage. A special issue of the Commercial Motor (Temple Press, London) on August 31st, I905, gave an exhaustive description of the progress made by market gardeners in the utilisation of motor power for traction purposes, together with illustrations of the various types of machines already in use. Reference to this journal will give much more information on the subject than our space will permit, but a few of the principal points are worthy of notice.

$\mathrm{Mr}$ W. J. Lobjoit, of Messrs W. J. Lobjoit \& Sons, Heston Farm, near Hounslow, has furnished the following account of the relative expenses of Tractor and horse haulage. The Tractors used were two of Wallis \& Steevens', and one of Wm. Foster \& Co.'s.

Annual Tractor costs-

First cost of three Tractors $=6$ I I 50

Interest at 5 per cent. per annum . $\quad £ 57$ Io 0 Depreciation at 20 per cent. per annum . $\quad 2300 \quad 0$

Carry forward . $\overline{£ 287 \text { 10 } 0}$ 


\section{44 THE BOOK OF MARKET GARDENING}

Repairs Brought forward $\quad £_{2} 287$ io 0

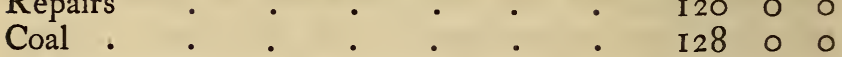

Oil and waste

Insurance and licenses . $\quad . \quad \cdot \quad \cdot \quad 4500$

Water

Wages

Total for three Tractors . 61045 10 0

Annual estimated horse expenses to do the work of three Tractors

First cost of $\mathrm{I} 2$ horses $=£ 54^{\circ}$

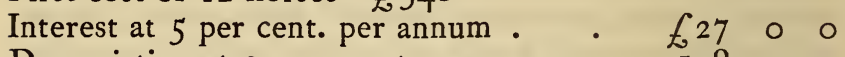

Depreciation at 20 per cent. per annum . I08 0 ०

Forage and straw $\quad \cdot \quad \cdot \quad \cdot \quad \cdot \quad \cdot \quad \cdot \quad \begin{array}{llllll}468 & 0 & 0\end{array}$

Veterinary Attendance . . . . $\quad$ I2 I2 0

Harness

Insurance

Water .

Shoeing

Wages

Total for I2 horses . . . $\oint_{1}$ II24 I 20

$\mathrm{Mr}$ Lobjoit adds " this shows only $£_{7} 79$ in favour of the Tractors-on paper. The advantage, however, in working is much more than that." He further remarks that when the agricultural motor comes along that can work the land and haul one's goods as well, the saving will be much greater than it is now.

The Ivel agricultural motor has been used to some extent for haulage but chiefly for land work, and in regard to the latter Messrs Reffell Bros., Manor Farm, Horton near Colnbrook, Bucks, supply this interesting comparison between horse, steam, and motor labour. 


\section{THE CONVEYANCE OF PRODUCE I 45}

Horses -

Nine horses for ploughing $2 \frac{1}{4}$ acres @

$$
\begin{aligned}
& \text { 2s.6d. } \\
& \text { f I } 26
\end{aligned}
$$

Steam-

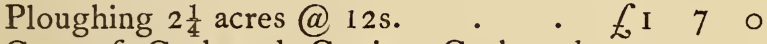

Cost of Coal and Carting Coal and

Wate

Motor-

$$
\text { Total } \frac{0}{f_{0} \mathrm{I}} \mathrm{I} \text { I } 3
$$

Ploughing 2 acres-

One driver . . . . . £o 46

One ploughman . . . . $\quad \begin{array}{ccc}0 & 2 & 6\end{array}$

Lubricants

Petrol

$$
\begin{aligned}
& \text {. } .0 \text { I } 0 \\
& \text { Total £o } 186
\end{aligned}
$$

Mr Joseph Rochford, Turnford Nurseries, near Broxbourn, uses a small tractor (Wallis \& Steevens) for cucumbers, grapes, and tomatoes, which carries 4 tons of the first or I ton of the second, thus doing "the work of four big horses, and $£ 3$ a week cheaper than they did." $\mathrm{He}$ also adds "The Wolseley people are now building me a 4 cylinder 24 -horse power van to carry 3 tons at 8 miles an hour. This will do the journey of I7 miles easily in $2 \frac{1}{2}$ hours, and we expect to use it daily for one journey to market and back (34 miles) but in one busy season it will do two journeys. Our produce varies from 2 tons a day in winter, to I5 tons a day in the summer months, from 35 acres of glasshouses. 


\section{46 THE BOOK OF MARKET GARDENING}

Messrs Mann \& Sons, Whitton Road, Twickenham, employ a Straker steam wagon which carries "from 4 to 5 tons on the motor and from 2 to 3 tons on the trailer, using our existing horse wagons as trailers. In this way we take produce to Covent Garden Market, a distance of about I 2 miles, which takes about two hours, and load back from London with manure. We consider after careful calculation the average work done is quite equal to that of five horses. We are of opinion that the steam wagon is more useful than the tractor for our work for several reasons. (I) Greater carrying capacity by having the two vehicles to load; (2) using our existing wagons for trailers instead of specially built ones ; (3) the steam wagon is much more easily manipulated in traffic and by carrying a greater total load there is a saving in drivers."

Messrs Baker Bros., of Feltham, have a Coulthard lorry which is used with a trailer and " displaces five horses."

Mr George Leonard, New Road, Shepperton, employs a Foden steam wagon which "does the work of 6 or 7 horses, going to Covent Garden every night when necessary, the journey there and back being about $3^{8}$ miles. It will carry about 200 bushels on the motor, and 200 on a trailer, a total load of 400 bushels." $\mathrm{Mr}$ Albert Vinson, Parsonage Farm, Belvedere, Kent, also uses a Foden motor with a trailer, which does the work of 6 to 8 horses, and takes 9-ton loads up considerable hills. In the Liverpool district a Lacre van has been used very successfully for strawberries carrying 300 to 500 baskets of $3 \mathrm{lbs}$. each, a distance of 30 miles in about 2 hours (part of the journey being on a Ferry Boat). "The cost of bringing the strawberries in by motor was a little in excess of the charges incurred when they were dispatched by railway, but the early arrival and the advertisement were of great benefit."

An excellent example of the work which can be per- 


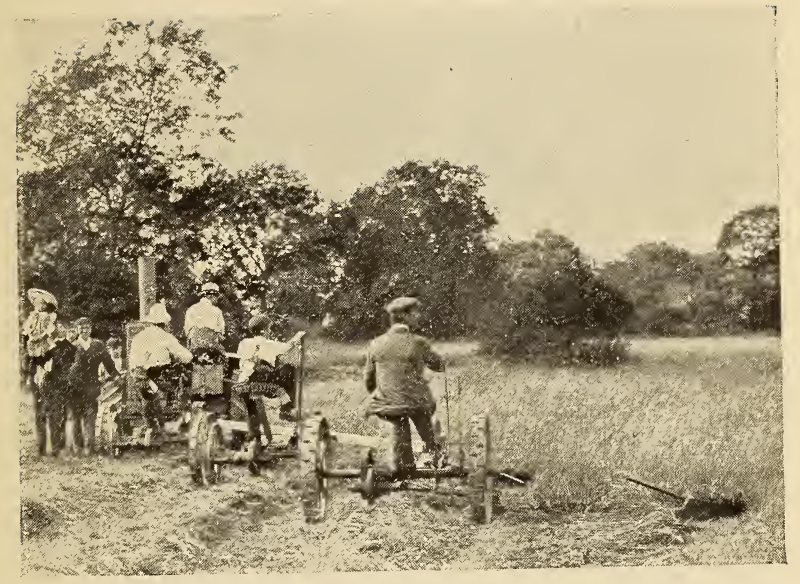

IVEI, MOTOR HAULING THREE REAPING MACIINFS, CUTTING A TOTAL WIDTH OF 18 FT. EIGHT ACRES WEKE CUT IN TWO HOURS. SIX HORSES REPLACED BY ONE MOTOR

I"The Commercial Motor" 



\section{THE CONVEYANCE OF PRODUCE 147}

formed by such power is afforded by the following statement by Messrs Lobjoit of what their three tractors have to do. "Two markets are served; Covent Garden every day, and Brentford on Mondays, Wednesdays, and Fridays. All three tractors go to Covent Garden on Tuesdays, Thursdays, and Saturdays. One always makes an extra journey on Saturdays to bring home the wagon left there in the early morning and the empties. They frequently make a journey on Saturdays with goods ordered for the West End. Each Monday one tractor washes out, and the third on alternate Wednesdays. Two manure contracts are kept clean averaging about 30 tons a week. The tractors draw all their own coal from the station, the corn for 35 horses employed on the land, and the coke for the greenhouse furnaces (about I 20 tons a year)."

Other examples could be given, for similar trials have been made in many places, but those cited will suffice for our purpose, which is chiefly to show that, notwithstanding the expense, the disappointments with some of the earlier machines, and the constant care demanded, practical results of a sufficiently satisfactory character can be obtained by those in the position to make the most of this form of power. As improvements are developed, and machines capable of being equally utilised on the land and for traction are secured at more moderate prices a distinct advance may be expected in the solution of the main problem for large producers, i.e. increasing the speed and diminishing the cost of distribution.

\section{Conveyance by Rail}

The greatest distributing agencies are necessarily the railways, and until some fundamental alteration is made in our systems, land cultivators will be as dependent upon them as other producers who cannot reach all 


\section{THE BOOK OF MARKET GARDENING}

their markets by road. That defects are numerous and charges heavy are well known to all who have to transact much business with the British railway companies, but how far remedies can be applied and rates reduced is an important and complicated question which has not yet been fully answered. Many of the Companies contend that they have brought their charges to the lowest level; that a good deal of the fruit and vegetable traffic on their lines as at present conducted, barely pays expenses; and that further improvement can only be brought about by the growers consigning their goods in greater weights. The feeling of dissatisfaction is, however, very general, and this is abundantly proved by the evidence taken before the Departmental Committee of the Board of Agriculture in 1904, which, though concerned with fruit traffic, practically embodies the experience of market-gardeners generally, many of whom are largely dependent upon fruit.

The complaints are classified as follows:

I. That the rates for carriage are too high for the services rendered.

2. That preferential rates are given in the case of foreign fruits coming into this country.

3. That preferential rates are given to one place over another in Great Britain; that the incidence of the charges is variable; and that the existing classification presses hardly on growers.

4. That deliveries are frequently unpunctual so that fruit misses the market.

5. That there is a great deal of bad handling of fruit.

6. That pilfering frequently occurs.

7. That the service given in many places is inadequate; and that the vehicles provided, especially on goods trains, are often most unsuitable.

8. That considerable delays and losses occur in connection with the conveyance of empties. 


\section{THE CONVEYANCE OF PRODUCE I 49}

9. That great difficulty is experienced by growers in getting the Companies to pay claims for damage or loss, especially in the case of fruit sent at owner's risk in the last two years, in consequence of a certain combination among the Companies.

IO. That other evil results follow from railway combination.

Much evidence was taken by the Committee on these points and naturally there was some conflict of opinion due to various circumstances the special influence of which we have found in our own experience. In the first place, large dealers, whether growers or agents, can command more attention and consideration from the Railway Companies than the smaller ones can. Secondly, in districts where Market-gardening and fruit growing constitute the chief industry, and large supplies of produce are being forwarded by rail throughout the year better facilities are afforded than where but few are engaged in cultivation. Thirdly, a marked difference is observable wherever two or more Companies are serving the same district. Even though the actual rates may be identical by arrangement, the competition for the trade tends to insure more speedy delivery and greater carefulness on the part of the officials, to the advantage of the sender. In the fourth place, some of the most advanced growers give more attention to their methods of packing and the security of the packages than others do.

The whole matter requires to be examined in a reasonable way; the Companies have to consider the interests of their shareholders, and it cannot be expected that they will conduct their business at a loss out of consideration for those engaged in any one industry, however important it may be. On the other hand, the Companies are engaged in the service of the public, and there is a common right to demand fair treatment, a 


\section{50 THE BOOK OF MARKET GARDENING}

demand that could be enforced by lawful methods of combination amongst producers, powerful as the Companies are. Just as the advance of electric lighting led to great improvements in gas lighting, we anticipate that the extension of motor, tractor, and tramway traffic will bring about important changes in railway accommodation for growers and all classes of producers.

In the meantime it is to the grower's interest to take the fullest advantage of such facilities as are already available, though sometimes the complainants are themselves at fault, and the railway officials receive a greater measure of blame than is their due. Inefficient preparation and packing of goods, lateness of delivery at the stations, and a blind way of continuing consignments to markets that are already glutted, lead to many unfavourable results that are entirely due to the grower's want of system in his business.

Another matter does not receive the attention it merits, and that is the utilisation of passenger train service for all the choicer and more valuable produce, confining the business done by goods trains to the rougher vegetables, which can be forwarded in greater bulk. With the best service of goods trains there is always much shunting to be done en route, which leads to considerable risk of damage, and delays too. When a goods train can be made up at a centre for a town or district this is reduced to a minimum; but if open trucks are employed with sheeting laid directly over the produce, it is far from being an ideal mode of conveying perishable goods. The greatly improved special vans constructed for garden produce, especially for fruits and flowers, has been an advance of a distinctly favourable character. Those in use on the Great Western and Midland lines are excellent in all respects, being well ventilated, spacious, and covered so that the contents are thoroughly protected from the weather. The ventilators are covered on the 


\section{THE CONVEYANCE OF PRODUCE $15 \mathrm{I}$}

inside with finely-perforated zinc, so that insects and dust are excluded to a great extent. The whole or part of the van can also be fitted with stout wire shelves to carry boxes of flowers, and these can be put into their places or removed in a few minutes. We have examined many vans on different lines, but have never seen any to surpass these-in fact it is difficult to see how they could be improved, except by the addition of refrigerating apparatus for summer use.

The Great Western Company has made a special feature of these vans for the development of the fruit traffic in Worcestershire and other counties served by their system, and an example of what a great railway organisation can accomplish was afforded early in October 1905. One of Elder, Fyffe \& Co.'s steamers arrived at Avonmouth, Bristol, loaded with bunches of Bananas; two special Great Western goods trains of fifty fruit vans each were immediately loaded with I4,000 bunches. The trains arrived at Paddington at 6 A.M. the next morning, where I00 pair-horse vans with 300 men awaited them, and they were all started with their loads by 8.I 5 A.M. for distribution amongst the London markets, fifty one-horse vans clearing the remainder at a later period in the day. It was a notable performance, and proved how a Company can rise to the occasion when the magnitude of the trade is sufficient to induce them to put forth their best efforts.

It must be admitted that the rates on some of the lines represent but a small proportion of the retail value of the produce. For example, the manager of one of the lines pointed out to us that in one season it was within his own knowledge that the same plums which only brought to the grower Id. per pound were being sold in a large northern town at $6 \mathrm{~d}$. per pound, yet the railway charge in conveying this fruit 200 miles by goods train was only one-sixth of a penny per pound 


\section{52 THE BOOK OF MARKET GARDENING}

in half-ton lots. He very truthfully remarked that the difference in the two prices was certainly not due to the amount required by his Company for their share of the transaction. On some of the lines which cover a shorter distance, the average rate is only one-half of the above, namely, one-twelfth of Id. per pound. By passenger train the rates are necessarily higher, but the advantages are proportionately greater; and where there is sufficient trade to justify the needful provision of vans, $24 \mathrm{lb}$. packages of fruit can be conveyed at an average rate of $\frac{1}{2} \mathrm{~d}$. per pound up to 200 miles, or one-third of Id. per pound in $5 \mathrm{cwt}$. lots for the same distance. Obviously in such cases there is little room for complaint as to charges, and if these were made uniform on all lines and in all districts a considerable help would be rendered to thousands of growers.

Consignments in larger weights, from I to 5 tons, can be conveyed at still lower rates, and in this direction co-operation amongst growers would produce substantial pecuniary results. Well-organised combination might be turned to excellent purpose, but it is a means of which British agriculturists and horticulturists have not as yet fully availed themselves.

Lord Onslow's Departmental Committee, in presenting their Report, furnished a series of summarised recommendations for the improvement of the railway traffic as regards fruit, which are worth repetition here as a guide to those who wish to promote the business relations between the great carrying companies and the growers. They are as follows :-

That it is highly desirable a more simple and uniform system of rates for fruit be introduced by Railway Companies. This can be done without a statutory re-classification with the assistance of the Board of Trade.

That Railway Companies should make greater 


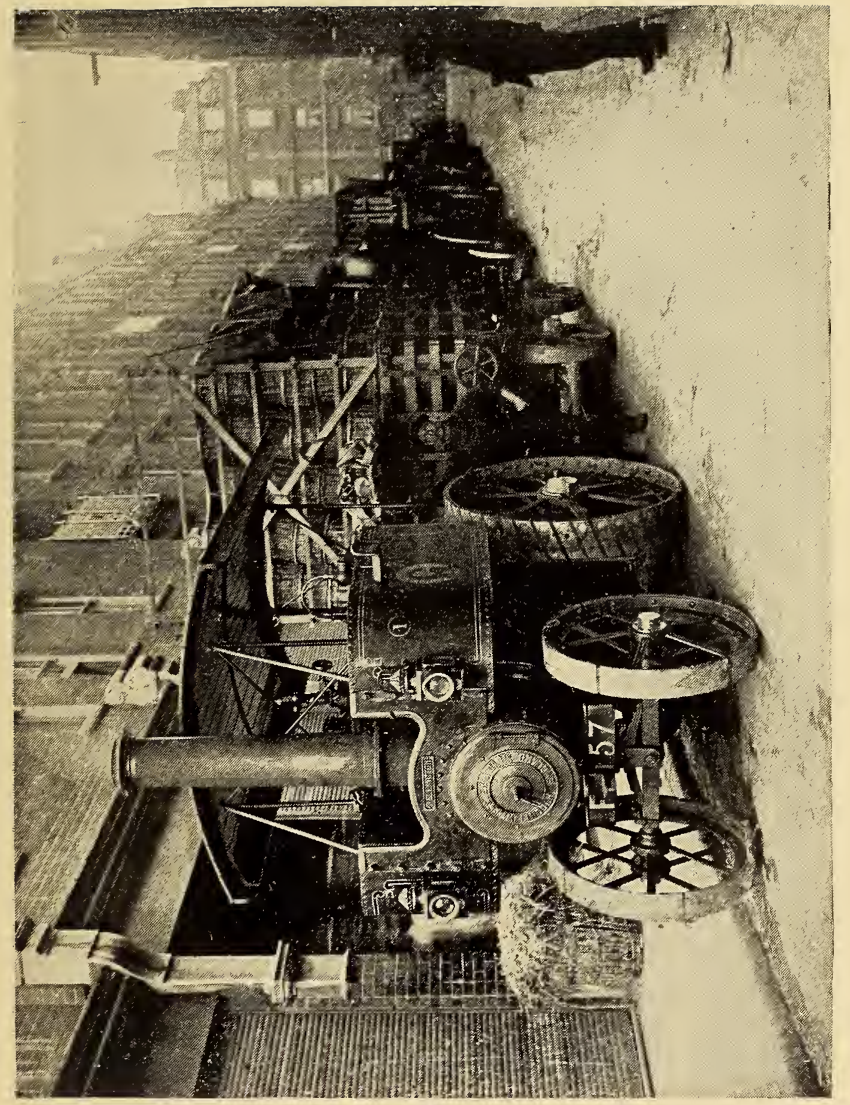

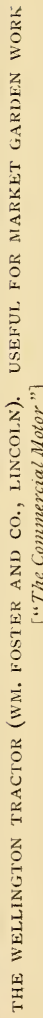





\section{THE CONVEYANCE OF PRODUCE I 53}

efforts for ensuring the prompt delivery of perishable fruit.

That the Companies be urged to provide suitably ventilated goods vans for fruit traffic. That sheeted trucks without sheet supporters should never be used.

That it is most desirable all fruit be consigned at Company's risk, and that the so-called owner's risk rates be abolished, the rates at Company's risk being reduced to a figure approximating to those now in force at owner's risk, providing the Companies with just a sufficient margin for the extra liability incurred. That 5 per cent would be a fair margin.

That, in the event of owner's risk rates being retained, the liability of the Railway Companies should not be confined to cases where only "wilful misconduct," but to those where "culpable negligence" can be proved.

The Committee also suggest that in view of the recent tendency to combine among the railways, it would be an advantage if the Government were to appoint an official or a Department to watch over the Companies' actions, and to report to Parliament.

That in the case of all serious grievances against the Railway Companies, growers and merchants should at once send their complaint to the Railway Department of the Board of Trade, and ask them to exercise their powers under the Conciliation Clause of the Act of I 888.

That in years of glut, the Companies should be urged to temporarily lower their rates for fruit, just as excursion passenger fares are lowered on special occasions, and that if this cannot be done by agreement, it is desirable that the Railway and Canal Traffic Act of 1894 should be amended for the purpose. 


\section{54 THE BOOK OF MARKET GARDENING}

\section{Conveyance by Canals}

Though this system might be utilised under some circumstances for the conveyance of heavy roots in large quantities, we have not succeeded in obtaining any statistics to illustrate how far it is employed. It is useless for anything of an immediately perishable nature, or where it is desirable to secure a quick market. For the transport of manures, canals are convenient in some districts, but so many have been acquired by Railway Companies to diminish the chances of competition that the rates are not so favourable as they otherwise would be in such a cheap system of conveyance.

The navigable rivers are chiefly employed for exports and imports, and they are but little used for internal traffic in the United Kingdom as regards market garden produce.

\section{Conveyance by Parcel Post}

Fruit, flowers, and vegetables in small quantities can be sent by parcel post throughout Great Britain and Ireland, but except for I lb. or under the rates are higher than those charged on the railway lines which make a special provision for parcels traffic. The restriction as to total weight, i.e. I I lb., is also an inconvenience, nor have we found the system favourable as regards the safety of the contents of the packages, in fact with fruits the results have been less satisfactory, on the whole, than with similar small packages sent by train.

The utmost care should be taken in packing any fruits to be sent by parcels post, for over-ripe or damaged fruit might cause a risk of injury to other parcels, in which case the postal authorities can, if they choose, detain the whole package. For flowers the method has been employed more largely, but the officials advise the use of tin or wooden boxes in preference to card-board, for fear 


\section{THE CONVEYANCE OF PRODUCE 155}

of injury, though we have had the first-named quite as badly smashed as the last. In fact the smaller size of card-board boxes are now made strong and durable. In all cases tie-on labels or tags must be used, and the address of the consigner should also be written on the parcel.

Where it is a long distance to the sender's nearest railway station, or in the numerous cases of provincial stations where there is no delivery of parcels, the postal system offers advantages. But delays are frequent in country districts, especially where there is only one delivery of letters daily, and the postmen have long distances to travel. 


\section{SUBJECTS WORTH ATTENTION}

\section{CO-OPERATION}

MaNY of the difficulties which affect small producers in connection with railway charges for the carriage of goods, the expenses attending sales, and the purchase of materials, might be greatly reduced by well organised systems of co-operation. In the general trade of the country as regards provisions, clothing, etc., methods of co-operation have proved highly successful, especially in the North of England. The number of members constituting these industrial societies now exceeds two millions, while the funds amount to over forty-five million pounds, and considerable profits have been realised for distribution amongst the members.

Amongst British farmers, fruit growers, and market gardeners the progress made in the direction of such combinations has been deplorably slow, though several Continental nations (like Denmark, for instance) have taken the fullest advantage of the benefits co-operation confers. The Agricultural Organisation Society, Ltd., Dacre House, Dacre Street, Victoria Street, London, S.W., has been registered under the Industrial and Provident Societies Acts as a non-trading society instituted for the purpose of advocating the principles of co-operation amongst all classes of land cultivators. Under its auspices many local societies have been formed for various purposes, and up to the end of 1905, 125 such bodies were registered and affiliated. Instructive leaflets are issued gratuitously dealing with the, methods 156 
available, full information respecting the formation of societies is readily furnished, and under some circumstances representatives are sent to explain the system of organising, and the directions in which co-operation can be of special service to growers. In districts where small cultivators are numerous, substantial help could be rendered in reducing expenses and aiding those with small capital.

All engaged in commercial horticulture should also make earnest efforts to assist themselves by extending their knowledge upon all matters relating to their business. In this connection it must be noted that the Board of Agriculture issue many important practical leaflets which can be obtained free by post from the offices, Whitehall Place, London, where also there is a large library which can be consulted on special subjects. The publication of Parliamentary Reports, or Acts dealing with the growers' interests, should also be watched, and most of them can be obtained at low prices from Messrs Spottiswoode \& Co., East Harding Street, Fleet Street, E.C., or from Messrs Wyman, Fetter Lane, E.C. In addition, the numerous excellent trade periodicals should be closely studied, for much more journalistic attention is now paid to commercial horticulture than formerly.

\section{Assessment. Taxes. Rates.}

Several grievances under these heads were carefully investigated by the Board of Agriculture Fruit Committee, and some valuable suggestions have been made that affect the interests of market gardeners generally, as well as fruit growers in particular. In reference to assessing market gardens and nurseries under Schedule $B$ of the income-tax, there is a special rule by which the tenant pays on the estimated profits, instead of on one-third the annual value, as other agricultural tenants 


\section{58 THE BOOK OF MARKET GARDENING}

do. It does not apply to fruit plantations generally, but to those considered to be market gardens and nurseries as well, though some confusion exists in the matter, as there is no accepted definition of a market garden and nursery. Hop gardens formerly came under the rule, but it has been abolished in their case, and the Committee recommend a similar course with regard to market gardens and fruit land, with the exception of nurseries.

In the assessment of fruit land for local rates, the chief complaint is that valuation is raised too soon after the planting, before the tenant or owner has had any chance to reap the slightest advantage from his outlay. It is strongly recommended by the Committee that such re-assessment should not be made until five years after planting small fruits, seven years for mixed plantations, and twelve years for orchards.

In the taxation of glass-houses the chief grievance is in reference to the income-tax as regards the allowance for depreciation, which only amounts to one-sixth, as in the case of dwelling-houses, though they are entirely different, the cost being considerably greater for the due maintenance of glass-houses. The committee named recommend that the allowance be increased to one-third, i.e. one-sixth for repairs, and one-sixth for depreciation. Another unjust arrangement is that for local rating purposes "glass-houses and the land upon which they stand, are excluded from the benefits of the Agricultural Rates Act of 1896." The Committee therefore recommend that this act be amended so "that glass-houses used for commercial purposes should be held to be land and not buildings for the purposes of the Act."

Excellent as the preceding recommendations undoubtedly are, they will be of little avail until they are incorporated in the law of the land. To this end 


\section{SUBJECTS WORTH ATTENTION I59}

parliamentary influence must be acquired by market gardeners and other cultivators, a matter of considerable difficulty. Lord Onslow (late President of the Board of Agriculture), in the course of a letter to $\mathrm{Mr}$ Pike Pease, M.P., had the following trenchant remarks : "The amount of time devoted by the House of Commons to Agriculture is out of all proportion to the magnitude of the interests involved. . . . If the Agricultural Rates Act were eliminated it would be found that to legislation promoted by the Board of Agriculture the House could find time to devote only six hours in the last four years (I902-I905). . . All classes interested in the cultivation of the soil should make clear to their representatives the conditions upon which they will continue to support them, and pertinaciously to press their needs in Parliament."

\section{COMPENSATION AND INSURANCE}

The liability of employers to claims for compensation in the event of accidents befalling their workpeople is so extended that it is only a matter of common prudence to provide against such risks by insurance. Many Companies undertake to secure the employer for moderate premiums, but it is advisable to endeavour to understand the extent of the liability, and how far the various Companies really go in providing the grower with security to cover the whole of this. The subject has been concisely treated by $\mathrm{Mr}$ W. FitzherbertBrockholes, President of the Lancashire Farmers' Association, in a leaflet (No. 6) issued by the Agricultural Organisation Society, which should be read by all who wish to gain an idea of a complicated and difficult subject. The following are the leading points.

The Acts of Parliament affecting the question are (I) the Workmen's Compensation Act of I897, which in- 


\section{I60 THE BOOK OF MARKET GARDENING}

cluded most employers.

(2) The Workmen's Compensation Act of I900, which extended the first Act to workmen employed in agriculture, horticulture, and forestry. (3) The Employers' Liability Act of I880, applied only to manual labour, and to accidents due to defective plant, or to the fault of the employer or his agents. (4) A workman might claim in some cases under the common law, and independent of the Acts named.

The compensation fixed by the 1897 Act is as follows: In case of death where dependants are left, three years' wages (with $f_{1} 50$ as the minimum and f 350 as the maximum sum), and where there are no dependants a sum not exceeding $£ I O$; in case of disablements, half-weekly wages (maximum $£ I$ per week) during the whole period of disablement after the first fourteen days. When preparing the estimates of wages paid for the purpose of insurance, include the value of board, lodging, or house-rent where this is provided or allowed in addition to money. Include females employed in farm or garden work, also casual labour.

\section{Fruit Preserving Factories}

Some large fruit growers have found it to their advantage to provide factories for reducing their produce to jam, or preserving fruits whole in bottles upon the premises. Properly worked, this should secure the profits that go to other dealers, and enable the grower to utilise his fruits in seasons of gluts when the market rates are unduly low. Great and flourishing businesses have been created by combinations of the kind referred to, but it is also fair to state that there have been some deplorable failures. It is obvious that the two departments are very distinct, and require a different kind of experience and knowledge. 
Because a man is highly successful as a fruit grower, it does not follow that he will be equally so as a jam maker. On the other hand, one who has established a business in fruit preserving may prove a dismal failure as a grower. A sufficiency of capital will go far to assist in averting failure in either direction, because qualified managers can be employed in the respective departments where the owner's knowledge is defective. But even that is not all, for if an up-to-date factory is duly fitted with appliances, the capital sunk will yield but a poor interest if they can be utilised for only a small part of the year. It therefore necessitates launching out into preserving generally as a business, including the preparation of pickles, jellies, etc., and the development of a wide connection with retailers.

\section{Farming and Market Gardening}

Some combination of farming with gardening is, under certain circumstances, both advisable and profitable. Thus, poultry-keeping may often be included in the scope of the work, and, in favourable localities, with careful selection of the best breeds and due attention, it can be made to pay. Ducks, also, where they can be reared early in the season, constitute a useful addition to the resources. In Buckinghamshire, and on the borders of Bedfordshire, where Plums and Damsons are extensively grown in grass, ducks form an important "crop," and often yield ample returns. Geese and turkeys may similarly be included, but the last named are delicate as young birds, difficult to rear up to a certain age, and they are large eaters.

Under the best management as to selection and cleanliness, with economical feeding pigs can be kept with advantage where there is suitable accommodation for them. But in a general way they pay best if sold young 


\section{I62 THE BOOK OF MARKET GARDENING}

as "stores," a succession of breeding sows being kept to furnish stock.

Where fruits are grown on an extensive scale it is an advantage to keep some hives of bees, as, apart from any direct profit they may yield, they render important assistance indirectly in promoting the fertilisation of flowers, which often determines the setting of the fruits and the consequent crop.

\section{Crop Returns, Values, and Profits}

The discussion of returns and profits has been avoided, because statements on these matters are apt to mislead the inexperienced, and raise expectations which are rarely realised. There is a wide range between a return of $£$ IO per acre, which may barely pay expenses, and fioo per acre, which should leave margin enough to satisfy any one. The influences are many, varied, and complicated which lead to the higher results. The skill of the grower, the nature of the soil, the situation, the crops grown, the character of the season, and the methods of selling all have a bearing upon the total values. With special crops like some high quality fruits, in certain seasons, the maximum mentioned may even be exceeded, also by exceptional crops like mushrooms, while under glass the acreage returns are still more largely increased. Crops of early Cabbages or Peas, and particularly fine Celery or Potatoes, sometimes yield the grower abundant returns, while at others the losses may be heavy. Profits will vary in the same way, the systems of working as well as the weather being important as determining factors. Under the most favourable conditions no form of land cultivation yields such satisfactory results as well-conducted market gardening; even with average advantages it affords a substantial advance upon ordinary agricultural methods. 


\section{SUBJECTS WORTH ATTENTION ${ }^{1} 6_{3}$}

The following are examples of the amount of vegetable and fruit crops per acre obtained within our own experience or knowledge. The first two figures represent the average range, the third shows extreme crops. Marketable produce only is included.

\section{Vegetables}

Asparagus, 200-400-600 bundles (I00).

Beans, Broad, 100-300-400 bushels.

Beans, Kidney, 150-250-300 bushels.

Beans, Runner, 200-400-500 bushels.

Beetroot, IO-1 5-20 tons.

Borecole, IO-I2-I4 tons.

Broccoli, 6-9-I 5 tons.

Brussels Sprouts, I 50-250-300 sieves.

Cabbages, 1000-2000-3000 dozen.

Cauliflowers, 5-10-I4 tons.

Carrots, 8-I 2-20 tons.

Coleworts, I 50-250-300 dozen bunches.

Cucumbers (out-doors), 1000-2000 dozen.

Celery, 800-I IOO-I 300 bundles (I2).

Horse-radish, 4-6-7 tons.

Lettuce, I000-I 200-I 400 scores.

Mushrooms (ridge beds), 3-5-8 tons.

Onions, 5-I 2-20 tons.

Onions, Spring Salad, 2000-3000-3500 dozen bunches.

Parsley, I000-I 200-I 400 dozen bunches.

Parsnips, IO-I 2-18 tons.

Peas, IOO-I 50-200 bushels.

Potatoes, 5-IO-I 5 tons.

Radishes, I000-I600-2000 dozen bunches.

Rhubarb, IO-I 5-20 tons.

Savoys, 800-I000-I 200 dozen.

Spinach, 2-4-5 tons.

Tomatoes (out-doors), 4-6-Io tons. 
Turnips, 400-700-900 bushels.

Vegetable Marrow, I000-I 200-I 500 dozen.

Watercress, 5-IO-I 2 tons.

\section{HARDY FrUITS}

Apples (dwarf), 2-4-6 tons.

Cherries, 2-5-7 tons.

Currants, Black, $\mathrm{I}-4-5$ tons.

Currants, Red, $2-3-4$ tons.

Gooseberries, 3-6-8 tons.

Pears, Standard, 4-6-8 tons.

Plums and Damsons, I-5-Io tons.

Raspberries, $2-4-5$ tons.

Strawberries, 2-4-6 tons.

Filberts, 5 cwt.-I ton-3 tons.

Under glass crops vary enormously. The following are examples of three important crops in amounts per acre covered with glass.

Grapes, 6-I 5-20 tons.

Tomatoes, I0-20-30 tons.

Cucumbers, 3000-5000-6000 dozen.

To conclude, the fact must be emphasised that commercial horticulture is a highly specialised industry, and practical experience in all departments is essential to any measure of success. The principles which underlie this and private gardening are identical, but the methods are so entirely different that the best training in either requires considerable modification to fit the practitioner for the other. Some experience in both is an advantage, as in private gardening the chief object is the highest cultural results, but in market gardening the striving for perfection is qualified and restricted by financial considerations in every direction. 


\section{APPENDIX}

WHILE this manual was passing through the press, some correspondence has taken place between the Board of Agriculture and the Local Government Board relative to the recommendation of the Fruit Committee concerning the assessment of fruit land. The reply of the latter Board is to the following effect: "The Board are not sure that any amendment of the law is required to meet the point referred to. If in fact any injustice is created by the over-assessment of the occupiers of an orchard, the fault would generally result from the action of the overseers or the Assessment Committee, and every such action is, under the existing law, subject to correction by means of an objection to the valuation list, or an appeal against the poor rate. The Board may at the same time point out that orchards, in the matter of the general district rate, and the separate rate for special expenses, have at the present time, under the Public Health (Rating of Orchards) Act I89I, the advantage of a partial exemption, and that orchards are also included in the definition 'agricultural land' for the purposes of the Agricultural Rate Act 1896, as continued in force by the Act of 1905. The Royal Commission on Local Taxation recommended that no further extension of the principles of exemption from liability to rates should be permitted." The effect of the Rating of Orchards Act mentioned is that the occupier of an orchard shall be assessed to the general district rate in an urban district, or to a separate special rate in rural districts, in the proportion of one-fourth of the net annual or rateable value of the land. 


\section{I66 THE BOOK OF MARKET GARDENING}

In connection with the difficulties caused by the railway companies having formed a "Joint Claims Committee," the avowed object of which is to investigate claims for loss or damage of goods, but which appears mainly concerned in refusing all claims for the loss of articles sent at owner's risk rates, market growers and others are endeavouring to protect themselves from much injustice. An influential Committee has been formed, known as the "Joint Railway and Parliamentary Committee," of which the President is Mr George Munro, Covent Garden Market, London.

A Committee presided over by Lord Jersey has also investigated the subject of preferential rates given by railway companies to foreign produce, and a report will be issued.

The King has appointed a Royal Commission on Canals and Waterways in the United Kingdom, and much valuable information will be obtained and published upon this important subject. Considerably improved modes of traction are also being tried on the canals.

The business hitherto transacted by the Advisory Business Department of the Agricultural Organisation Society has now been taken over by the Agricultural Co-operative Federation, which has been registered under the Industrial and Provident Societies Act. The first-named Society now includes I0,000 members in the I25 affiliated Societies, with a total turn-over for the past year of $f_{250,000}$. 


\section{N D E X}

Accessibility of land, 9

Acreage under market gardens and fruit, $3 \mathbf{I}$

Agricultural motors, 26, 145

- organisation, 156, 166

Air drainage, 15

Alternate system of planting, 32

Altitude and elevation, 13

Appearance and quality, 54

Apples, 27, 30, 56, 62, 68, 102, 164

Approach roads, 9

Apricots, 67,103

Arrangement of crops, 11, 17, 23, 28, 32, 35

Asparagus, $27,40,98, \mathrm{II}_{3}, 16_{3}$

- sprays, 119

Aspect, value of, 13

Aspen wood wool, 95

Assessment of market gardens, 157,165

Asters, $3 \mathbf{I}$

Auction sales at markets, 133

BABY baskets, 85, 106

Bags and sacks, 92

Bananas, imported, 151

Barrels, fruit, $9 \mathrm{I}$

Baskets, 60, 65, 80, 84

Beans, broad, $84,16_{3}$

- French (kidney), 115,163

- runner, $84,116,163$

Bedding plants, 120

Beetroot, $117,{ }_{1} 6_{3}$

Belts of trees, 16

Board of Agriculture, 8, 76, 82, I $48,152,157$

Borecole (kale), 85,163

Boundary hedges, 15
Boxes for fruit and flowers, 87

Bracken for packing, 97

Broccoli, 1 16, 16 3

Brussels sprouts, 27, 84, 163

Buckwheat husk, 97

Bulbs, 3I

Buncling flowers, I 17

— vegetables, I II

Cabbages, $27,49,63,84,85,163$

Californian pears, 67

Canals, conveyance by, ${ }_{54}$

Canvas, Hessian, 92

Cardboard boxes, 86, 90

Carnations, 7 I

Carriage of produce, 139

Carrots, $63,64,9$ I, 98, 11 I

Carts for produce, 136

Cauliflowers, $27,84,85,16_{3}$

Celery, 27, $63,11_{3}, 16_{3}$

Channel Islands, 6, 107

Cherries, $30,67,70,107,164$

Cherry-plum hedge, 18

Chip baskets and punnets, 86

Chrysanthemums, 27, 31, 40, 71, II 7

Claigmar Vineyard, $4 \mathrm{I}$

Cleanliness, 43,62

Climatic characters, to

Coleworts, 98, 115, 16 63

Collecting crops, 59

Colour in fruits, 56, 69

Commercial gardening, 46

Comparison of varieties, 49

Compensation for crops, 7 injuries, 159

Competition in production, I

Concentration in cities, I

Consignment to market, 126 
Consumers, direct sale to, 134

Continental wood wool, 95

Conveyance of produce, 139

Co-operation, 156

Copper sulphate, 37

Cork dust, 97

Corrugated iron sheds, 22

Costermongers, 132

Cottages for workmen, 19

- Lord Carrington's, 20 rent of, 20

Cotton wool, 95

County Council trials, $5^{I}$

Crates for fruit and vegetables, $8_{3}$, 85

Crops, arrangement, $11,1_{7}, 23,28$,

32,35

gathering, 59

- management, 26

per acre, 162

Crotons, 122

Cucumbers, 27, 49, 70, 76, 108, I10, 117,163

Cultivation, persistent, 144

- under glass, 37

Cultivating by horse labour, 25

Cultural essentiaIs, 43

Currants, 27, 30, 76, 105, 164

Cut flowers, packing, $11_{7}$

Dafrodils, 27, 31, 71, 84

Dahlias, 3I, 71

Damsons in hedges, 18

Diseases of crops, 36,44

Distribution of produce, 125

Districts, market garden, IO

Ditches as boundaries, 16

Dracænas, 122

Drainage, 14

Ducks, I6I

EARLiness, value of, 51

East and western counties, 12

Economy in production, 34

Employer's liability, 159

Evesham, 6, 8, 84, I1 3, 14 I

Essentials, cultural, 43
FARMING and market-gardening, 161

Farms, manual labour on, 20

Fences, care of, 15

Ferns, 122

Fertilisers, use of, 36

Fertility, maintaining, 44

Figs, $69,76,110$

Filberts, 164

Fillis for tying, 100

Finchley Vineyard, $4 \mathrm{I}$

Flat baskets, 84

Flower crops, 31

Flowers, bunching and packing, I 17

- gathering, 70

keeping and gumming, 72

Foden motors and waggons, 146

Foliage, bunching, 119 plants, packing, 122

Forcing fruits and flowers, 39

Foreign supplies, 1

Form of glass-houses, 39

Foul land, expense of, 14

Freehold land, purchase of, 9 ?

Freshness, importance of, 60

Fruit, acreage under, $3^{x}$

- baskets for, $60,65,80,84$

boxes for, 87

by Parcel Post, 154

Committee Report, 31, 152,

157

gathering, 65

grading, 78

packing, 101

Fruiterers' displays, 137

Fruits, hardy, 28

Fruit-preserving factories, 160

Fungicides, 36, 44

GatHering crops, 59

Geese, 16 I

Glass-houses, cultivation in, 37,44

- forms and sizes, 39 water-supplies for, $4 \mathrm{I}$

Gooseberries, 27, 30, 67, 76, I 64

Grading for profit, 74

__ machines, 77 
Grapes, 27, 69, 76, 107, 164

Growers as salesmen, 128

Guernsey, land in, 6

Gumming flowers, 72

HaNDLE baskets, 85

Hardy fruits, 28

- plants, 3 I

Heavy soils, working, 25

Hedges, boundary and protection, I5

Hessian canvas, 92

Holdings, small, 5

Horse labour, 25

Horse, steam, and motor ploughing, 145

Horse-radish, 91, $16_{3}$

Horticultural Society (Royal), 5 I

Hydraulic rams, 42

Income from land, 4

Insects, destroying, 36, 44

Insurance, I 59

Intercropping, 32

Irises, $3 \mathrm{I}$

Iron buildings, corrugated, 22

Ivel ag ricultural motor, 144

KaLE (Borecole), $85, \mathrm{r}_{3}$

Kay, Mr Peter, Finchley, $4 \mathbf{I}$

Knapsack sprayers, 36

LABOUR difficulties, I9

- horse, 25

permanent and temporary, 20

Labourers, cottages for, 19, 20

Lacre, van, 142

Land, acreage cultirated, 3 I

- altitude and elevation, 13

compensation for, 7

freehold, value of, 9

- income from, 4

- selection of, 4

- situation of, 9

- tenure, 7

Late crops, 52

Leeks, I 13

Lettuces, $16_{3}$

Lilies, $3 \mathbf{I}$
Lobjoits' (Messers) tractors, 143

Lorry, useful forms of, r 4 I

Machines, grading, 77

Management of crops, 27

Manilla cord, 99

Manures, artificial, 36

Market garden districts, 10

- gardening, importance and prospects, I

- important details, 46 under glass, 37,44 gardens, labour in, I9

76 prices, Board of Agriculture, salesmen, I 26

Markets, 76, 133 auctions at, 133

Materials for packing, 93

Melons, 69, rog

Men and women in market gardens, 24

Methods of packing, ror

Moss for packing, 96

Motor ploughing, cost of, I 45

Motors, agricultural, 26

- and tractors, 142

Mushrooms, 27, 86, 163

Myrobalan hedges, 18

Myrsiphyllum, I 9

Narcissus packing, I 7

New and old varieties, 50

Novelties, testing, 5

ONIONS, I 12 , I 17,143

Packages, 74

Packing cut-flowers, II 7 for export, 123 fruit, ror garden produce, 79, ror materials, 93 - plants, 120 sheds, 42, 77 tables and trays, 77 vegetables, I I I

Pæonies, 3 I

Palms, 122 
Paper shavings, 96, 97

Parcel post boxes, 86,90

Paris green, 36 fruit and flowers by, 154

Parsley, $115,16_{3}$

Parsnips, 63,163

Peaches, 67, 69, 76, 1०2

Pears, 27, 62, 67, 76, 102, 164

Peas, I $16,16_{3}$

Pershore plums, 67, 84

Petroleum, 36

Piece-work, 22

Pigs, I6I

Planet junior cultivators, 26

Plans of arrangement, I0, 34

Plants and flowers, $3 \mathbf{1}$

- packing, 120

Ploughing, 25

Plums, 30, 63, 67, 76, 84, 102, 107,164 in hedges, 18

Poplars for protection, 18

Pot baskets, $8_{3}$

Potatoes, 27, 63, 84, 91, 93, 16 3

Poultry, I6I

Power, steam, on land, 26

Produce, distribution of, 125

preparing for sale, 59

Production, economy in, 34 home, I

Productive power of land, 2

Productiveness of varieties, 52

Prospects of market gardening, I

Protection for crops, 40

Punnets, 92 gardens, 16

Quality in produce, 54

Quassia, 36

Quick hedges, 16

Radishes, 63, 98, I I I, $16_{3}$

Raffia, 99

Rail, conveyance by, 147

Railway and Parliamentary Committee, I66

$$
\text { Companies' boxes, } 87
$$$$
\text { waggons and vans, } 150
$$

Rain storage, 41

Rainfall, 12

Raspberries, 27, 66, 76, 105, I 64

Rates on market gardens, 157,165

Regular work, 2 I

Rent of cottages, 20 of land, 9

Reserve work, 2 I

Retailers, selling to, 130

Rhubarb, 40, I I 4, I6 3

River valleys, 15

Road, conveyance by, I 39

Roads, approach, 9

Rochford's tractors, 145

Roots in bags, 92

Roses, 17, 31, I 17

Royal Horticultural Society, 5I

SAcks and bags, 92

Salesmen, market, 126

Savoys, I $16,16_{3}$

Seakale, $40,6_{3}$, I 14

Seed saving and raising, 50

Selection of kinds and varieties, 47

- of land, 4

Selling price of land, 4

Sheds, cart and waggon, 42

packing, 42, 77

Shops, supplying, I 30

Situations for market gardens, 9

Small holdings, 5

Smilax, I 9

Soils, the best, 13

- working heavy, 25

Special districts, Io

Specialisation, 27

Spinach, $16_{3}$

Spraying apparatus, 36

Steanı power on land, 26

Stephanotis, 73

Storing fruits, 42

Strawberries, $27,65,66,76,103$, 164

Sunlight and sun heat, 45

Tables and trays for packing, 77

Tank space for rain, 41

Taxation of glass-houses, $15^{8}$ 
Temporary labour, 22

- protection, $4 \circ$

Tents for casual labourers, 22

Tenure of land, 7

Thinning fruits, 26

Tomatoes, $49,69,76, \mathbf{1} 10,163$

Tractors, work of, 142

Tuberoses, 73

Tubs for fruits, $\sigma_{3}$

Turnips, 164

Tying materials, 98

VALLEYS of rivers, 15

Value of land, 4

Vans for fruits, I $5 \mathrm{I}$

Variety trials, 49

Vegetable marrows, 164

Vegetables, bunching, I I I
VegetabIes, special crops, 28

Ventilation in glass-houses, 45

Violets, 31, II 8

WADDING, cotton, 95

Waggon sheds, 42

Waggons, railway, 151

Wallfowers, 71, 84, i 7

Washing vegetables, 63

Watercress, I I 5, I 64

Water-supply, I 5, 4I, 45

Weeds, 14, 43

Willows for protection, 18

Windbreaks, 16

Wood wool, 93

Workmen's compensation, I 59

Whitethorn, 16 




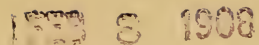

Deacidified using the Bookkeeper process. Neutralizing agent: Magnesium Oxide Treatment Date: September 2012

PreservationTechnologies A WORLD LEADER IN COLLECTIONS PRESERVATION 111 Thomson Park Drive Cranberry Township, PA 16066 (724) $779-2111$ 


\section{LIBRARY OF CONGRESS

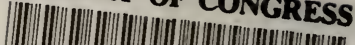 \\ IIII III II | | \\ 00009388710}

